\title{
AN ASSESSMENT OF THE SULFATE SOLUBILITY LIMIT FOR THE FRIT 418 - SLUDGE BATCH 2/3 SYSTEM
}

DK Peeler

CC Herman

ME Smith

TH Lorier

DR Best

TB Edwards

MA Baich

February 2004 
This document was prepared in conjunction with work accomplished under Contract No. DE-AC09-96SR18500 with the U. S. Department of Energy.

\section{DISCLAIMER}

This report was prepared as an account of work sponsored by an agency of the United States Government. Neither the United States Government nor any agency thereof, nor any of their employees, makes any warranty, express or implied, or assumes any legal liability or responsibility for the accuracy, completeness, or usefulness of any information, apparatus, product or process disclosed, or represents that its use would not infringe privately owned rights. Reference herein to any specific commercial product, process or service by trade name, trademark, manufacturer, or otherwise does not necessarily constitute or imply its endorsement, recommendation, or favoring by the United States Government or any agency thereof. The views and opinions of authors expressed herein do not necessarily state or reflect those of the United States Government or any agency thereof.

This report has been reproduced directly from the best available copy.

Available for sale to the public, in paper, from: U.S. Department of Commerce, National Technical Information Service, 5285 Port Royal Road, Springfield, VA 22161, phone: (800) 553-6847, fax: (703) 605-6900

email: orders@ntis.fedworld.gov

online ordering: http://www.ntis.gov/help/index.asp

Available electronically at http://www.osti.gov/bridge

Available for a processing fee to U.S. Department of Energy and its contractors, in paper, from: U.S. Department of Energy, Office of Scientific and Technical Information, P.O. Box 62, Oak Ridge, TN 37831-0062,

phone: (865)576-8401,

fax: (865)576-5728

email: $\underline{\text { reports@ adonis.osti.gov }}$ 
Key Words: salt layer, DWPF, sulfate, sludge batch 3

Retention: Permanent

\section{AN ASSESSMENT OF THE SULFATE SOLUBILITY LIMIT FOR THE FRIT 418 - SLUDGE BATCH 2/3 SYSTEM}

DK Peeler

CC Herman

ME Smith

TH Lorier

DR Best

TB Edwards

MA Baich

February 2004 
This page was intentionally left blank 


\section{EXECUTIVE SUMMARY}

The objective of this report is to establish a "single point" sulfate $\left(\mathrm{SO}_{4}{ }{ }^{\prime}\right)$ solubility limit or constraint for the Frit 418 - Sludge Batch 2/3 (SB2/3) system. Based on the results of this study, it is recommended that the glass $\mathrm{SO}_{4}{ }$ limit in the Product Composition Control System (PCCS) for the Frit $418-\mathrm{SB} 2 / 3$ system be set at $0.60 \mathrm{wt} \%\left(\mathrm{~g} \mathrm{SO}_{4}{ }{ }^{\prime} / 100 \mathrm{~g}\right.$ glass) (or $0.88 \mathrm{wt} \%$ expressed as $\mathrm{Na}_{2} \mathrm{SO}_{4}$ ). The new limit has been set based solely on sealed crucible scale data and does not take credit or account for potential volatilization that may occur in the Defense Waste Processing Facility (DWPF) melter. Although the limit is established based on sealed crucible scale tests, supplementary testing using the Slurry-Fed Melt Rate Furnace (SMRF) provides a measure of confidence that applying the $0.6 \mathrm{wt} \% \mathrm{SO}_{4}{ }^{=}$limit in PCCS will prevent the formation of a salt layer in the melter.

The critical data point that was used to define the $\mathrm{SO}_{4}{ }^{=}$solubility limit for this system was from a "spiked" $30 \%$ waste loading (WL) glass targeting $0.65 \mathrm{wt} \% \mathrm{SO}_{4}{ }^{\prime}$. The measured $\mathrm{SO}_{4}{ }^{=}$content in this glass was $0.62 \mathrm{wt} \%$. Applying the Savannah River Technology Center - Mobile Laboratory (SRTCML) inductively coupled plasma (ICP) atomic emission spectroscopy (AES) uncertainties (0.02 wt\%) to establish a $\mathrm{SO}_{4}{ }^{=}$solubility limit for the Frit $418-\mathrm{SB} 2 / 3$ system of $0.60 \mathrm{wt} \%$ (in glass) provides a "single point" limit that covers the anticipated WL interval of interest. It is noted that there are glasses above the $0.60 \mathrm{wt} \% \mathrm{SO}_{4}{ }^{=}$limit that were homogeneous, thus reinforcing the theory of a compositional effect on $\mathrm{SO}_{4}{ }$ solubility within this specific system. In general, higher $\mathrm{SO}_{4}{ }^{=}$ solubilities were observed at higher targeted waste loadings. 


\section{TABLE OF CONTENTS}

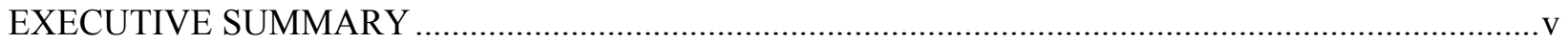

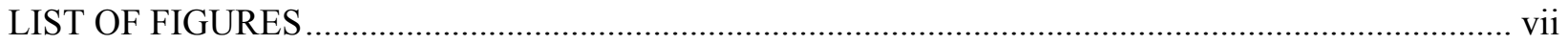

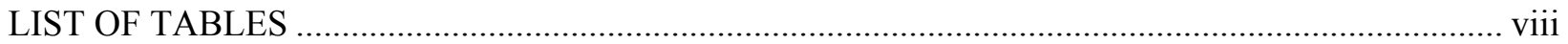

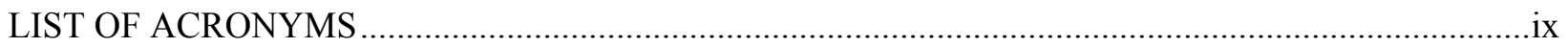

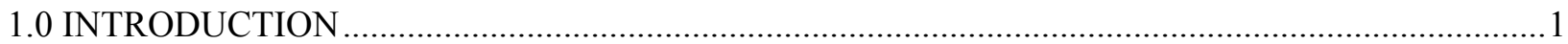

2.0 OBJECTIVE.

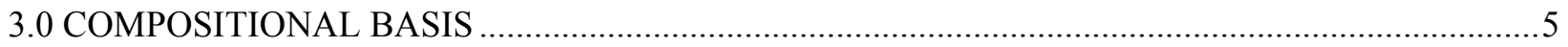

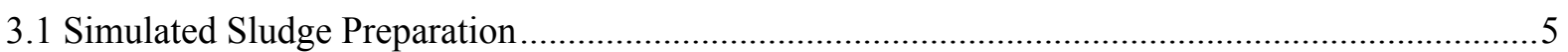

3.2 SRAT Product Preparation: Crucible Scale Tests.....................................................................

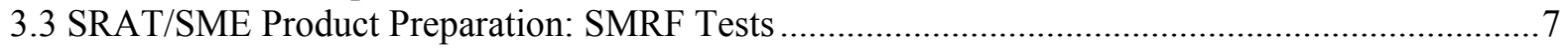

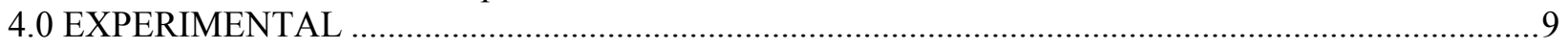

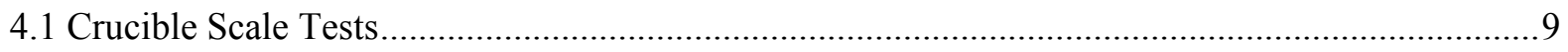

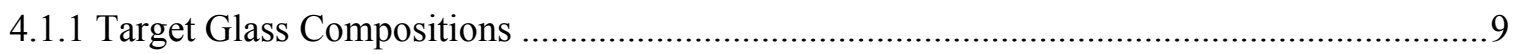

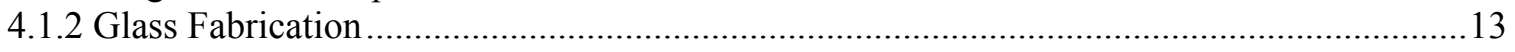

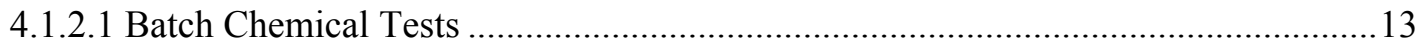

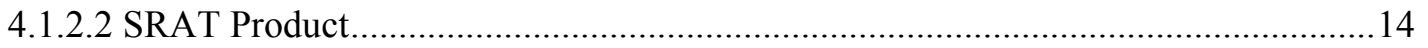

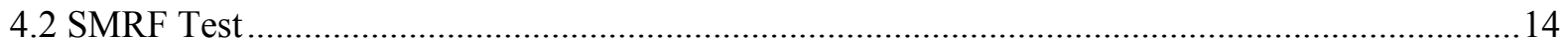

4.3 Glass: Chemical and Physical Property Measurements .......................................................... 16

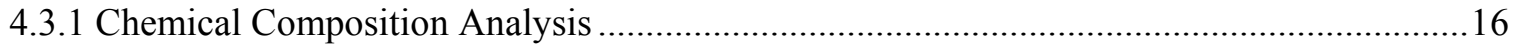

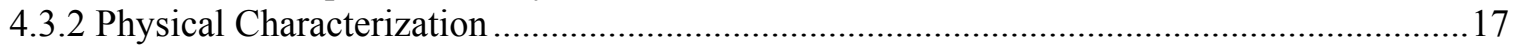

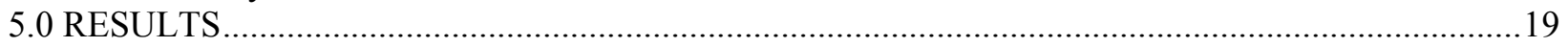

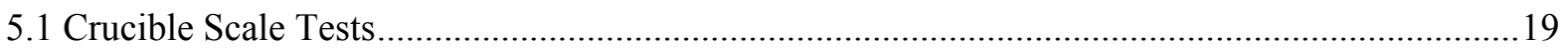

5.1.1 Chemical Compositions: Target Versus Measured …….................................................... 19

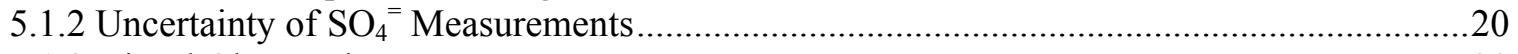

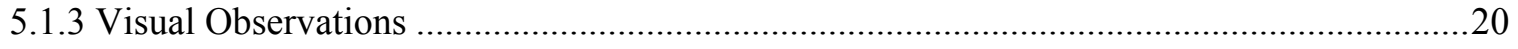

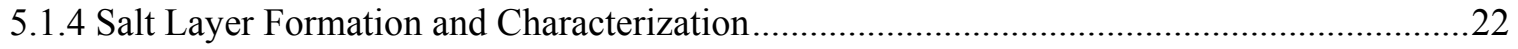

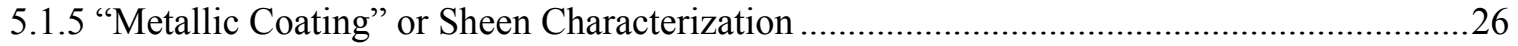

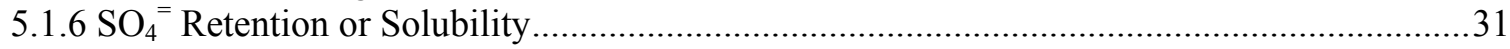

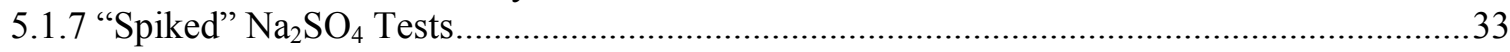

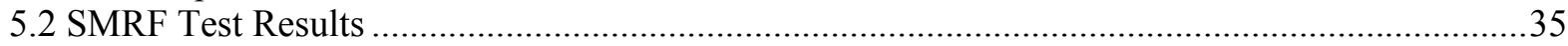

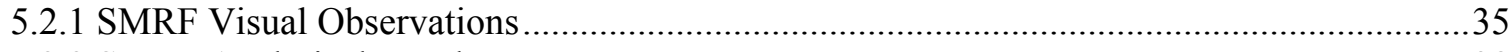

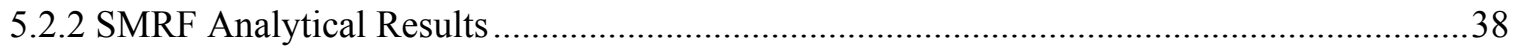

6.0 DEFINING THE $\mathrm{SO}_{4}$ SOLUBILITY LIMIT FOR THE FRIT 418 - SB2/3 SYSTEM: TECHNICAL

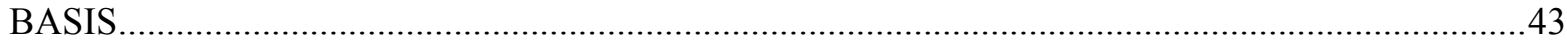

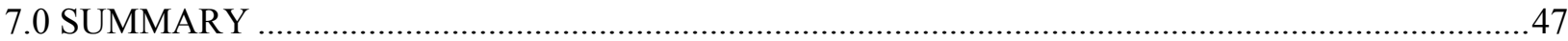

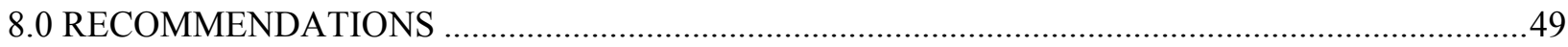

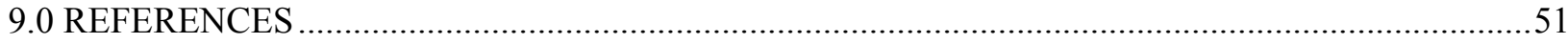

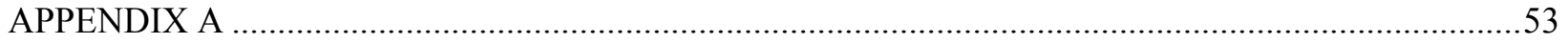

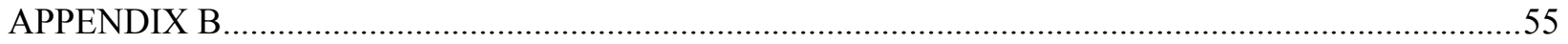

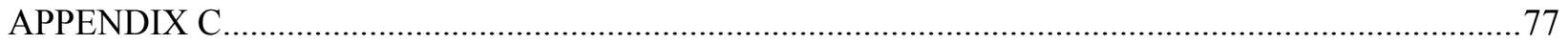




\section{LIST OF FIGURES}

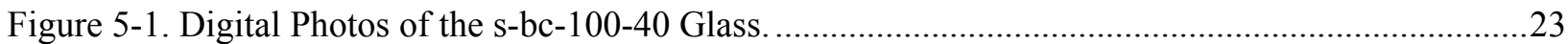

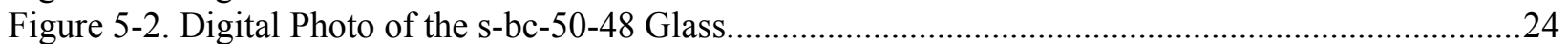

Figure 5-3. SEM Micrograph of the White Layer Associated with s-bc-100-40 .....................................24

Figure 5-4. EDS Analysis of the White Layer Associated with s-bc-100-40 .........................................25

Figure 5-5. SEM Micrograph of a "Rinsed" s-bc-100-40 Sample. .........................................................25

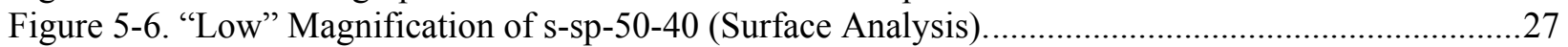

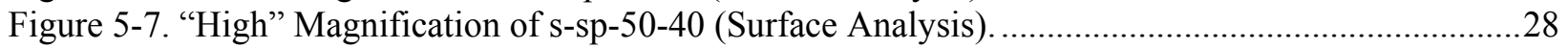

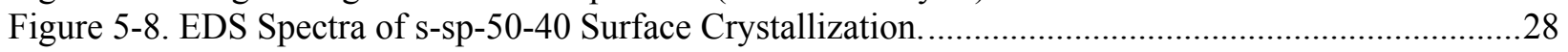

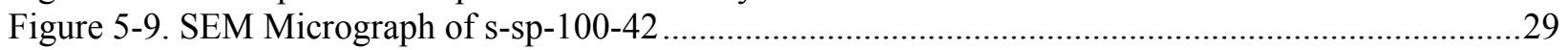

Figure 5-10. EDS Spectra of Surface Crystallization Associated with s-sp-100-42 .............................29

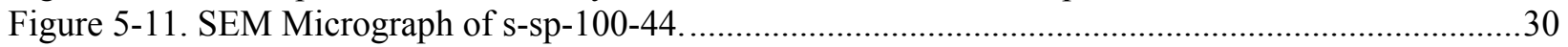

Figure 5-12. EDS Spectra of Surface Crystallization Associated with s-sp-100-44 ................................30

Figure 5-13. Cold Cap Sample at End of SMRF 1.2\% Target Sulfate Test. ...............................................36

Figure 5-14. Top of Glass Sample (30 Minutes after Feeding Stopped) at End of SMRF 1.2\% Target

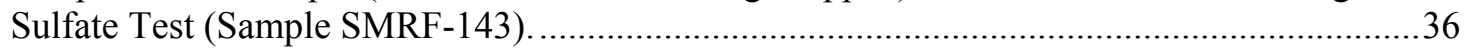

Figure 5-15. Cold Cap Sample at End of SMRF 1.5\% Target Sulfate Test (Sample SMRF-147) .............37

Figure 5-16. Top of Glass Sample (90 Minutes after Feeding Stopped) at End of SMRF 1.5\% Target Sulfate Test (Sample SMRF-149) …............................................................................ 37

Figure 5-17. SEM Micrograph of Top of Glass Sample at End of SMRF 0.7\% Target Sulfate Test. .........39

Figure 5-18. EDS Spectra of Spot 1 Shown in Figure 5-17 ...............................................................40

Figure 6-1. Sulfur Retention vs Waste Loading for Crucible Study Glasses. ..........................................43

Figure 6-2. Application of the $0.60 \mathrm{wt} \% \mathrm{SO}_{4}{ }^{2}$ Limit of the Crucible Scale Glasses..................................45 


\section{LIST OF TABLES}

Table 3-1. Target and Measured Composition of the $100 \%$ and $50 \%$ Np SB2/3 Sludge Simulants (wt $\%$ Calcined Oxide Basis).

Table 3-2. SRAT Product Analytical Results (Calcined Oxide Bases) .....................................................7

Table 3-3. Measured Waste Loadings and Sulfate Concentrations (wt\%) for SMRF Feed........................8

Table 3-4. Revised Sulfate Estimates Based on Actual Additions (wt \%, Calcined Solids Basis)...............8

Table 4-1. Targeted Compositions of the 100\% Np-Transfer Glasses as a Function of Waste Loading Produced from Batch Chemicals........................................................................................... 10

Table 4-2. Targeted Compositions of the 50\% Np-Transfer Glasses as a Function of Waste Loading

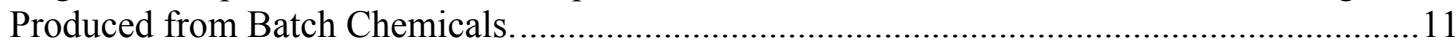

Table 4-3. Targeted Compositions of the $100 \% \mathrm{~Np}$-Transfer Glasses as a Function of Waste Loading Produced from SRAT Product. ............................................................................................... 12

Table 4-4. Targeted Compositions of the 50\% Np-Transfer Glasses as a Function of Waste Loading

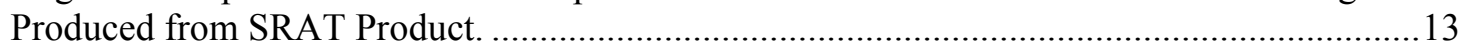

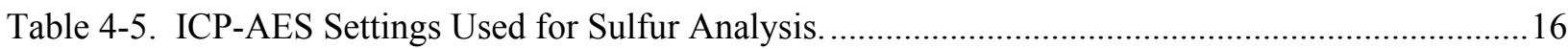

Table 5-1. Visual Observations of the Batch Chemical Sealed Crucible Tests........................................21

Table 5-2. ICP-AES Analysis of the Rinsed Yellow Layer on s-bc-100-40 .......................................26

Table 5-3. Target Versus Measured $\mathrm{SO}_{4}{ }^{=}$Concentrations in Glass. ........................................................32

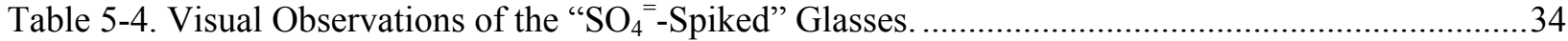

Table 5-5. Target Versus Measured $\mathrm{SO}_{4}{ }^{\prime}$ Contents in Glass for the "Spiked" Series...............................35

Table 5-6. Sulfate Levels (Weight \%) in SMRF Glass Samples............................................................38

Table 5-7. Summary of SMRF SB2/3 Frit 418 High Sulfate Tests.......................................................40 


\section{LIST OF ACRONYMS}

\begin{tabular}{ll} 
ADS & Analytical Development Section \\
AES & atomic emission spectroscopy \\
ANOVA & analysis of variance \\
CETL & Clemson Environmental Technology Laboratory \\
DIW & deionized water \\
DWPF & Defense Waste Processing Facility \\
EDS & energy dispersive spectroscopy \\
HLW & high-level waste \\
ICP & inductively coupled plasma \\
LM & lithium-metaborate \\
MAR & Measurement Acceptability Region \\
PCCS & Product Composition Control System \\
PF & peroxide fusion \\
PSCM & Pilot Scale Ceramic Melter \\
REDOX & REDuction/OXidation \\
SB & sludge batch \\
SC & Shielded Cells \\
SEM & scanning electron microscopy \\
SME & Slurry Mix Evaporator \\
SMRF & Slurry Fed Melt Rate Furnace \\
SRAT & Sludge Receipt and Adjustment Tank \\
SRS & Savannah River Site \\
SRTC & Savannah River Technology Center \\
SRTC-ML & Savannah River Technology Center - Mobile Laboratory \\
TL & liquidus temperature \\
TTR & technical task request \\
WL & waste loading \\
XRD & X-ray diffraction fluorescence \\
\hline &
\end{tabular}


WSRC-TR-2004-00081

Revision 0

This page intentionally left blank. 


\subsection{INTRODUCTION}

The Defense Waste Processing Facility (DWPF) is preparing to vitrify Sludge Batch 3 (SB3) which may contain higher than previously processed sulfate $\left(\mathrm{SO}_{4}{ }^{-}\right)$levels. A large portion of this sulfate is from ferrous sulfamate associated with a Np-based stream that may be added to SB3 directly from Savannah River Site's (SRS) H-canyon after the sludge has already been prepared. Based on the latest compositional information, the total amount of $\mathrm{SO}_{4}{ }^{=}$in $\mathrm{SB} 3$ will be higher than the sulfate processed in any of the previous DWPF sludge batches (SB1A, SB1B, or SB2) and, when processed, may exceed the current Product Composition Control System (PCCS) Slurry Mix Evaporator (SME) limit for $\mathrm{SO}_{4}{ }^{=}$. The current $\mathrm{SME} \mathrm{SO}_{4}{ }{ }$ solubility limit for the glass product in PCCS is expressed as $0.59 \mathrm{wt} \% \mathrm{Na}_{2} \mathrm{SO}_{4}$ which is equivalent to $0.4 \mathrm{wt} \% \mathrm{SO}_{4}{ }^{=}$in glass (measurement uncertainty of the soluble $\mathrm{SO}_{4}{ }^{=}$in the supernate is not currently applied to this value in PCCS). The current sulfate solubility limit in PCCS is based on two references by Bickford, et al. $(1986,1990)$ which in turn cite pilot scale tests performed at Battelle Pacific Northwest Laboratory in the Pilot Scale Ceramic Melter (PSCM).

The $\mathrm{SO}_{4}{ }^{=}$limit in PCCS was implemented to avoid the formation of sulfate inclusions and/or the formation of a molten sulfate-rich phase on the melt pool in the DWPF melter. The presence of this low viscosity melt phase on the surface of the melt pool increases corrosion rates of the materials of construction (off-gas, refractories [primarily at the melt line], and top head components (e.g., thermowells, level dip tube and upper electrodes) [due to splatter]). The molten salt layer is purported to enhance the potential for steam explosions in waste glass melters that are slurry fed (Schumacher et al. 1991). In addition, there is potential for undesirable current paths that could deplete energy delivered to the melter due to the electrical conductivity of the molten salt layer and the formation of corrosive offgases.

The sulfate limit is therefore an integral part of the PCCS SME acceptability decision process to mitigate or eliminate these potential negative effects. The $\mathrm{SO}_{4}{ }^{2}$ solubility limit in the glass represents the total sulfate that the glass can accommodate from the soluble $\left(\mathrm{Na}_{2} \mathrm{SO}_{4}\right)$ and insoluble $\left(\mathrm{CaSO}_{4}, \mathrm{BaSO}_{4}, \mathrm{PbSO}_{4}\right)$ fractions of DWPF High Level Waste (HLW) sludge.

As previously mentioned, the current blending strategy for SB3 includes the addition of a Np-based stream containing a significant fraction of ferrous sulfamate. Recent compositional measurements of SB3 (prior to blending with SB2) coupled with the volumes of Np-based solutions desired to be transferred to DWPF have resulted in a need to revisit the $\mathrm{SO}_{4}{ }^{2}$ limit and determine if the limit can be increased. If the $\mathrm{SO}_{4}{ }^{=}$limit can be increased, the magnitude of the increase could drive a business decision with respect to the volume of Np-solution transferred or the waste loading (WL) targeted in DWPF. For example, assume an intermediate $\mathrm{SO}_{4}{ }$ limit is established that allows the full transfer of the qualified level of Npsolution from the canyon but when implemented restricts DWPF from obtaining WLs of interest. A decision may be made to transfer a smaller volume of Np-solution which could allow DWPF more operational flexibility with respect to WL adjustments. An ideal situation would be to establish a new $\mathrm{SO}_{4}{ }^{=}$limit which would allow full transfer of the volume of $\mathrm{Np}$-solution that has been qualified as well as allow adequate flexibility in DWPF to target higher WLs to maximize throughput.

It should be noted that Lilliston and Elder (2003) have previously identified that a maximum volume of $\sim 60 \%$ (approximately 28,000 gallons) of the neutralized Np-solution can be transferred due to issues associated with nitrate levels. Any amount of the Np stream above this could cause the nitrate level to exceed that qualified in the Savannah River Technology Center (SRTC) Shielded Cells (SC). Throughout this report, the $\sim 60 \%$ (by volume) is referred to as the $100 \% \mathrm{~Np}$-transfer case given it is $100 \%$ of the $\mathrm{Np}$ stream that has been qualified. References to the $50 \% \mathrm{~Np}$ case represent one-half of this amount. 
In this report, the $\mathrm{SO}_{4}{ }^{=}$solubility limit for the Frit $418-\mathrm{SB} 2 / 3$ system is assessed using a series of crucible scale melts and Slurry-Fed Melt Rate Furnace (SMRF) tests. A testing program was defined to provide a sound technical basis from which a new $\mathrm{SO}_{4}{ }^{-}$limit can be established specifically for the Frit 418 - SB2/3 system. The program was developed in such a manner not only to establish a new limit, but to provide insight into potential trade-offs that may be realized. Sulfate solubility will be assessed for both the $50 \%$ and $100 \% \mathrm{~Np}$ transfer cases as a function of WL. This information coupled with a newly defined limit should provide valuable insight into any business related decisions regarding potential Nptransfer volumes and/or targeted WL issues in DWPF. 


\subsection{OBJECTIVE}

The objective of this report is to establish a "single point" $\mathrm{SO}_{4}{ }^{=}$solubility limit or constraint for the Frit 418 - SB2/3 system. The limit will be data driven and established based on the results of sealed, crucible-scale tests spanning a waste loading interval of interest. The new limit will address potential compositional effects on $\mathrm{SO}_{4}{ }^{2}$ solubility (established as a result of waste loading effects) and will be based on the measured $\mathrm{SO}_{4}{ }{ }^{-}$content in the glass. The approach will not account (or take credit) for potential sulfur volatility that could occur in the DWPF, which is conservative.

This work has been prepared to address technical issues identified in the Technical Task Request (TTR) issued by Rios-Armstrong (2004) and in accordance with the Task Technical and Quality Assurance Plan (Peeler 2003). 
WSRC-TR-2004-00081

Revision 0

This page intentionally left blank. 


\subsection{COMPOSITIONAL BASIS}

Sludge Batch 3 is currently scheduled to be blended with SB2 in the March 2004 time frame. This blend will be approximately $60 \% \mathrm{SB} 3$ and $40 \%$ SB2 on a mass basis. A projection of the actual sludge composition was made using the Tank 51 qualification sample composition (adjusted for decanting and the addition of the Np stream and corrosion inhibitors) (Click and Pareizs 2003) and DWPF SB2 composition. Since the testing to be completed would be non-radioactive (i.e., no uranium), the projected composition was adjusted to eliminate uranium but the ratios of all other elements to iron were maintained. No significant adjustments were made to the anions or solids content to account for the missing uranium. The sulfate target, $1.92 \mathrm{wt} \%$ in the calcined solids, was based on the blend of the two sludge batches with $\sim 28,000$ gallons of the neutralized Np stream (100\% case). The corresponding SB3 sulfate concentration including the Np contribution was based on the Tank 51 qualification Sludge Receipt and Adjustment Tank (SRAT) feed analysis reported value of $0.631 \mathrm{wt} \%$ sulfur in the total solids from inductively coupled plasma (ICP) analysis (Click and Pareizs 2003).

\subsection{Simulated Sludge Preparation}

The SB2 and SB3 simulants fabricated at the Clemson Environmental Technologies Laboratory (CETL) were blended together in the proper ratios and then chemical additions were made to more closely match the soluble species and minor components in the SB2/3 sludge. Sodium sulfate was added to bring the composition to the target $1.92 \mathrm{wt} \%$ sulfate concentration ( $100 \% \mathrm{~Np}$-transfer case). The total sodium in the sludge was not affected by the sodium sulfate trim addition. A large batch $(\sim 93 \mathrm{~kg})$ of the feed at this target composition was made to support slurry fed melt rate testing and crucible testing. A smaller batch of feed was also made targeting the $50 \% \mathrm{~Np}$ case. This feed was needed to support crucible scale testing. As mentioned above, the $50 \%$ case targets half of the $\mathrm{Np}$ volume and its corresponding sulfate concentration was $1.63 \mathrm{wt} \%$ in the calcined solids. The same baseline sludge simulant composition was used, but the sodium sulfate concentration was once again adjusted to allow the sulfate target to be met. As in the $100 \% \mathrm{~Np}$-transfer case, the total sodium was held constant by adjusting other trim chemicals. The target and measured compositions of both simulated sludges are given in Table 3-1. Measured compositions suggest that the targets, including $\mathrm{SO}_{4}{ }^{2}$, were fairly well met. 
WSRC-TR-2004-00081

Revision 0

Table 3-1. Target and Measured Composition of the 100\% and 50\% Np SB2/3 Sludge Simulants (wt\% Calcined Oxide Basis).

\begin{tabular}{||c|c|c|c|c||}
\hline \multirow{2}{*}{ Oxide } & \multicolumn{2}{|c|}{$\mathbf{1 0 0 \%}$ Np SB2/3 Sludge } & \multicolumn{2}{c|}{ 50\% Np SB2/3 Sludge } \\
\cline { 2 - 5 } & Target & Measured & Target & Measured \\
\hline $\mathrm{Al}_{2} \mathrm{O}_{3}$ & 16.9 & 17.3 & 16.8 & 17.6 \\
\hline $\mathrm{BaO}$ & 0.139 & 0.158 & 0.139 & 0.156 \\
\hline $\mathrm{CaO}$ & 3.64 & 3.91 & 3.63 & 3.64 \\
\hline $\mathrm{Cr}_{2} \mathrm{O}_{3}$ & 0.230 & 0.285 & 0.229 & 0.239 \\
\hline $\mathrm{CuO}$ & 0.191 & 0.197 & 0.191 & 0.208 \\
\hline $\mathrm{Fe}_{2} \mathrm{O}_{3}$ & 41.0 & 41.4 & 40.9 & 41.6 \\
\hline $\mathrm{K}_{2} \mathrm{O}$ & 0.046 & 0.134 & 0.046 & 0.207 \\
\hline $\mathrm{MgO}$ & 4.22 & 4.03 & 4.21 & 4.38 \\
\hline $\mathrm{MnO}$ & 6.41 & 6.07 & 6.40 & 5.96 \\
\hline $\mathrm{Na}_{2} \mathrm{O}$ & 20.7 & 19.1 & 20.7 & 20.0 \\
\hline $\mathrm{NiO}$ & 1.26 & 1.21 & 1.26 & 1.20 \\
\hline $\mathrm{PbO}^{\mathrm{SO} O}$ & 0.063 & 0.034 & 0.062 & 0.036 \\
\hline $\mathrm{SiO}_{2}$ & 1.96 & 1.91 & 1.63 & 1.66 \\
\hline $\mathrm{ZnO}_{\mathrm{ZrO}}$ & 2.32 & 2.29 & 2.27 & 2.44 \\
\hline $\mathrm{Totals}_{2}$ & 0.367 & 0.421 & 0.366 & 0.438 \\
\hline
\end{tabular}

\subsection{SRAT Product Preparation: Crucible Scale Tests}

Two 4-L SRAT runs were performed to supply SRAT product for crucible testing. One run used the $100 \% \mathrm{~Np}$ sludge, while the other used the $50 \% \mathrm{~Np}$ sludge. Based on previous flowsheet testing (Baich et al. 2004) the acid stoichiometry was $155 \%$ and the REDuction/Oxidation (REDOX) (expressed as $\mathrm{Fe}^{2+} / \Sigma \mathrm{Fe}$ ) target was 0.2 . The SRAT products were measured after the runs to ensure that the sulfate targets had been met and to determine the calcined and total solids so the feed could be blended with frit. The results are given in Table 3-2. It should be noted that the measured SRAT product sulfate concentrations are close to the targeted and measured sludge values (see Table 3-1 for targeted values).

\footnotetext{
${ }^{1}$ Totals are slightly less than $100 \%$ for targets since minor additions of noble metals are not accounted for in the table.
} 
Table 3-2. SRAT Product Analytical Results (Calcined Oxide Bases).

\begin{tabular}{|c|c|c|}
\hline Oxide & $\begin{array}{l}100 \% \text { Np SRAT } \\
\text { Product }(W t \%)\end{array}$ & $\begin{array}{l}50 \% \text { Np SRAT } \\
\text { Product (Wt\%) }\end{array}$ \\
\hline $\mathrm{Al}_{2} \mathrm{O}_{3}$ & 17.1 & 17.3 \\
\hline $\mathrm{BaO}$ & 0.13 & 0.13 \\
\hline $\mathrm{CaO}$ & 4.11 & 3.81 \\
\hline $\mathrm{Cr}_{2} \mathrm{O}_{3}$ & 0.22 & 0.22 \\
\hline $\mathrm{CuO}$ & 0.16 & 0.19 \\
\hline $\mathrm{Fe}_{2} \mathrm{O}_{3}$ & 40.1 & 41.7 \\
\hline $\mathrm{K}_{2} \mathrm{O}$ & 0.24 & 0.24 \\
\hline $\mathrm{MgO}$ & 4.34 & 4.47 \\
\hline $\mathrm{MnO}$ & 6.08 & 6.30 \\
\hline $\mathrm{Na}_{2} \mathrm{O}$ & 21.0 & 22.3 \\
\hline $\mathrm{NiO}$ & 1.21 & 1.25 \\
\hline $\mathrm{PbO}$ & 0.04 & 0.04 \\
\hline $\mathrm{SO}_{4}$ & 1.95 & 1.68 \\
\hline $\mathrm{SiO}_{2}$ & 2.75 & 2.80 \\
\hline $\mathrm{ZnO}$ & 0.40 & 0.40 \\
\hline $\mathrm{ZrO}_{2}$ & 0.52 & 0.52 \\
\hline Totals & 99.79 & 103.26 \\
\hline Calcined Solids $(\mathrm{Wt} \%)$ & 18.1 & 18.1 \\
\hline Total Solids $(\mathrm{Wt} \%)$ & 29.04 & 29.66 \\
\hline
\end{tabular}

\subsection{SRAT/SME Product Preparation: SMRF Tests}

A total of 6-22L SRAT/Slurry Mix Evaporator (SME) runs were performed to produce feed for the SMRF testing. However, only four of the runs were necessary for the studies. The target acid stoichiometry was $155 \%$ with a REDOX target of 0.2 . The targets were based on previous flowsheet testing (Baich et al. 2004) and standard SRAT and SME cycles were performed. Frit 418 was used and a waste loading of $40 \mathrm{wt} \%$ was targeted to maximize the sulfate in the system during testing. This waste loading would correspond to roughly $0.77 \mathrm{wt} \%$ sulfate in the SME calcined solids (or melter feed calcined solids).

After the SME cycles were completed, the resulting products (i.e., melter feed) were analyzed. Elemental analysis of the calcined solids indicated that neither the waste loading nor sulfate concentration targets had been met. The lithium contents of the product and the frit were used to estimate the waste loading. The estimated waste loadings are presented in Table 3-3. The error in waste loading is believed to have occurred because the assumed calcine factor in the frit calculation was too high; thus, less calcined solids were present in the SRAT product than believed to be based on the estimated solids. Sulfate analytical results were also lower than expected based on the $0.77 \mathrm{wt} \%$ target and the reported data are given in Table 3-3. Due to the lower than anticipated sulfate and waste loading numbers, a mass balance was performed on the SRAT/SME cycles to try to determine the revised sulfate target. This was performed assuming no loss of material during the cycles, which gave an estimated SRAT product calcined solids 
value that was used to estimate what the sulfate would have been had a $40 \%$ waste loading been achieved. This value was $0.70 \mathrm{wt} \%$ sulfate in the calcined solids.

Table 3-3. Measured Waste Loadings and Sulfate Concentrations (wt\%) for SMRF Feed.

\begin{tabular}{||c|c|c||}
\hline \hline Run ID & Waste Loading $^{2}$ & $\begin{array}{c}\text { Measured SO } \\
\text { in SME Product }\end{array}$ \\
\hline 3 & 38.5 & 0.635 \\
\hline 4 & 36.4 & 0.596 \\
\hline 5 & 36.6 & 0.483 \\
\hline 6 & 36.8 & 0.536 \\
\hline
\end{tabular}

Since the analytical data suggested that all of the feeds were below target, it was decided to spike the SMRF-based feeds with sodium sulfate to obtain the targets. ${ }^{3}$ However, it was also decided to not spike all of the feed to the same level until testing had commenced. This would allow the sulfate level to be adjusted to target a higher sulfate number if no sulfate layer were seen at the lower $0.70 \mathrm{wt} \%$ target. Runs $\# 3$ and \#4 were both spiked (using $\mathrm{Na}_{2} \mathrm{SO}_{4}$ ) to target $0.70 \mathrm{wt} \%$ and the amount necessary was estimated from the SME product mass and sulfate measurements on the SME products. As the SMRF runs proceeded, it was decided to spike Run \#5 to $1.2 \mathrm{wt} \% \mathrm{SO}_{4}{ }^{-}$(given initial indications of the $0.7 \mathrm{wt} \% \mathrm{SO}_{4}{ }^{=}$ tests suggested no salt layer). For Run $\# 6$, the target was $1.5 \mathrm{wt} \% \mathrm{SO}_{4}{ }^{\prime}$. The $\mathrm{Na}_{2} \mathrm{SO}_{4}$ additions resulted in $<0.5 \mathrm{wt} \%$ changes to the $\mathrm{Na}_{2} \mathrm{O}$ content.

After more analytical data were available on the SRAT product total and calcined solids and cycle mass losses were determined, additional calculations were performed to determine the actual amount of sulfate added to each run. Assuming the sludge was well mixed and that sulfate was homogeneously distributed in the runs, estimated targets were revised for each run and the values are given in Table 3-4. In addition, SMRF feed samples were reanalyzed for sulfate using a revised SRTC-ML ICP-AES technique in which the feed was dried at $110^{\circ} \mathrm{C}$ and the results converted to calcined solids versus calcining the feed at $1100^{\circ} \mathrm{C}$ (see Section 4.3.1). This was done in an effort to minimize the amount of sulfate that was volatilized during the calcining step. The results agree quite well with the revised sulfate target estimates.

Table 3-4. Revised Sulfate Estimates Based on Actual Additions (wt\%, Calcined Solids Basis).

\begin{tabular}{||c|c|c||}
\hline Run ID & $\begin{array}{c}\text { Revised Target } \\
\text { Estimate }\end{array}$ & $\begin{array}{c}\text { Measured } \text { SO}_{4}{ }^{\circ} \\
\text { (Dried at 110 }\end{array}$ \\
\hline 3 & 0.75 & $0.70^{4}$ \\
\hline 4 & 0.80 & 0.70 \\
\hline 5 & 1.40 & 1.32 \\
\hline 6 & 1.64 & 1.54 \\
\hline
\end{tabular}

\footnotetext{
${ }^{2}$ Waste loading determined by $\mathrm{Li}_{2} \mathrm{O}$ "normalization" method.

${ }^{3}$ It is noted that the use of $\mathrm{Na}_{2} \mathrm{SO}_{4}$ does add not only $\mathrm{SO}_{4}{ }^{=}$to the system but $\mathrm{Na}_{2} \mathrm{O}$ as well. Previous research (and this study) has demonstrated that $\mathrm{SO}_{4}{ }^{=}$solubility is a function of the overall glass composition. However, the amount of $\mathrm{Na}_{2} \mathrm{SO}_{4}$ needed to increase the $\mathrm{SO}_{4}{ }^{2}$ content to the "spiked" concentrations is extremely small and should have a negligible impact on $\mathrm{SO}_{4}{ }^{=}$ solubility.

${ }^{4}$ The measured $\mathrm{SO}_{4}=$ contents shown for Runs \#3 and \#4 are based on a blended or mixed sample.
} 


\subsection{EXPERIMENTAL}

The approach used to assess the $\mathrm{SO}_{4}{ }^{=}$solubility limit for the Frit 418 - SB2/3 system utilized both sealed crucible scale tests and SMRF runs. Two series of sealed crucible scale tests were performed. The first was based on the use of reagent grade (or batch) chemicals targeting specific WLs for both the $100 \% \mathrm{~Np}$ transfer and $50 \% \mathrm{~Np}$-transfer cases. The second series was based on the use of SRAT product blended with Frit 418 targeting specific WLs. The WLs of primary interest ranged from 30\% to 40\% (although higher WLs were tested). This WL range is based on the model-based assessments (Nominal and Variation Stage) performed by Peeler and Edwards (2003) using projections of the SB2/3 blend. ${ }^{5}$ In that study, projected operating windows were defined based on model predictions using the Measurement Acceptability Region (MAR) criteria as defined in SME Acceptability (Brown et al. 2002). For the Nominal Stage assessment, the projected operating window for the Frit 418 - SB2/3 system was 25 $45 \%$ WL. Application of $\pm 7.5 \%$ compositional uncertainty around the sludge resulted in an operational window of $25-40 \% \mathrm{WL}$ over which all the extreme vertices could be processed. It should be noted that these assessments were performed in the absence of projected $\mathrm{SO}_{4}{ }^{=}$concentrations for both $\mathrm{Np}$-transfer options.

\subsection{Crucible Scale Tests}

\subsubsection{Target Glass Compositions}

Table 4-1 and Table 4-2 summarize the targeted glass compositions for the $50 \%$ and $100 \% \mathrm{~Np}$-transfer cases as a function of WL using batch chemicals. Tables 4.3 and 4.4 summarize the targeted glass compositions for the $50 \%$ and $100 \%$ Np-transfer cases as a function of WL using SRAT product. It is noted that the targeted compositions between the batch chemical series and the SRAT product series are slightly different. The differences are a result of using the measured composition of the SRAT product (see Table 3-2) blended with Frit 418.

A specific nomenclature is used throughout this report to track each targeted glass composition in terms of the source of raw materials used (batch chemicals (bc) or SRAT product (sp)), the Np-transfer volume $(100 \%$ or $50 \%)$ and the targeted WL. For example, s-bc-100-30 represents a $\mathrm{SO}_{4}{ }^{\circ}$ study glass (s) produced using batch chemicals (bc), based on the $100 \% \mathrm{~Np}$ transfer case (100), and targeting a 30\% WL (30). As a second example, consider s-sp-50-44. This is a $\mathrm{SO}_{4}{ }^{\prime}$ study glass (s) produced using SRAT product (sp) based on the $50 \% \mathrm{~Np}$ transfer case (50) targeting a $44 \%$ WL (44).

\footnotetext{
${ }^{5}$ More specifically, the SB2/3 composition utilized was the $1.20 \mathrm{M}, 113$-canister option provided by Lilliston (2003).
} 
Table 4-1. Targeted Compositions of the $100 \%$ Np-Transfer Glasses as a Function of Waste Loading Produced from Batch Chemicals.

\begin{tabular}{|c|c|c|c|c|c|}
\hline Oxide & s-bc-100-30 & \begin{tabular}{|l} 
s-bc-100-33 \\
\end{tabular} & s-bc-100-35 & s-bc-100-37 & s-bc-100-40 \\
\hline $\mathrm{Al}_{2} \mathrm{O}_{3}$ & 5.029 & 5.533 & 5.870 & 6.206 & 6.711 \\
\hline $\mathrm{B}_{2} \mathrm{O}_{3}$ & 5.615 & 5.376 & 5.216 & 5.057 & 4.817 \\
\hline $\mathrm{CaO}$ & 1.085 & 1.194 & 1.266 & 1.339 & 1.448 \\
\hline $\mathrm{Cr}_{2} \mathrm{O}_{3}$ & 0.067 & 0.074 & 0.079 & 0.083 & 0.090 \\
\hline $\mathrm{Fe}_{2} \mathrm{O}_{3}$ & 12.243 & 13.471 & 14.289 & 15.109 & 16.338 \\
\hline $\mathrm{K}_{2} \mathrm{O}$ & 0.010 & 0.011 & 0.012 & 0.012 & 0.013 \\
\hline $\mathrm{Li}_{2} \mathrm{O}$ & 5.615 & 5.376 & 5.216 & 5.057 & 4.817 \\
\hline $\mathrm{MnO}$ & 1.916 & 2.108 & 2.236 & 2.364 & 2.557 \\
\hline $\mathrm{Na}_{2} \mathrm{O}$ & 11.836 & 12.220 & 12.477 & 12.734 & 13.119 \\
\hline $\mathrm{NiO}$ & 0.373 & 0.411 & 0.436 & 0.461 & 0.498 \\
\hline $\mathrm{P}_{2} \mathrm{O}_{5}$ & 0.067 & 0.074 & 0.079 & 0.083 & 0.090 \\
\hline $\mathrm{SiO}_{2}$ & 53.908 & 51.692 & 50.214 & 48.736 & 46.517 \\
\hline $\mathrm{ZnO}$ & 0.110 & 0.121 & 0.128 & 0.135 & 0.146 \\
\hline $\mathrm{ZrO}_{2}$ & 0.115 & 0.126 & 0.134 & 0.142 & 0.153 \\
\hline $\mathrm{Ag}_{2} \mathrm{O}$ & 0.005 & 0.006 & 0.006 & 0.006 & 0.007 \\
\hline $\mathrm{BaO}$ & 0.042 & 0.046 & 0.049 & 0.052 & 0.056 \\
\hline $\mathrm{CuO}$ & 0.058 & 0.063 & 0.067 & 0.071 & 0.077 \\
\hline $\mathrm{Gd}_{2} \mathrm{O}_{3}$ & 0.024 & 0.027 & 0.028 & 0.030 & 0.032 \\
\hline $\mathrm{MgO}$ & 1.258 & 1.384 & 1.468 & 1.552 & 1.679 \\
\hline $\mathrm{PbO}$ & 0.018 & 0.020 & 0.021 & 0.022 & 0.024 \\
\hline $\mathrm{RuO}_{2}$ & 0.020 & 0.022 & 0.023 & 0.024 & 0.026 \\
\hline $\mathrm{SO}_{4}$ & 0.586 & 0.645 & 0.685 & 0.724 & 0.783 \\
\hline Total & 100.000 & 100.000 & 100.000 & 100.000 & 100.000 \\
\hline WL & 30 & 33 & 35 & 37 & 40 \\
\hline
\end{tabular}


WSRC-TR-2004-00081

Revision 0

Table 4-2. Targeted Compositions of the 50\% Np-Transfer Glasses as a Function of Waste Loading Produced from Batch Chemicals.

\begin{tabular}{||c|c|c|c|c|c|c||}
\hline \hline Oxide & s-bc-50-30 & s-bc-50-33 & s-bc-50-35 & s-bc-50-37 & s-bc-50-40 & s-bc-40-48 \\
\hline $\mathrm{Al}_{2} \mathrm{O}_{3}$ & 5.034 & 5.539 & 5.876 & 6.214 & 6.720 & 8.074 \\
\hline $\mathrm{B}_{2} \mathrm{O}_{3}$ & 5.621 & 5.382 & 5.222 & 5.063 & 4.824 & 4.185 \\
\hline $\mathrm{CaO}$ & 1.086 & 1.195 & 1.268 & 1.341 & 1.450 & 1.742 \\
\hline $\mathrm{Cr}_{2} \mathrm{O}_{3}$ & 0.067 & 0.074 & 0.079 & 0.083 & 0.090 & 0.108 \\
\hline $\mathrm{Fe}_{2} \mathrm{O}_{3}$ & 12.255 & 13.485 & 14.306 & 15.127 & 16.360 & 19.654 \\
\hline $\mathrm{K}_{2} \mathrm{O}$ & 0.010 & 0.011 & 0.012 & 0.012 & 0.013 & 0.016 \\
\hline $\mathrm{Li}_{2} \mathrm{O}$ & 5.621 & 5.382 & 5.222 & 5.063 & 4.824 & 4.185 \\
\hline $\mathrm{MnO}$ & 1.918 & 2.110 & 2.239 & 2.367 & 2.560 & 3.076 \\
\hline $\mathrm{Na}_{2} \mathrm{O}$ & 11.847 & 12.234 & 12.491 & 12.749 & 13.136 & 14.172 \\
\hline $\mathrm{NiO}$ & 0.374 & 0.411 & 0.436 & 0.461 & 0.499 & 0.599 \\
\hline $\mathrm{P}_{2} \mathrm{O}_{5}$ & 0.067 & 0.074 & 0.079 & 0.083 & 0.090 & 0.108 \\
\hline $\mathrm{SiO} 2$ & 53.961 & 51.748 & 50.272 & 48.795 & 46.579 & 40.667 \\
\hline $\mathrm{ZnO}$ & 0.110 & 0.121 & 0.128 & 0.135 & 0.146 & 0.176 \\
\hline $\mathrm{ZrO}_{2}$ & 0.115 & 0.127 & 0.134 & 0.142 & 0.154 & 0.185 \\
\hline $\mathrm{Ag}_{2} \mathrm{O}$ & 0.005 & 0.006 & 0.006 & 0.006 & 0.007 & 0.008 \\
\hline $\mathrm{BaO}$ & 0.042 & 0.046 & 0.049 & 0.052 & 0.056 & 0.068 \\
\hline $\mathrm{CuO}$ & 0.058 & 0.064 & 0.067 & 0.071 & 0.077 & 0.093 \\
\hline $\mathrm{Gd}_{2} \mathrm{O}_{3}$ & 0.024 & 0.027 & 0.028 & 0.030 & 0.032 & 0.039 \\
\hline $\mathrm{MgO}$ & 1.259 & 1.386 & 1.470 & 1.554 & 1.681 & 2.019 \\
\hline $\mathrm{PbO}^{2} \mathrm{OuO}$ & 0.018 & 0.020 & 0.021 & 0.022 & 0.024 & 0.029 \\
\hline $\mathrm{SO}_{4}$ & 0.020 & 0.022 & 0.023 & 0.024 & 0.026 & 0.032 \\
\hline & & 0.538 & 0.571 & 0.603 & 0.652 & 0.766 \\
\hline $\mathrm{Total}$ & 100.000 & 100.000 & 100.000 & 100.000 & 100.000 & 100.000 \\
\hline & & & & & & \\
\hline $\mathrm{WL}$ & 30 & 33 & 35 & 37 & 40 & 48 \\
\hline \hline
\end{tabular}


WSRC-TR-2004-00081

Revision 0

Table 4-3. Targeted Compositions of the $100 \%$ Np-Transfer Glasses as a Function of Waste Loading Produced from SRAT Product.

\begin{tabular}{|c|c|c|c|c|c|c|c|}
\hline Oxide & s-sp-100-30 & s-sp-100-33 & s-sp-100-35 & s-sp-100-37 & s-sp-100-40 & s-sp-100-42 & s-sp-100-44 \\
\hline $\mathrm{Al}_{2} \mathrm{O}_{3}$ & 5.11 & 5.62 & 5.96 & 6.30 & 6.82 & 7.16 & 7.50 \\
\hline $\mathrm{BaO}$ & 0.039 & 0.043 & 0.045 & 0.048 & 0.052 & 0.054 & 0.057 \\
\hline $\mathrm{B}_{2} \mathrm{O}_{3}$ & 5.41 & 5.17 & 5.02 & 4.87 & 4.63 & 4.48 & 4.32 \\
\hline $\mathrm{CaO}$ & 1.23 & 1.35 & 1.43 & 1.52 & 1.64 & 1.72 & 1.80 \\
\hline $\mathrm{Cr}_{2} \mathrm{O}_{3}$ & 0.067 & 0.074 & 0.078 & 0.083 & 0.089 & 0.094 & 0.098 \\
\hline $\mathrm{CuO}$ & 0.049 & 0.054 & 0.057 & 0.060 & 0.065 & 0.068 & 0.072 \\
\hline $\mathrm{Fe}_{2} \mathrm{O}_{3}$ & 12.0 & 13.2 & 14.0 & 14.8 & 16.0 & 16.8 & 17.6 \\
\hline $\mathrm{K}_{2} \mathrm{O}$ & 0.073 & 0.080 & 0.085 & 0.090 & 0.097 & 0.102 & 0.107 \\
\hline $\mathrm{Li}_{2} \mathrm{O}$ & 5.59 & 5.35 & 5.19 & 5.03 & 4.79 & 4.63 & 4.47 \\
\hline $\mathrm{MgO}$ & 1.30 & 1.43 & 1.51 & 1.60 & 1.73 & 1.82 & 1.90 \\
\hline $\mathrm{MnO}$ & 1.82 & 2.00 & 2.12 & 2.24 & 2.42 & 2.55 & 2.67 \\
\hline $\mathrm{Na}_{2} \mathrm{O}$ & 11.9 & 12.3 & 12.5 & 12.8 & 13.2 & 13.4 & 13.7 \\
\hline $\mathrm{NiO}$ & 0.362 & 0.398 & 0.422 & 0.446 & 0.483 & 0.507 & 0.531 \\
\hline $\mathrm{PbO}$ & 0.011 & 0.012 & 0.013 & 0.013 & 0.014 & 0.015 & 0.016 \\
\hline $\mathrm{SO}_{4}$ & 0.583 & 0.641 & 0.680 & 0.719 & 0.777 & 0.816 & 0.855 \\
\hline $\mathrm{SiO}_{2}$ & 53.0 & 50.8 & 49.4 & 48.0 & 45.8 & 44.4 & 42.9 \\
\hline $\mathrm{ZnO}$ & 0.120 & 0.132 & 0.140 & 0.148 & 0.160 & 0.168 & 0.176 \\
\hline $\mathrm{ZrO}_{2}$ & 0.155 & 0.170 & 0.181 & 0.191 & 0.206 & 0.217 & 0.227 \\
\hline Totals & 98.76 & 98.81 & 98.85 & 98.88 & 98.94 & 98.97 & 99.01 \\
\hline WL & 30 & 33 & 35 & 37 & 40 & 42 & 44 \\
\hline
\end{tabular}


WSRC-TR-2004-00081

Revision 0

Table 4-4. Targeted Compositions of the 50\% Np-Transfer Glasses as a Function of Waste Loading Produced from SRAT Product.

\begin{tabular}{|c|c|c|c|c|c|c|}
\hline Oxide & 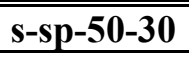 & s-sp-50-33 & s-sp-50-35 & 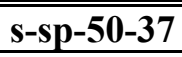 & s-sp-50-40 & s-sp-50-45 \\
\hline $\mathrm{Al}_{2} \mathrm{O}_{3}$ & 5.01 & 5.52 & 5.85 & 6.18 & 6.69 & 7.52 \\
\hline $\mathrm{BaO}$ & 5.41 & 5.17 & 5.02 & 4.87 & 4.63 & 4.25 \\
\hline $\mathrm{B}_{2} \mathrm{O}_{3}$ & 0.038 & 0.042 & 0.045 & 0.047 & 0.051 & 0.058 \\
\hline $\mathrm{CaO}$ & 1.11 & 1.22 & 1.29 & 1.37 & 1.48 & 1.66 \\
\hline $\mathrm{Cr}_{2} \mathrm{O}_{3}$ & 0.065 & 0.072 & 0.076 & 0.080 & 0.087 & 0.098 \\
\hline $\mathrm{CuO}$ & 0.055 & 0.061 & 0.064 & 0.068 & 0.074 & 0.083 \\
\hline $\mathrm{Fe}_{2} \mathrm{O}_{3}$ & 12.1 & 13.3 & 14.1 & 14.9 & 16.1 & 18.2 \\
\hline $\mathrm{K}_{2} \mathrm{O}$ & 0.071 & 0.078 & 0.083 & 0.087 & 0.095 & 0.106 \\
\hline $\mathrm{Li}_{2} \mathrm{O}$ & 5.59 & 5.35 & 5.19 & 5.03 & 4.79 & 4.40 \\
\hline $\mathrm{MgO}$ & 1.30 & 1.43 & 1.52 & 1.60 & 1.73 & 1.95 \\
\hline $\mathrm{MnO}$ & 1.83 & 2.01 & 2.14 & 2.26 & 2.44 & 2.75 \\
\hline $\mathrm{Na}_{2} \mathrm{O}$ & 12.1 & 12.5 & 12.8 & 13.0 & 13.4 & 14.1 \\
\hline $\mathrm{NiO}$ & 0.363 & 0.399 & 0.424 & 0.448 & 0.484 & 0.545 \\
\hline $\mathrm{PbO}$ & 0.010 & 0.012 & 0.012 & 0.013 & 0.014 & 0.016 \\
\hline $\mathrm{SO}_{4}$ & 0.488 & 0.537 & 0.569 & 0.602 & 0.651 & 0.732 \\
\hline $\mathrm{SiO}_{2}$ & 53.0 & 50.8 & 49.4 & 47.9 & 45.8 & 42.2 \\
\hline $\mathrm{ZnO}$ & 0.117 & 0.128 & 0.136 & 0.144 & 0.156 & 0.175 \\
\hline $\mathrm{ZrO}_{2}$ & 0.150 & 0.165 & 0.175 & 0.185 & 0.200 & 0.225 \\
\hline Totals & 98.76 & 98.81 & 98.85 & 98.88 & 98.94 & 99.03 \\
\hline WL & 30 & 33 & 35 & 37 & 40 & 45 \\
\hline
\end{tabular}

\subsubsection{Glass Fabrication}

\subsubsection{Batch Chemical Tests}

Each glass was prepared from the proper proportions of reagent-grade metal oxides, carbonates, $\mathrm{H}_{3} \mathrm{BO}_{3}$, and salts (including $\mathrm{Na}_{2} \mathrm{SO}_{4}$ ) to produce 250 -g of glass. Batch sheets were filled out as the materials were weighed. Once batched, the raw materials were thoroughly mixed and placed into a $250 \mathrm{ml}$ high purity alumina crucible. Lids were "sealed" onto the crucibles with a nepheline gel. The crucible was subsequently placed into a high-temperature furnace at $1150^{\circ} \mathrm{C}$. After an isothermal hold at $1150^{\circ} \mathrm{C}$ for 2.0 hours, the crucible was removed, placed in a stainless steel pan, covered with a stainless beaker, and allowed to cool to room temperature with the lid on. The cooling process took approximately $2-3$ hours. Once cooled, the lid was removed and visual observations of the resulting glass were documented. Of particular interest were the formation (or lack thereof) of a salt layer around the meniscus of the melt (at the glass/crucible interface), any coatings on the surface of the glass, and the presence of salt/unreacted material along the crucible wall. Digital photos of the crucibles and resulting glass products were also 
taken. ${ }^{6}$ When not in use, glasses were stored in marked containers using a unique nomenclature (see Section 4.1.1).

\subsubsection{SRAT Product}

For this series of tests, the SB2/3 SRAT products ( $100 \%$ and $50 \%$ cases) were thoroughly mixed and then the appropriate amounts of SRAT product were combined with Frit 418. The amount of SRAT product to add was determined using the measured calcined and total solids numbers given in Table 3-2. After the SRAT product and frit were mixed, the feed was dried in an oven at $\sim 105^{\circ} \mathrm{C}$ in the crucible that was to be used for melting.

The crucible was subsequently sealed with nepheline gel and placed into a high-temperature furnace at $1150^{\circ} \mathrm{C}$. After an isothermal hold at $1150^{\circ} \mathrm{C}$ for 2.0 hours, the crucible was removed, placed in a stainless steel pan, covered with a stainless beaker, and allowed to cool to room temperature with the lid on. The cooling process took approximately $2-3$ hours. Once cooled, the lid was removed and visual observations of the resulting glass were documented. Of particular interest were the formation (or lack thereof) of a salt layer around the meniscus of the melt (at the glass/crucible interface), any coatings on the surface of the glass, and the presence of salt/unreacted material along the crucible wall. Digital photos of the crucibles and resulting glass products were also taken. ${ }^{7}$ When not in use, glasses were stored in marked containers using a unique nomenclature (see Section 4.1.1).

\subsection{SMRF Test}

The main purpose of the SMRF tests was to determine if the conditions of slurry feeding Frit $418-\mathrm{SB} 2 / 3$ in a small-scale melter would lower the sulfate solubility limit of the resultant glass versus the value determined by the crucible tests (kinetic versus "equilibrium"). If the sulfate solubility of the glass produced in the SMRF tests was found to be lower than that determined by the crucible tests at similar waste loadings, then setting a limit based on the crucible tests would be problematic. If the SMRF tests showed similar or higher sulfate solubility (for the same waste loading) than the crucible tests, then the limit determined by the crucible tests would be deemed conservative and thus acceptable for use by DWPF.

The test sequence was to start up the SMRF with $8 \mathrm{~kg}$ of a prefabricated glass targeting $40 \%$ waste loading with a sulfate level equal to the $100 \% \mathrm{~Np}$ case $(0.77$ weight $\%$ sulfate $)$. The feed produced from the SRAT/SME runs was found to have a lower than targeted waste loading but the decision was made to continue the SMRF tests due to their confirmatory nature. The run plan used for the SMRF tests was SRT-GPD-2004-00002 ("Run Plan for the SB2/SB3 Frit 418 High Sulfate Run in the Slurry Fed Melter Rate Furnace"). The SRTC log notebook used was WSRC-NB-2003-00163. The basic steps for the high sulfate SMRF tests were as follows:

- $\quad$ Startup SMRF with $8 \mathrm{~kg}$ of $40 \%$ waste loaded Frit 418 - SB2/3 glass with $0.77 \mathrm{wt} \%$ sulfate

- Feed SMRF with Frit 418 - SB2/3 feed (two SRAT/SME batches) with a target of $0.7 \mathrm{wt} \%$ sulfate and look for signs of sulfate layer on top of glass

\footnotetext{
${ }^{6}$ Visual observations and digital photos of the batch chemical-based glasses are documented in WSRC-NB-2003-00044.

${ }^{7}$ Visual observations and digital photos of the SRAT-based glasses are documented in WSRC-NB-2003-00044.
} 
- Feed SMRF with Frit 418 - SB2/3 feed (one SRAT/SME batch) spiked with sodium sulfate (target $1.2 \mathrm{wt} \%$ sodium sulfate) and look for signs of sulfate layer on top of glass

- Feed SMRF with Frit 418 - SB2/3 feed (one SRAT/SME batch) spiked with sodium sulfate (target $1.5 \mathrm{wt} \%$ sodium sulfate) and look for signs of sulfate layer on top of glass

- If a sulfate layer was not observed after feeding the $1.5 \mathrm{wt} \%$ sulfate feed, then continue doping the feed at higher levels until the layer was seen

- Take glass pour samples after each $4 \mathrm{~kg}$ of glass produced

- Take top of cold cap samples at end of each level of sulfate feeding and then take a subsequent top of glass sample after cold cap burnoff (30 to 90 minutes)

- Take glass samples during the draining of the SMRF

- Determine melt rate for the $0.7 \%$ target sulfate feed

- Use Scanning Electron Microscopy (SEM) with Energy Dispersive Spectroscopy (EDS) analysis to determine if indeed free sulfate was in the cold cap, top of glass, and glass pour/drain samples

Details about the SMRF are documented elsewhere by Smith et al. (2003). As discussed in Section 3.3, SRAT/SME runs 3 and 4 were used for the $0.7 \mathrm{wt} \%$ sulfate test. Run 5 was used for the $1.2 \%$ sulfate tests and run 6 was used for the $1.5 \%$ sulfate tests. Samples taken of the feed for each level of sulfate tested were analyzed and the results can be found in Appendix A. The sulfate levels measured are lower than expected, which was probably due to the preparation steps taken for the ICP analysis (calcining feed at $1100^{\circ} \mathrm{C}$ ) that may have volatilized some of the sulfate. ${ }^{8}$ Calculations made after the test determined that the sulfate $\mathrm{wt} \%$ levels in the feed (calcined) for the $0.7,1.2$, and 1.5 tests should be about $0.77,1.4$, and 1.64 respectively. These are more in line with the resultant sulfate levels measured in the SMRF glass samples taken during the test (see Section 5.2.2) and help substantiate the belief that the sulfate levels measured in the feed analyses were indeed low.

The melt pool and vapor space setpoints were $1125^{\circ} \mathrm{C}$ and $750^{\circ} \mathrm{C}$, respectively. The time for each feed cycle after the vapor space had reached the vapor space feed initiation setpoint of $750^{\circ} \mathrm{C}$ was 20 seconds. The measured amps for the melt pool and vapor space heaters were about 20.4 and 20.8. All of the settings/readings were the same (including clamping of the vapor space temperature) as those for the SB2/3 Frit 418 (Case $6 b-250$ canisters) 40\% waste loading SMRF test performed in August 2003 (Smith et al. 2003).

The SMRF was charged with $8 \mathrm{~kg}$ of startup glass on 1/16/04 and heated up to operating temperatures. The $0.7 \%$ target sulfate SMRF test was started on $1 / 20 / 04$ at 0820 with a mix of SRAT/SME batches 3 and 4. Feeding and pouring continued until 2335 that night. About $11.9 \mathrm{~kg}$ of glass was produced the first day. Due to the fact that only $5 \mathrm{~kg}$ of glass could be drained from the SMRF in the test run in November 2003 and that $8 \mathrm{~kg}$ of startup glass was used for this test, the amount of glass produced from the feed vitrified in the SMRF during this first day was actually about $8.9 \mathrm{~kg}(11.9 \mathrm{~kg}-3 \mathrm{~kg}$ that remained in SMRF from previous test). Therefore a little over one SMRF melter turnover of glass $(8 \mathrm{~kg})$ was produced.

On $1 / 21 / 04$, feeding of $0.7 \%$ target sulfate material was continued until it was stopped at 1200 due to lack of feed. Approximately $2.3 \mathrm{~kg}$ of glass was poured this day for a total of $14.2 \mathrm{~kg}$ poured throughout the $0.7 \%$ sulfate test (or $11.2 \mathrm{~kg}$ total produced from $0.7 \%$ target sulfate feed). A cold cap sample was immediately taken and a top of glass sample was taken 30 minutes later. At 1233 on 1/21/04, the $1.2 \%$ target sulfate feed test was started with SRAT/SME batch 5. This test was stopped at 1946 when feed was depleted. A total of $5.4 \mathrm{~kg}$ of glass was produced during the $1.2 \%$ target sulfate test. A cold cap sample was immediately taken and a top-of-glass sample was taken 30 minutes later.

\footnotetext{
${ }^{8}$ Melter feed analysis preparation methods are being refined.
} 
On $1 / 22 / 04$, feeding of the $1.5 \%$ target sulfate material was conducted until 1526 when there was not enough feed to continue the test. A total of $5.4 \mathrm{~kg}$ of glass was produced during the $1.5 \%$ sulfate test. A cold cap sample was taken and then top-of-glass samples were taken 30 and 90 minutes later. Immediately after this, the draining of the SMRF was performed and drain samples were taken. A total of $5.5 \mathrm{~kg}$ of glass was drained.

\subsection{Glass: Chemical and Physical Property Measurements}

This section provides a general discussion of the analysis of chemical compositions and additional physical characterization techniques.

\subsubsection{Chemical Composition Analysis}

Inductively coupled plasma - atomic emission spectroscopy (ICP - AES) was used to support two objectives: 1) to assess the retention or solubility of $\mathrm{SO}_{4}{ }^{=}$in glass and 2) to confirm the target glass compositions of the sealed crucible tests. To meet both objectives, a representative sample from each glass was submitted to the SRTC Mobile Laboratory (SRTC-ML) for chemical analysis. Edwards (2004) provided analytical plans that accompanied these samples. Four sets of glasses were submitted: (1) 100\% Np-transfer with batch chemicals (Set \#1), (2) 50\% Np-transfer with batch chemicals (Set \#2), (3) 100\% Np-transfer with SRAT product (Set \#3), and (4) 50\% Np-transfer with SRAT product (Set \#4). These plans identified the cations to be analyzed and the dissolution techniques (i.e., sodium peroxide fusion $[\mathrm{PF}]$ and lithium-metaborate $[\mathrm{LM}]$ fusion) to be used. Each glass was prepared in duplicate for the cation dissolution techniques ( $\mathrm{PF}$ and $\mathrm{LM}$ ). Concentrations (as wt \%) for the cations of interest were measured by ICP - AES. Specifically, sulfur was determined via the LM fusion and subsequent dissolution (see discussion below for more details). Each analytical plan was developed in such a way as to provide the opportunity to evaluate potential sources of error. Glass standards were intermittently run to assess the performance of the ICP - AES over the course of these analyses and for potential bias-correction needs. Representative samples from the SMRF test were also submitted for compositional analysis to assess $\mathrm{SO}_{4}{ }^{=}$retention and total glass chemistry.

Given the primary focus on $\mathrm{SO}_{4}{ }^{\circ}$ measurements, a brief discussion of the SRTC-ML measurement technique is warranted. The SRTC-ML analyzed sulfur using a Varian Vista AX ICP-AES at the 181.972nm wavelength. Table 4-5 summarizes the settings used which were determined to give the most intense signal for sulfur in the sample preparation matrix used to digest the sludge and glass samples.

Table 4-5. ICP-AES Settings Used for Sulfur Analysis.

\begin{tabular}{||c|c||}
\hline Parameter & Setting \\
\hline RF Power & $1.35 \mathrm{Kw}$ \\
\hline Nebulizer Mass Flow Controller & $0.95 \mathrm{~L} / \mathrm{min}$ \\
\hline Plasma Gas & $15.0 \mathrm{~L} / \mathrm{min}$ \\
\hline Aux. Gas & $1.50 \mathrm{~L} / \mathrm{min}$ \\
\hline Sample Pump Rate & $15 \mathrm{rpm}$ \\
\hline Polychromator Purge Gas & $\mathrm{ON}$ \\
\hline Nebulizer & Meinhard C-3 $(3 \mathrm{ml} / \mathrm{min})$ \\
\hline
\end{tabular}

A lithium metaborate fusion sample digestion was used to prepare glass samples and dried or calcined $\left(1100^{\circ} \mathrm{C}\right)$ sludge samples. The sample preparation consisted of fusing $0.1 \mathrm{~g}$ of sample and $0.3 \mathrm{~g} \mathrm{LiBO}_{2}$ in 
an oven at $900^{\circ} \mathrm{C}$ for 15 minutes. The fused sample was then dissolved in $20 \mathrm{ml}$ of $4 \% \mathrm{HNO}_{3}$ and $1 \mathrm{ml}$ of concentrated $\mathrm{HCl}$. The sample was then diluted to $100 \mathrm{ml}$ with deionized water (DIW).

The ICP-AES was calibrated using matrix matched standards. Calibration concentrations included a blank, 1.0, 5.0 and $10.0 \mathrm{mg} / \mathrm{L}$ standards. The $\mathrm{LiBO}_{2}$ sample digestion required no dilution prior to entry into the instrument due to the low sulfur concentration. A total of 10 replicates were run and averaged for each measurement.

\subsubsection{Physical Characterization}

In addition to visual observations, select samples were submitted for SEM/EDS analysis to characterize the glass surface and any unique glass features observed. EDS analysis will be used for elemental analysis (i.e., if a salt layer is observed, EDS will be used to assess if enriched in $\mathrm{Na}$ and S). Select glasses from both the crucible study series as well as the SMRF tests were evaluated. 
WSRC-TR-2004-00081

Revision 0

This page intentionally left blank. 


\subsection{RESULTS}

The results of the crucible scale tests and the SMRF tests are presented in Section 5.1 and 5.2, respectively. The primary focus of the discussion will center on $\mathrm{SO}_{4}{ }^{=}$solubility given the objective of the tests.

\subsection{Crucible Scale Tests}

\subsubsection{Chemical Compositions: Target Versus Measured}

In this section, the measured versus targeted compositions of the $\mathrm{SO}_{4}{ }^{=}$study glasses are presented and compared. Chemical composition measurements for these glasses were conducted by the SRTC-ML following four analytical plans. Two dissolution methods were utilized in measuring these chemical compositions: in all plans samples prepared by LM dissolution were used to measure elemental concentrations of calcium $(\mathrm{Ca})$, chromium $(\mathrm{Cr})$, copper $(\mathrm{Cu})$, potassium $(\mathrm{K})$, magnesium $(\mathrm{Mg})$, manganese $(\mathrm{Mn})$, sodium $(\mathrm{Na})$, nickel $(\mathrm{Ni})$, phosphorous $(\mathrm{P})$, sulfur $(\mathrm{S})$, zinc $(\mathrm{Zn})$, and zirconium $(\mathrm{Zr})$ and in all plans samples from glasses prepared by PF dissolution were used to measure elemental concentrations of boron (B) and lithium (Li). In analytical plan 2, aluminum (Al), iron (Fe), and silicon (Si), were measured by PF while in plans 1, 3, and 4 these elements are measured using LM. For each study glass, measurements were obtained from samples prepared in duplicate by each of these dissolution methods. All of the prepared samples were analyzed (twice for each element of interest) by ICP - AES (with the instrumentation being re-calibrated between the duplicate analyses). The analytical plans and a detailed assessment of the compositional measurements for these glasses are provided by Edwards (2004).

The elemental concentrations were converted to oxide concentrations by multiplying the values for each element by the gravimetric factor for the corresponding oxide. During this process, an elemental concentration that was determined to be below the detection limit of the analytical procedures used by the SRTC-ML was reduced to half of that detection limit as the oxide concentration was determined.

The four measurements for each oxide for each glass (over both preparation methods) were averaged to determine a representative chemical composition for each glass. These determinations were conducted both for the measured and for the bias-corrected data. A sum of oxides was also computed for each glass based upon both the measured and bias-corrected values. Figure B-1 in Appendix B provides plots showing results for each glass for each oxide to help highlight the comparisons among the measured, bias-corrected, and targeted values.

Table B-1 in Appendix B provides a summary of the average compositions as well as the targeted compositions and some associated differences and relative differences. Notice that the targeted sums of oxides for Batch 1 (a standard glass included in the plans and used to conduct the bias-correction (see Edwards 2004)) do not sum to 100\% due to an incomplete coverage of the oxides in this glass. All of the sums of oxides (both measured and bias-corrected) for the study glasses fall within the interval of 95 to $105 \mathrm{wt} \%$.

Entries in Table B-1 show the relative differences between the measured or bias-corrected values and the targeted values. These differences are shaded when they are greater than or equal to $5 \%$. Overall, these

comparisons between the measured and targeted compositions suggest that there were some difficulties in hitting the targeted compositions for some of the oxides for some of the glasses. However, these differences are not seen as being of practical concern. 


\subsubsection{Uncertainty of $\mathrm{SO}_{4}{ }^{=}$Measurements}

The average $\mathrm{SO}_{4}{ }^{=}$values (measured and targeted) for each of the study glasses appear as part of Table B1. Table B-1 lists the individual measurements for these results along with some additional measurements of $\mathrm{SO}_{4}{ }^{~}$ for these glasses. The information appearing in this table includes the "Prep" number (a 1 or 2 for glasses that were prepared twice) and the "ICP Blk" number (a 1 or 2 for prepared glasses that were measured by ICP-AES under two different calibrations). Thus, to understand the uncertainty of the average $\mathrm{SO}_{4}{ }^{=}$values, there is a need to estimate the contributions to this uncertainty due to variations in sample preparation and ICP calibration.

An estimate of the variation due to ICP Blank is derived from Figure B-2 in Appendix B. For this analysis, the $\mathrm{SO}_{4}{ }^{=}$values for each glass have been averaged across the preps for each ICP Blk. The exhibit provides a pooled estimate of the variation due to ICP Blk for these glasses. This estimate (expressed as a standard deviation) is provided by the "Root Mean Square Error" in the exhibit and is given by $0.009109 \mathrm{wt} \%$.

An estimate of the variation due to sample preparation is derived from Figure B-3 in Appendix B. For this analysis, the $\mathrm{SO}_{4}{ }^{=}$values for each glass have been averaged across ICP Blocks for each prep. The exhibit provides a pooled estimate of the variation due to prep for these glasses. This estimate (expressed as a standard deviation) is provided by the "Root Mean Square Error" in the exhibit and is $0.006713 \mathrm{wt} \%$.

The standard error ( $\mathrm{wt} \%$ ) for an average $\mathrm{SO}_{4}{ }^{2}$ value for one of the study glasses may be expressed by combining the standard deviations adjusting for the 2 preps and 2 calibrations used in the study as follows

Estimated Standard Error (wt\%) of the Sample Mean $=\sqrt{\frac{(0.006713)^{2}}{2}+\frac{(0.009109)^{2}}{2}}=0.008$

The degrees of freedom associated with the estimated standard deviations are conservatively taken to be 24 for sample preparation and 4 for ICP calibration. Using the smaller of these two (i.e., the 4) and assuming normality for the distribution of these errors, then a lower bound on the average $\mathrm{SO}_{4}{ }^{=}$value for a study glass (with $95 \%$ confidence) is given by subtracting a quantity equal to

$$
\mathrm{t}_{5 \%, 4} * 0.008=2.132 * 0.008=0.0172 \approx 0.02 \mathrm{wt} \%
$$

from the average $\mathrm{SO}_{4}{ }^{=}$value for that glass (where $t_{5 \%, 4}$ is the upper $5 \%$ tail of the Student's $\mathrm{t}$ distribution with 4 degrees of freedom, which has a value of 2.132).

\subsubsection{Visual Observations}

Visual observations for sealed crucible scale tests are summarized in Table 5-1. Note that two columns of observations are provided: (1) observations specific to the formation of a salt layer and (2) other observations of interest. The use of "no layer, deposits or coating" recorded in the " $\mathrm{SO}_{4}=$ observation" column implies that no sign of a salt layer, deposits, or a coating was observed on the surface of the glass, around the melt line meniscus, or along the walls of the crucible. The " $\mathrm{SO}_{4}{ }^{=}$observation" descriptor does not imply that the overall glass was homogeneous or "single phased". More specifically, the "Other" column is provided to summarize secondary observations with respect to the glass product. Only two secondary observations were recorded: (1) a homogeneous or "single phase" system and (2) the presence of "metallic coating or sheen" across the surface of select glasses. The use of "single phase" for this 
"secondary" descriptor implies that the resulting glass was homogeneous - no visual signs of a salt layer, deposits, or a coating (either $\mathrm{SO}_{4}{ }^{=}$or metallic in nature).

Table 5-1. Visual Observations of the Batch Chemical Sealed Crucible Tests.

\begin{tabular}{|c|c|c|c|}
\hline Glass ID & $\begin{array}{c}\mathrm{SO}_{4}{ }^{=} \text {Target } \\
(\mathrm{wt} \%)\end{array}$ & $\mathrm{SO}_{4}{ }^{=}$Observation & Other \\
\hline \multicolumn{4}{|c|}{ Batch Chemical } \\
\hline \multicolumn{4}{|l|}{$100 \% \mathrm{~Np}$} \\
\hline s-bc-100-30 & 0.58 & No layer, deposits or coating & Single phase \\
\hline s-bc-100-33 & 0.63 & No layer, deposits or coating & Single phase \\
\hline s-bc-100-35 & 0.67 & No layer, deposits or coating & $\begin{array}{l}\text { Slight metallic haze on surface (partial } \\
\text { coverage; center only) }\end{array}$ \\
\hline s-bc-100-37 & 0.71 & No layer, deposits or coating & Metallic haze on surface (full coverage) \\
\hline s-bc-100-40 & 0.77 & $\mathrm{SO}_{4}{ }^{=}$(yellow meniscus/white surface) & Metallic haze on surface (full coverage) \\
\hline \multicolumn{4}{|l|}{$50 \% \mathrm{~Np}$} \\
\hline s-bc-50-30 & 0.49 & No layer, deposits or coating & Single phase \\
\hline s-bc-50-33 & 0.54 & No layer, deposits or coating & Single phase \\
\hline s-bc-50-35 & 0.57 & No layer, deposits or coating & $\begin{array}{c}\text { Slight metallic haze on surface (partial } \\
\text { coverage) }\end{array}$ \\
\hline s-bc-50-37 & 0.60 & No layer, deposits or coating & Metallic haze on surface (full coverage) \\
\hline s-bc-50-40 & 0.65 & No layer, deposits or coating & Metallic haze on surface (full coverage) \\
\hline s-bc-50-48 & 0.78 & $\mathrm{SO}_{4}{ }^{=}$(yellow meniscus/white surface) & Metallic haze on surface (full coverage) \\
\hline \multicolumn{4}{|c|}{ SRAT Product } \\
\hline \multicolumn{4}{|l|}{$100 \% \mathrm{~Np}$} \\
\hline s-sp-100-30 & 0.59 & No layer, deposits or coating & Single phase \\
\hline s-sp-100-33 & 0.64 & No layer, deposits or coating & $\begin{array}{l}\text { Slight metallic haze on surface (partial } \\
\text { coverage; agglomerate near meniscus) }\end{array}$ \\
\hline s-sp-100-35 & 0.68 & No layer, deposits or coating & $\begin{array}{l}\text { Slight metallic haze on surface (partial } \\
\text { coverage; center only) }\end{array}$ \\
\hline s-sp-100-37 & 0.72 & No layer, deposits or coating & $\begin{array}{c}\text { Metallic haze on surface (partial coverage; } \\
\text { agglomerates near meniscus) }\end{array}$ \\
\hline s-sp-100-40 & 0.78 & No layer, deposits or coating ${ }^{9}$ & Metallic haze on surface (full coverage) \\
\hline s-sp-100-42 & 0.82 & No layer, deposits or coating & $\begin{array}{l}\text { Metallic haze on surface (full coverage) } \\
\text { and agglomerates }\end{array}$ \\
\hline s-sp-100-44 & 0.86 & No layer, deposits or coating & $\begin{array}{l}\text { Metallic haze on surface (full coverage) } \\
\text { and agglomerates }\end{array}$ \\
\hline \multicolumn{4}{|l|}{$50 \% \mathrm{~Np}$} \\
\hline s-sp-50-30 & 0.50 & No layer, deposits or coating & Single phase \\
\hline
\end{tabular}

9 Observations on the initial s-sp-100-40 melt indicated that the product was partially reacted (e.g., the sample was not "glassy" like other products in this series - including the higher WL glasses). Several "white spots" (presumably $\mathrm{SO}_{4}{ }^{\overline{ }}$ ) were observed on the crucible walls of this initial sample - although $\mathrm{SO}_{4}{ }^{=}$was not observed in higher WL tests (s-sp-100-42 and s-sp-100-44). Two additional melts were made targeting the s-sp-100-40 glass with both melts producing a more vitreous product lacking the presence of $\mathrm{SO}_{4}{ }^{=}$on the glass surface or along the crucible walls. 
WSRC-TR-2004-00081

Revision 0

\begin{tabular}{||l|c|c|c||}
\hline Glass ID & $\begin{array}{c}\mathbf{S O}_{4}{ }^{{ }} \text {Target } \\
(\mathbf{w t} \%)\end{array}$ & $\mathbf{S O}_{4}{ }^{{ }^{\prime}}$ Observation & Other \\
\hline s-sp-50-33 & 0.55 & No layer, deposits or coating & Single phase \\
\hline s-sp-50-35 & 0.59 & No layer, deposits or coating & $\begin{array}{c}\text { Slight metallic haze on surface (partial } \\
\text { coverage) with an agglomerate }\end{array}$ \\
\hline s-sp-50-37 & 0.62 & No layer, deposits or coating & $\begin{array}{c}\text { Metallic haze on surface (full coverage) } \\
\text { and agglomerates }\end{array}$ \\
\hline s-sp-50-40 & 0.67 & No layer, deposits or coating & $\begin{array}{c}\text { Metallic haze on surface (full coverage) } \\
\text { and agglomerates }\end{array}$ \\
\hline s-sp-50-45 & 0.76 & No layer, deposits or coating & $\begin{array}{c}\text { Metallic haze on surface (full coverage) } \\
\text { and agglomerates }\end{array}$ \\
\hline
\end{tabular}

\subsubsection{Salt Layer Formation and Characterization}

The primary observation was the formation of $\mathrm{a} \mathrm{SO}_{4}{ }^{=}$(yellow) salt layer around the meniscus of the s-bc100-40 and s-bc-50-48 glasses - both batch chemical-based glasses. In addition to the yellow salt layer, a white haze was observed on the surface (full coverage) on both glasses. All other glasses were characterized as being homogeneous with respect to a potential salt layer.

Figure 5-1 and Figure 5-2 are digital photos of the s-bc-100-40 and s-bc-50-48 glasses, respectively. The formation of a $\mathrm{SO}_{4}{ }$ layer on the surface of these two glasses provides a measure of consistency with respect to the $\mathrm{SO}_{4}{ }^{-}$limit for this particular glass. More specifically, the targeted $\mathrm{SO}_{4}{ }^{=}$concentration for these two glasses were 0.77 and $0.78 \mathrm{wt}^{2} \mathrm{SO}_{4}{ }^{\circ}$, respectively (assuming no volatilization). The results indicated that the $\mathrm{SO}_{4}{ }^{=}$solubility limit for these two glasses had been exceeded, forcing $\mathrm{SO}_{4}{ }^{-}$to the surface of the glass as $\mathrm{Na}_{2} \mathrm{SO}_{4}$ (a situation to be avoided in DWPF). With respect to establishing a new $\mathrm{SO}_{4}{ }{ }$ solubility limit for DWPF, the primary driver will be the retention of $\mathrm{SO}_{4}{ }^{=}$in the glass as measured by ICP-AES. These results are reported and discussed in Sections 5.1.5, 5.1.6, and 6.0. 


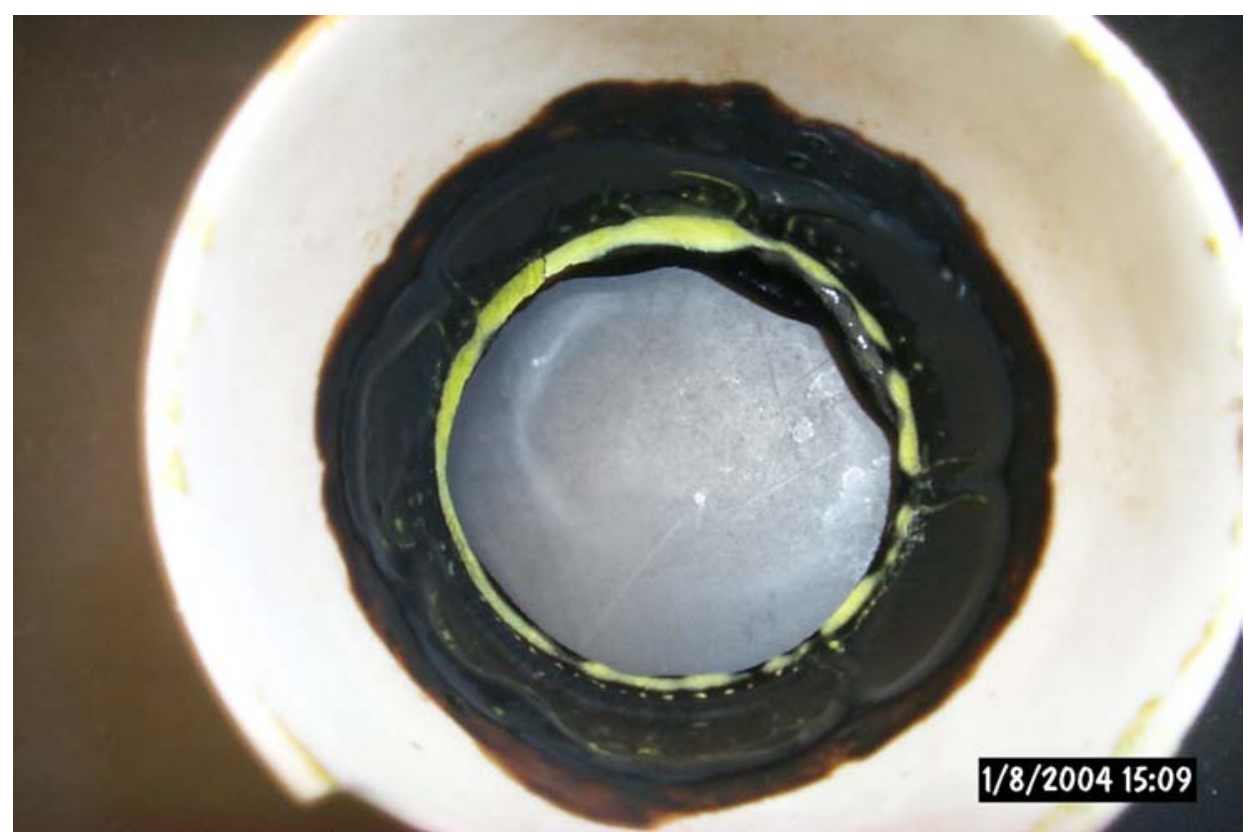

(a)

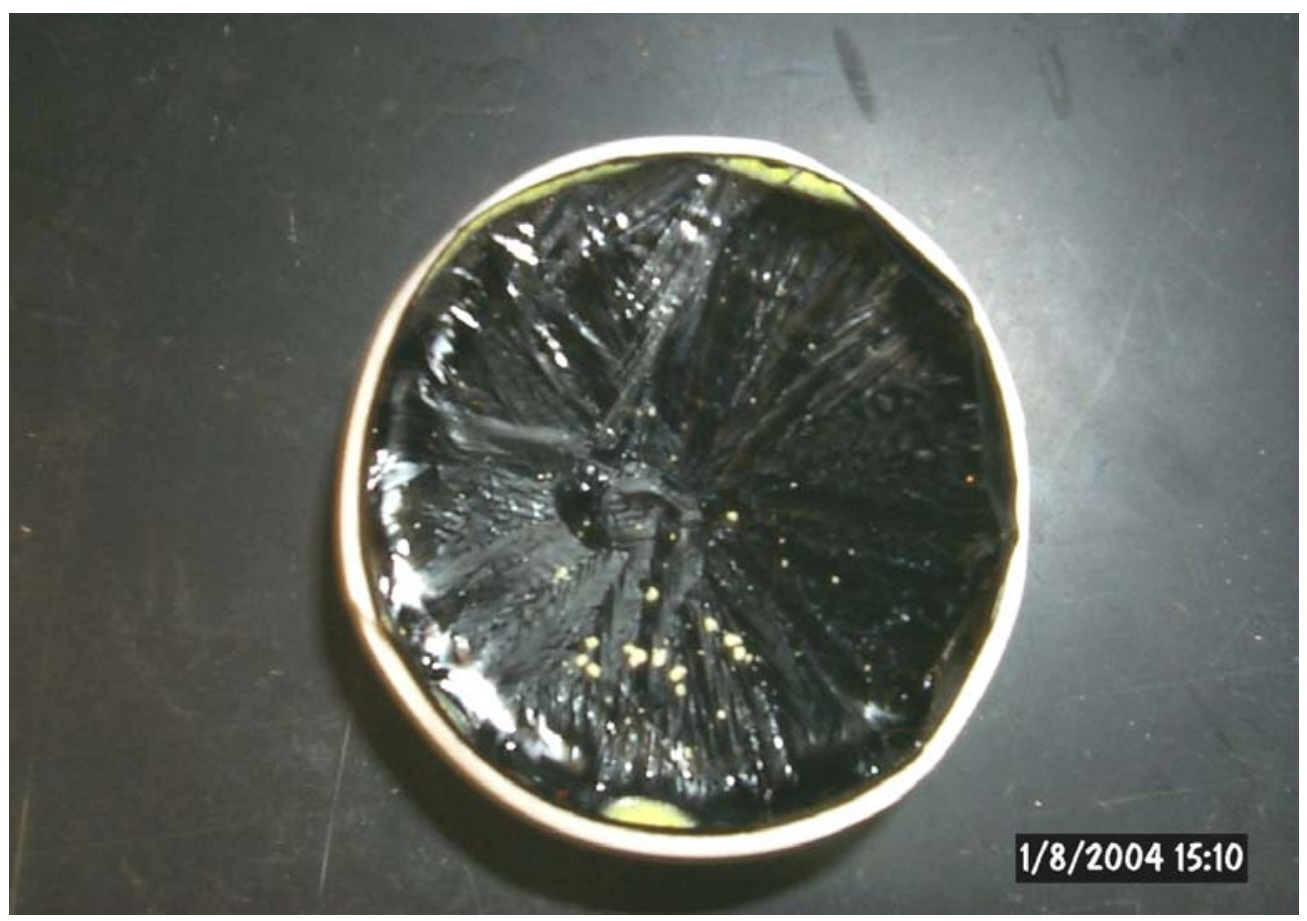

(b)

Figure 5-1. Digital Photos of the s-bc-100-40 Glass. 


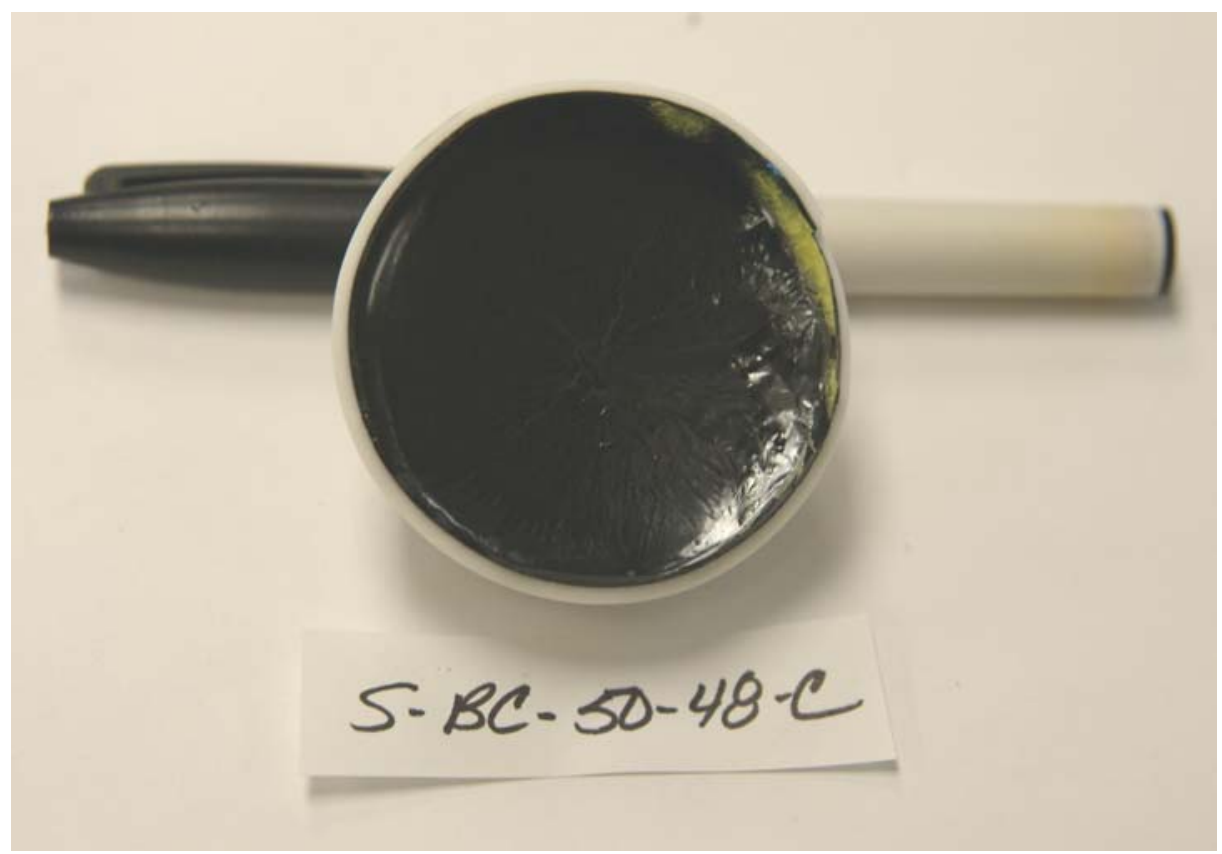

Figure 5-2. Digital Photo of the s-bc-50-48 Glass.

Physical and compositional characterizations on both the yellow and white layers observed were performed using SEM/EDS and ICP-AES. SEM/EDS analysis was performed on the white coating observed on the s-bc-100-40 sample (see Figure 5-1(b)). Figure 5-3 shows a SEM micrograph of the highly dendritic, crystalline phase (or white coating). EDS analysis indicates that this coating is enriched in sulfur (see Figure 5-4). This layer was soluble in DIW as shown in a SEM micrograph after the sample had been rinsed (see Figure 5-5).

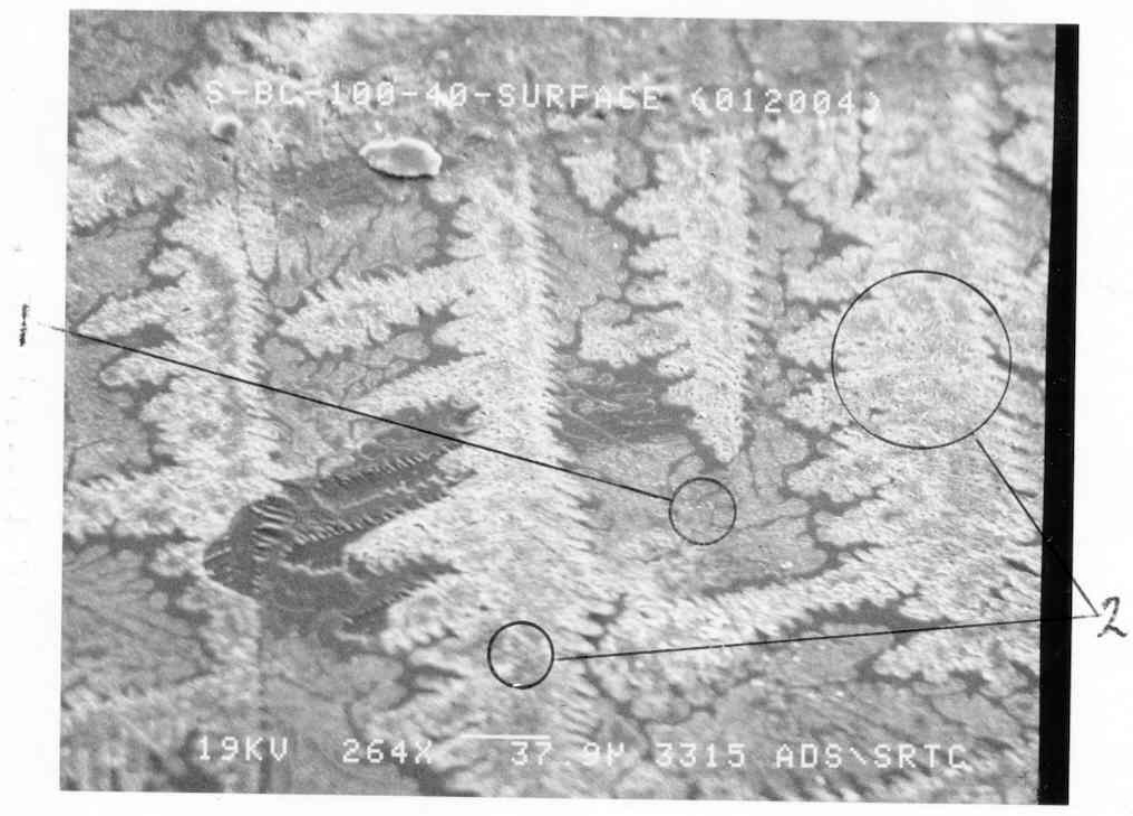

Figure 5-3. SEM Micrograph of the White Layer Associated with s-bc-100-40. 
Thermo NORAN

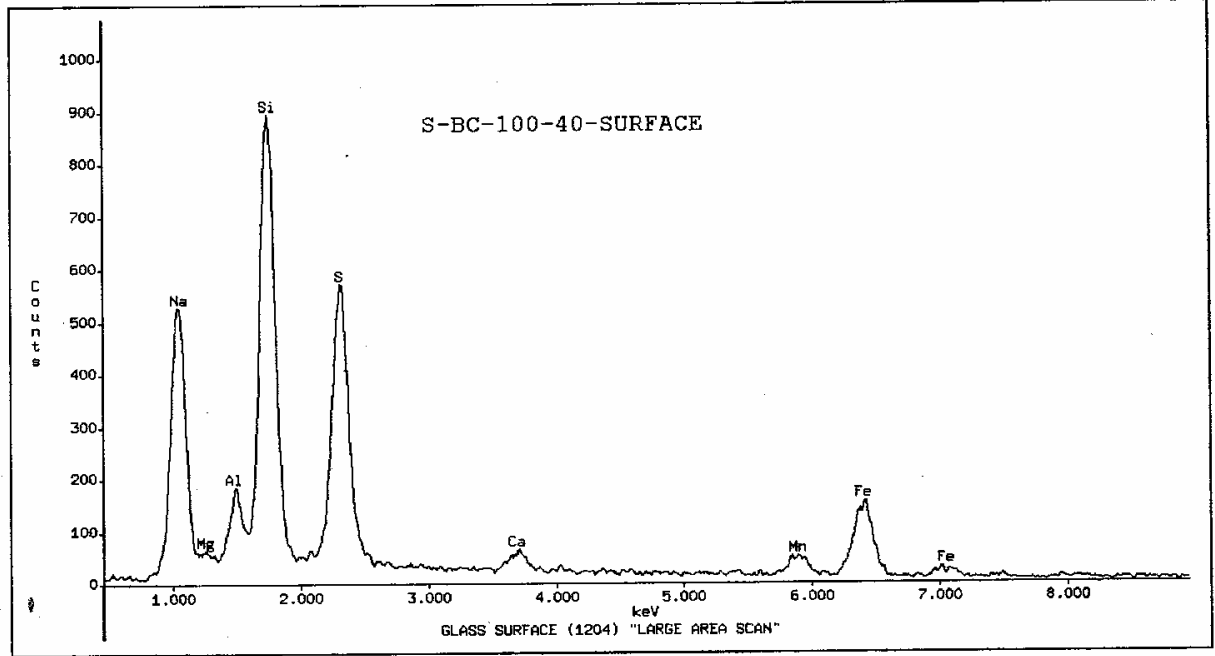

GLASS SURFACE (1204) "LARGE AREA SCAN"

Accelerating Voltage: $19 \mathrm{KeV}$

Take Off Angle: $10.0806^{\circ}$

Live Time: $\mathbf{4 7 . 2 5}$ seconds

Dead Time: 3.313 seconds

Figure 5-4. EDS Analysis of the White Layer Associated with s-bc-100-40.
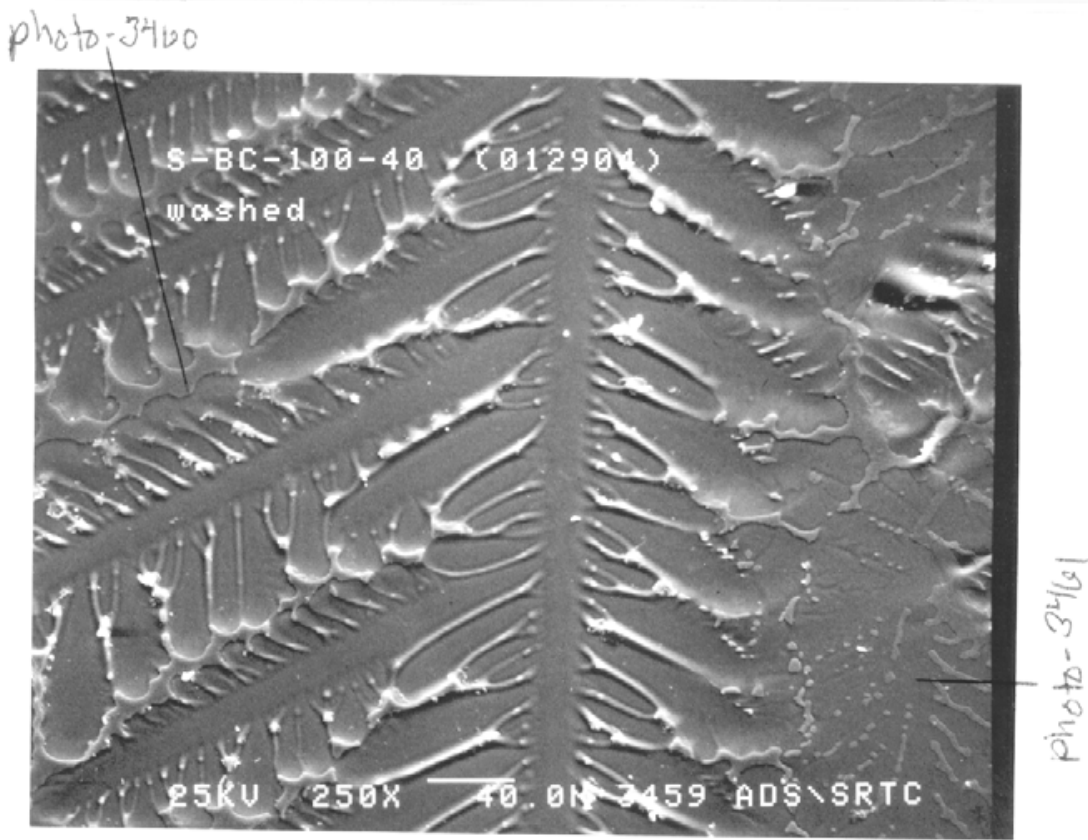

Figure 5-5. SEM Micrograph of a "Rinsed" s-bc-100-40 Sample. 
To support ICP-AES analysis, the yellow salt observed around the meniscus of the s-bc-100-40 glass (see Figure 5-1(a)) was rinsed with a known volume of DIW. The "salt" layer was soluble - like the white coating shown in Figure 5-3 through Figure 5-5. An approximate weight (before and after rinsing) of the salt layer was obtained ( 0.1297 grams) to support material balance efforts. ICP-AES analysis indicates that the yellow layer is enriched in $\mathrm{Na}$ and $\mathrm{S}$ (see Table 5-2).

Table 5-2. ICP-AES Analysis of the Rinsed Yellow Layer on s-bc-100-40.

\begin{tabular}{||c|c|c||}
\hline Element & $\mathbf{m g} / \mathbf{k g}$ & Elemental wt\% \\
\hline $\mathrm{Al}$ & 98.7 & 0.01 \\
\hline $\mathrm{B}$ & 481 & 0.05 \\
\hline $\mathrm{Ca}$ & 4000 & 0.40 \\
\hline $\mathrm{Cr}$ & 4380 & 0.44 \\
\hline $\mathrm{Cu}$ & 16.2 & 0.00 \\
\hline $\mathrm{Fe}$ & $<0.100$ & 0.00 \\
\hline $\mathrm{Li}$ & 14800 & 1.48 \\
\hline $\mathrm{Mg}$ & $<0.100$ & 0.00 \\
\hline $\mathrm{Mn}$ & $<0.100$ & 0.00 \\
\hline $\mathrm{Na}$ & $\mathbf{2 7 0 6 0 0}$ & $\mathbf{2 7 . 0 6}$ \\
\hline $\mathrm{Ni}$ & $<0.100$ & 0.00 \\
\hline $\mathrm{P}$ & 689 & 0.07 \\
\hline $\mathrm{S}$ & $\mathbf{2 1 4 0 0 0}$ & $\mathbf{2 1 . 4 0}$ \\
\hline $\mathrm{Si}$ & $<0.100$ & 0.00 \\
\hline $\mathrm{Zn}$ & $<0.100$ & 0.00 \\
\hline $\mathrm{Zr}$ & 15.4 & 0.00 \\
\hline \hline
\end{tabular}

As previously mentioned, the presence of a salt layer on the surface of s-bc-100-40 and s-bc-50-48 indicates that the $\mathrm{SO}_{4}{ }^{\circ}$ solubility limit in the glass has been exceeded. In Section 6.0, measured $\mathrm{SO}_{4}{ }^{=}$ values (in glass) are reported and discussed with respect to establishing a new $\mathrm{SO}_{4}{ }^{\circ}$ solubility limit for DWPF. The formation of the white coating may be the result of $\mathrm{Na}_{2} \mathrm{SO}_{4}$ condensing on the surface of the glass as the sealed crucible cooled from the nominal melt temperature.

\subsection{5 "Metallic Coating" or Sheen Characterization}

As noted in Table 5-1, a "metallic coating or sheen" was observed on the surface of several glasses (both batch chemical and SRAT product based). For both the 100\% and 50\% Np-transfer cases, the presence of this morphology was initially detected at $33 \%$ or $35 \% \mathrm{WL}$ and became more obvious as WL increased. In fact at the higher WLs, the surface was almost "mirror-like". It should be noted that observations of the glass cross-section indicated that the coating or sheen was solely a surface phenomenon.

Figure 5-6 through Figure 5-12 summarizes the SEM/EDS analysis of several SRAT-product based glasses. Figure 5-6 and Figure 5-8 show the surface of s-sp-50-40. In Table 5-1, this glass was characterized via visual observations as having a "metallic haze on surface (full coverage)". At lower magnifications (see Figure 5-6), a "non-uniform" coating is observed on the surface of this glass. At 
higher magnifications (see Figure 5-7), the coating is associated with the "classic" morphology of spinel crystals. EDS analysis (see Figure 5-8) of the crystals indicates that the crystals are enriched in Fe, Mn, $\mathrm{Ni}$, and $\mathrm{Cr}$ (all spinel formers).

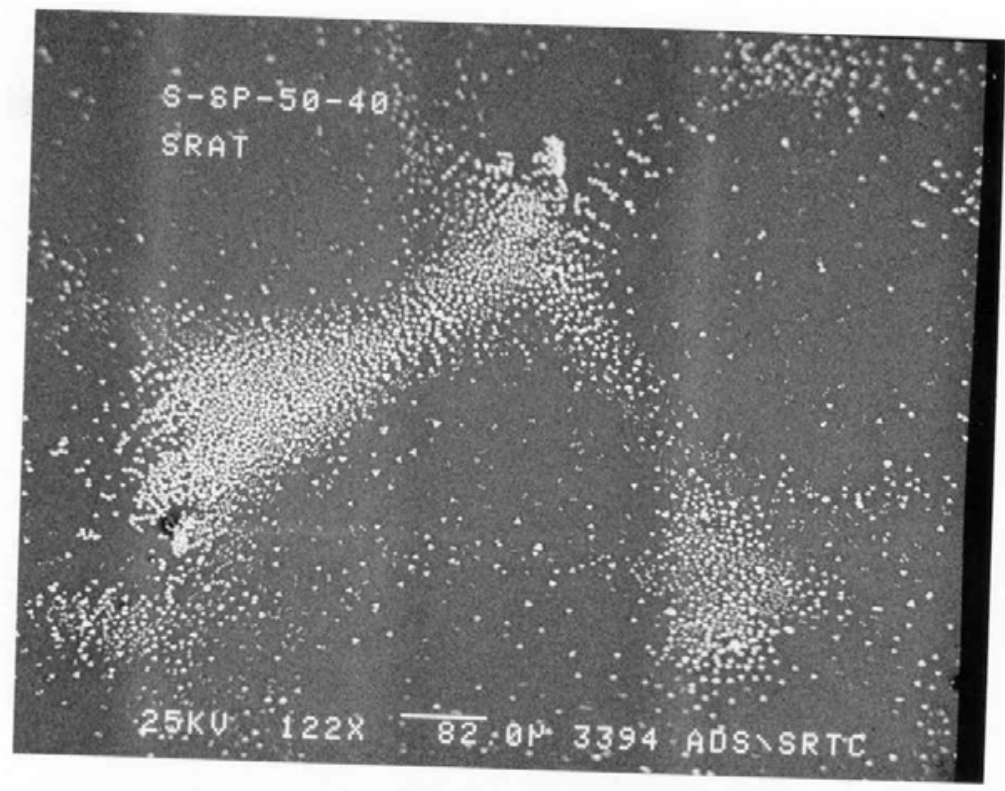

Figure 5-6. "Low" Magnification of s-sp-50-40 (Surface Analysis). 


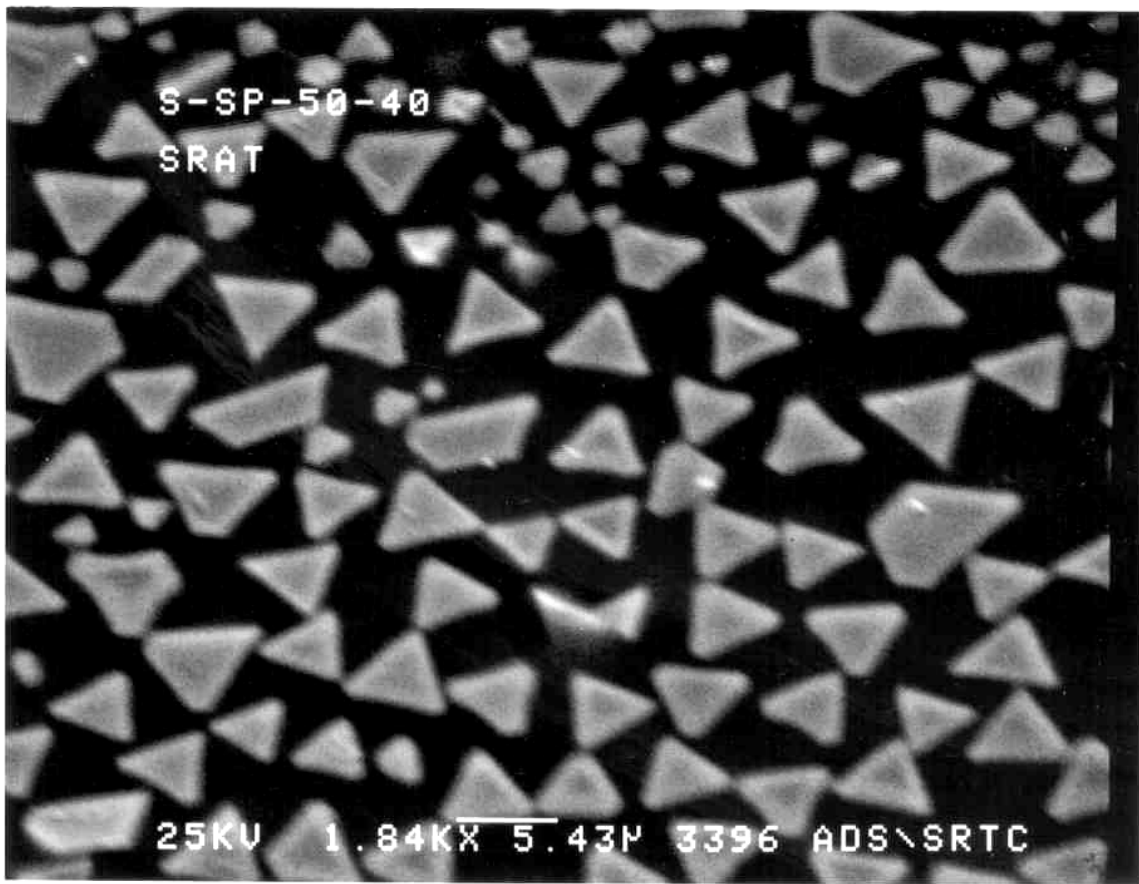

Figure 5-7. "High" Magnification of s-sp-50-40 (Surface Analysis).

ThermoNORAN

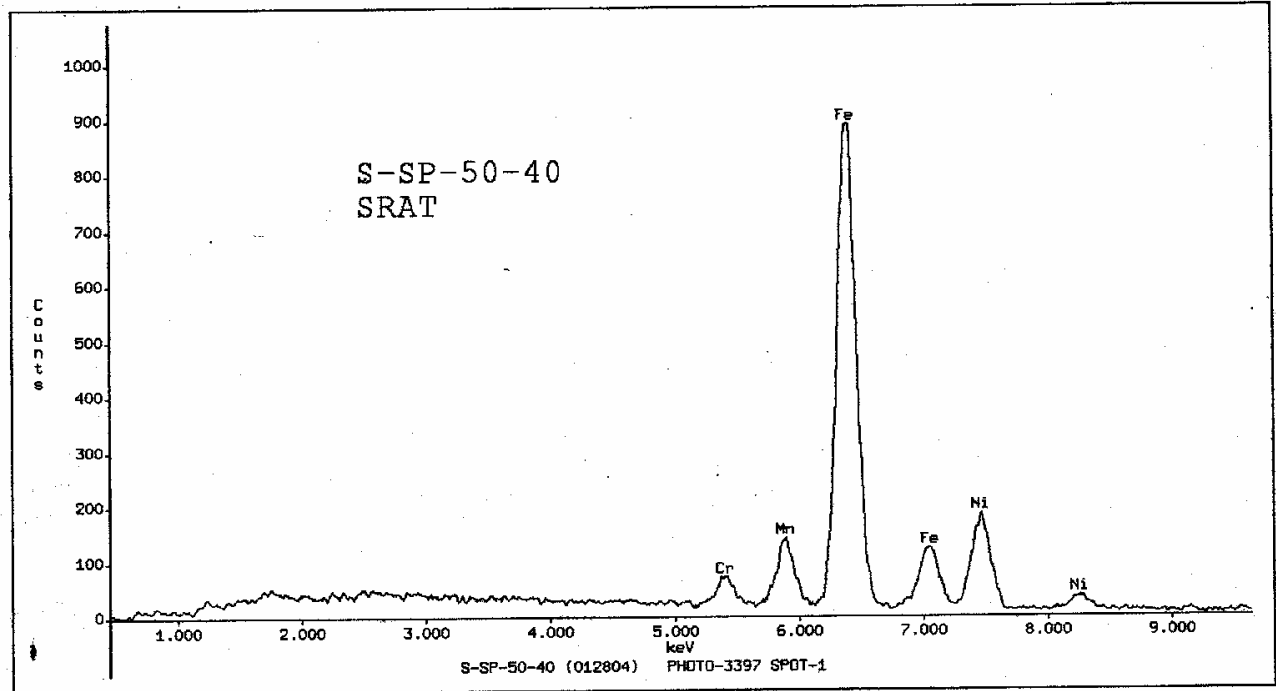

S-SP-50-40 (012804) PHOTO-3397 SPOT-1

Accelerating Voltage: $19 \mathrm{KeV}$ Take Off Angle: $10.0806^{\circ} \quad$ Live Time: 29.15 seconds

Dead Time: 2.397 seconds

Figure 5-8. EDS Spectra of s-sp-50-40 Surface Crystallization. 
Additional SEM/EDS analyses of select glasses are shown in Figure 5-9 through Figure 5-12. As with ssp-50-40, each surface is characterized by the presence of Fe, Mn, Ni, and Cr-enriched crystals (typical of a spinel).

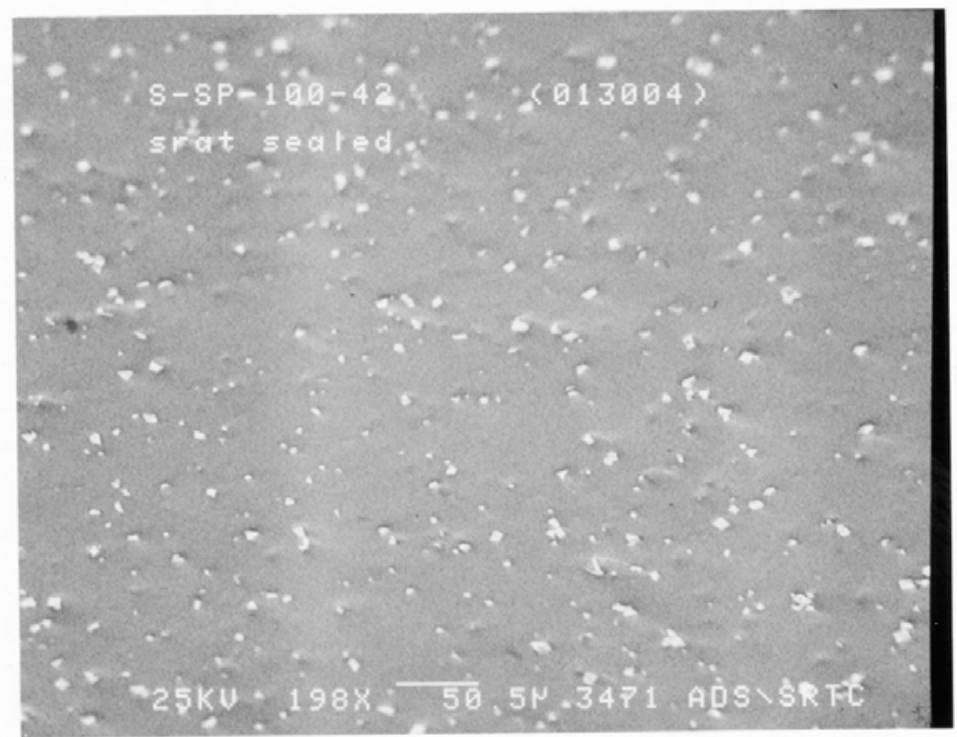

Figure 5-9. SEM Micrograph of s-sp-100-42

ThermoNORAN

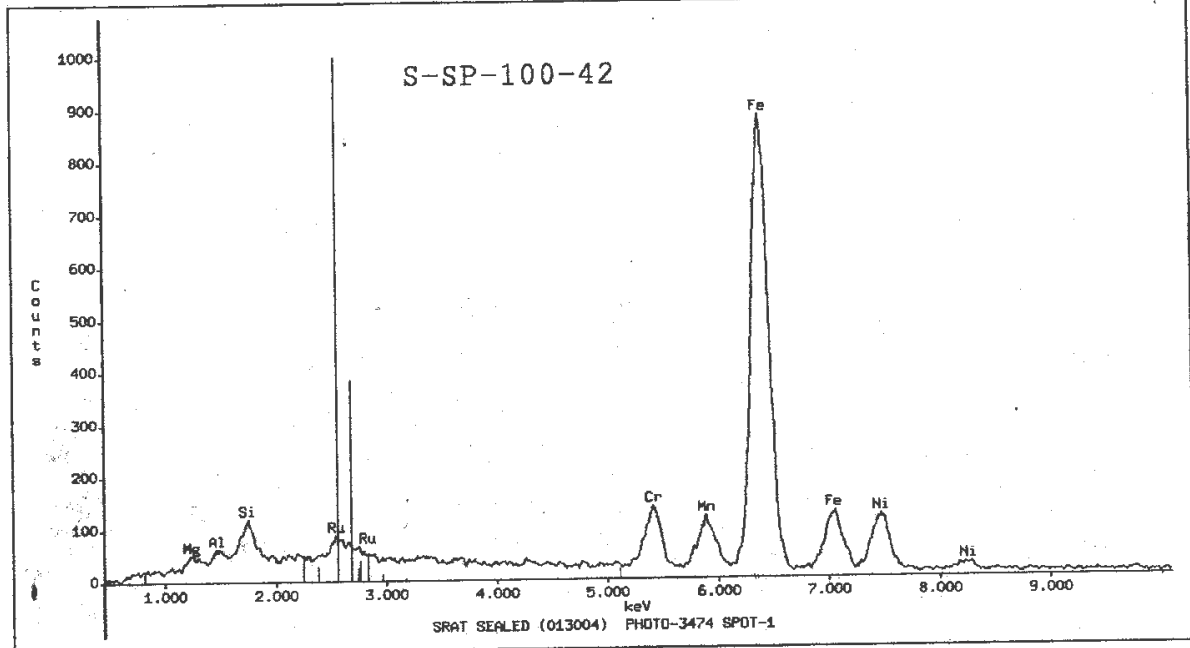

SRAT SEALED (013004) PHOTO-3474 SPOT-1

Accelerating Voltage: $19 \mathrm{KeV}$

Take Off Angle: $10.0806^{\circ}$

Live Time: 44.67 seconds

Dead Time: 3.213 seconds

Figure 5-10. EDS Spectra of Surface Crystallization Associated with s-sp-100-42 


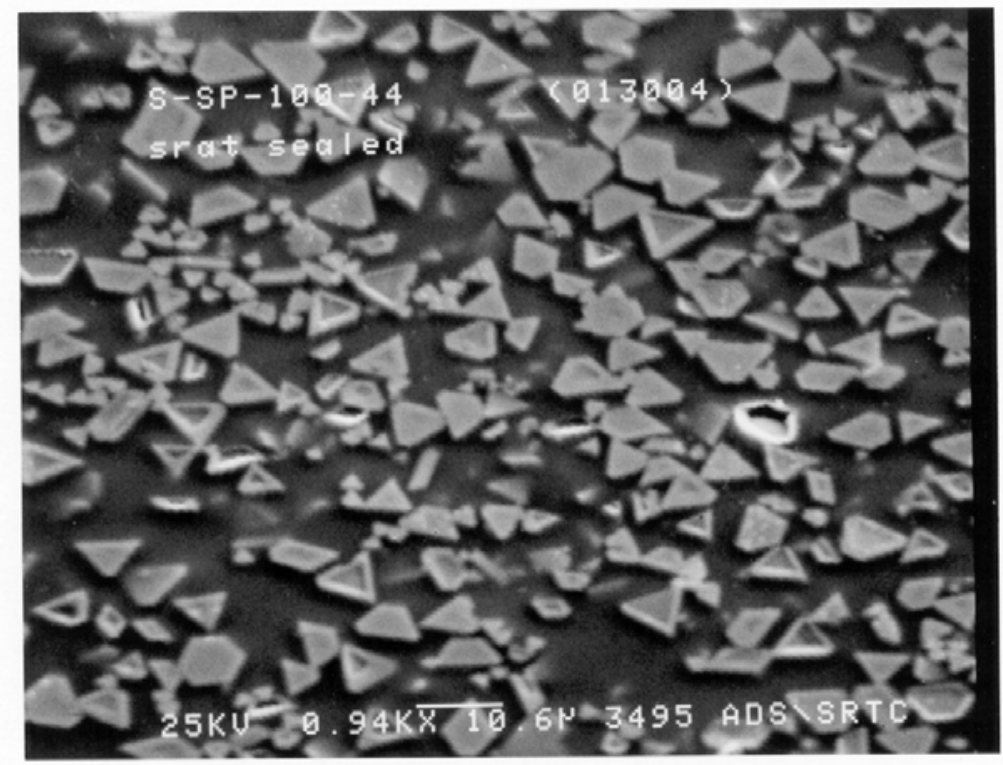

Figure 5-11. SEM Micrograph of s-sp-100-44.

ThermoNORAN

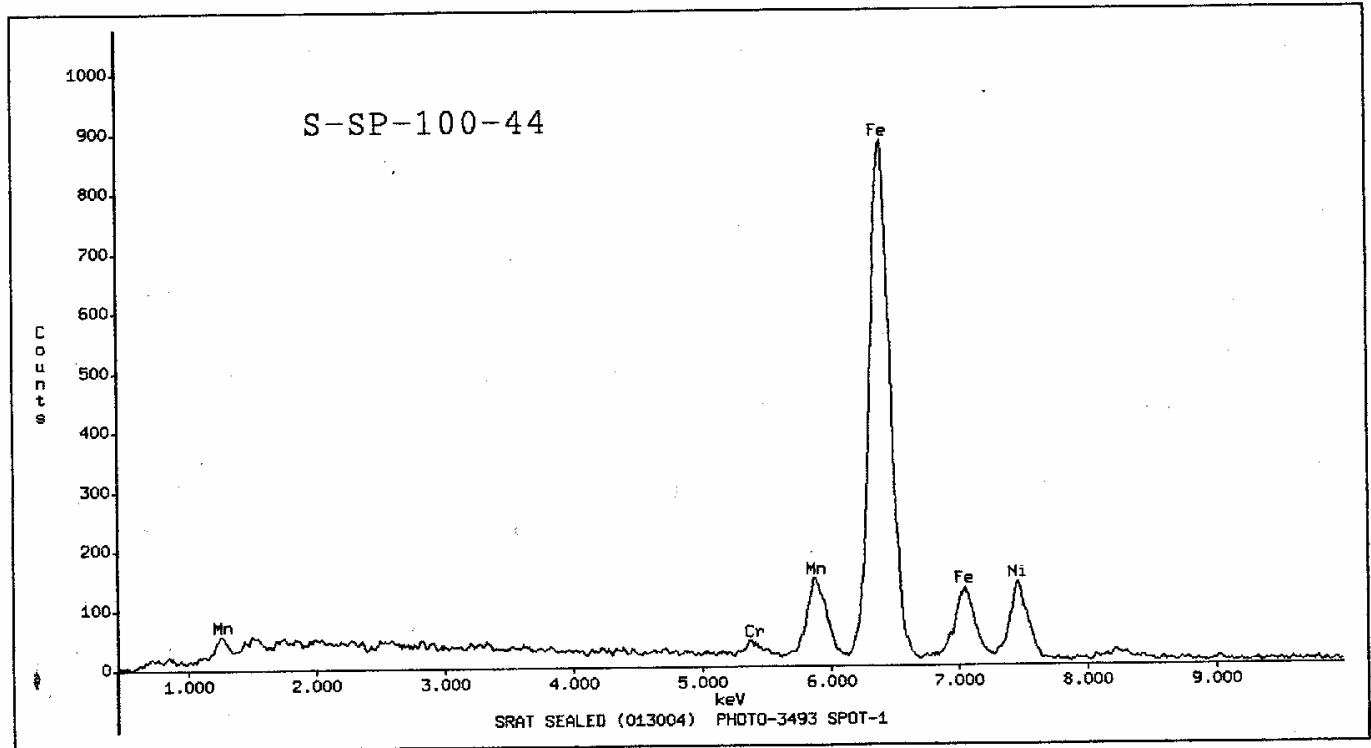

SRAT SEALED (013004) PHOTO-3493 SPOT-1

Accelerating Voltage: $19 \mathrm{KeV}$ Take Off Angle: $10.0806^{\circ}$ Live Time: 25.97 seconds Dead Time: 2.383 seconds

Figure 5-12. EDS Spectra of Surface Crystallization Associated with s-sp-100-44. 
Based on SEM/EDS analysis, the metallic coating or sheen is a result of spinel formation. As WL increases, the concentration of spinel-formers (e.g., $\mathrm{Fe}, \mathrm{Ni}$, and $\mathrm{Cr}$ ) in glass increases. As mentioned in Section 4.1.2, the crucibles were removed after the 2 hour isothermal hold and allowed to cool to room temperature (with the lid on) over a $2-3$ hour time period. This relatively slow cooling process coupled with the enhanced concentration of spinel-formers increases the likelihood of forming spinels on the surface of the glasses - the degree of spinel formation increasing with WL. This would support the observations regarding the transition of the coating from partial to full coverage as well as the "degree" of reflectiveness as WL increased. It should be noted that the formation of spinel on a surface during cooling is not linked to the liquidus temperature $\left(T_{L}\right)$ processing constraint - this is confirmed by the absence of devitrification within the bulk glass.

It was critical to the objectives of this report to establish that the "metallic coating" was not associated with a salt layer of any sort. Although SEM/EDS analysis played a critical role, the surface was also evaluated for its propensity to dissolve in water. The "metallic coating" was insoluble in DIW.

\subsection{6 $\mathrm{SO}_{4}{ }^{=}$Retention or Solubility}

With respect to the test objectives, the most critical data assessment is the $\mathrm{SO}_{4}{ }^{=}$concentration retained in the glass product. Table 5-3 summarizes the targeted and measured $\mathrm{SO}_{4}{ }^{-}$values for the batch chemical and SRAT product glasses. 
Table 5-3. Target Versus Measured $\mathrm{SO}_{4}{ }{ }$ Concentrations in Glass.

\begin{tabular}{|c|c|c|c|}
\hline \multicolumn{4}{|c|}{ Batch Chemicals } \\
\hline \multicolumn{4}{|l|}{$100 \% \mathrm{~Np}$} \\
\hline Glass ID & WL & Target $\mathrm{SO}_{4}{ }^{=}$ & Measured $\mathrm{SO}_{4}{ }^{=}$ \\
\hline s-bc-100-30 & 30 & 0.58 & 0.58 \\
\hline s-bc-100-33 & 33 & 0.63 & 0.61 \\
\hline s-bc-100-35 & 35 & 0.67 & 0.68 \\
\hline s-bc-100-37 & 37 & 0.71 & 0.69 \\
\hline s-bc-100-40 & 40 & 0.77 & 0.68 \\
\hline \multicolumn{4}{|l|}{$50 \% \mathrm{~Np}$} \\
\hline s-bc-50-30 & 30 & 0.49 & 0.49 \\
\hline s-bc-50-33 & 33 & 0.54 & 0.54 \\
\hline s-bc-50-35 & 35 & 0.57 & 0.59 \\
\hline s-bc-50-37 & 37 & 0.60 & 0.59 \\
\hline s-bc-50-40 & 40 & 0.65 & 0.64 \\
\hline s-bc-50-48 & 48 & 0.78 & 0.71 \\
\hline \multicolumn{4}{|l|}{ SRAT Product } \\
\hline \multicolumn{4}{|l|}{$100 \% \mathrm{~Np}$} \\
\hline Glass ID & WL & Target $\mathrm{SO}_{4}{ }^{=}$ & Measured $\mathrm{SO}_{4}{ }^{=}$ \\
\hline s-sp-100-30 & 30 & $0.59^{10}$ & 0.49 \\
\hline s-sp-100-33 & 33 & 0.64 & 0.51 \\
\hline s-sp-100-35 & 35 & 0.68 & 0.54 \\
\hline s-sp-100-37 & 37 & 0.72 & 0.53 \\
\hline s-sp-100-40 & 40 & 0.78 & 0.47 \\
\hline s-sp-100-42 & 42 & 0.82 & 0.66 \\
\hline s-sp-100-44 & 44 & 0.86 & 0.72 \\
\hline \multicolumn{4}{|l|}{$50 \% \mathrm{~Np}$} \\
\hline s-sp-50-30 & 30 & 0.50 & 0.38 \\
\hline s-sp-50-33 & 33 & 0.55 & 0.49 \\
\hline s-sp-50-35 & 35 & 0.59 & 0.46 \\
\hline s-sp-50-37 & 37 & 0.62 & 0.48 \\
\hline s-sp-50-40 & 40 & 0.67 & 0.50 \\
\hline s-sp-50-45 & 45 & 0.76 & 0.56 \\
\hline
\end{tabular}

First consider the batch chemical based tests (shaded gray in Table 5-3). In general, the results indicate full retention (no volatilization) of $\mathrm{SO}_{4}{ }^{=}$for all glasses which were visually homogeneous with respect to a salt layer. For s-bc-100-40 and s-bc-50-48 (with salt layers present), the $\mathrm{SO}_{4}{ }^{{ }}$concentrations measured in glass are 0.68 and $0.71 \mathrm{wt} \%$, respectively - significantly lower than the targeted concentrations. The $\mathrm{SO}_{4}{ }^{=}$difference or balance being associated with the observed salt layer and/or potential partitioning to the off-gas. It should be noted that these glasses were batched and melted under oxidizing conditions. Jantzen and Smith (2003) indicate that as melting conditions become more reducing, sulfur volatility is expected to increase (sulfur volatilizing primarily as $\mathrm{SO}_{2}$ instead of $\mathrm{Na}_{2} \mathrm{SO}_{4}$ vapor). Therefore, the

\footnotetext{
${ }^{10}$ The targeted $\mathrm{SO}_{4}{ }^{=}$contents are based on the measured $\mathrm{SO}_{4}{ }^{=}$content in the SRAT multiplied by the WL (and assume no volatilization occurs).
} 
oxidizing fabrication conditions coupled with the sealed crucibles should translate into minimizing (or eliminating within analytical uncertainties) volatility for the batch chemical series of tests.

Next consider the SRAT-based tests. There was no salt layer observed on any of the SRAT-based crucible scaled tests. The visual observations suggest either complete solubility of $\mathrm{SO}_{4}{ }^{=}$or some degree of volatilization. The targeted $\mathrm{SO}_{4}{ }{ }$ concentrations of s-sp-100-42 and s-sp-100-44 were 0.82 and 0.86 $\mathrm{wt} \%$, respectively (based on the measured $\mathrm{SO}_{4}{ }{ }$ content in the SRAT and the projected WL). Both of these values exceeded the $\mathrm{SO}_{4}{ }^{=}$contents of s-bc-100-40 and s-bc-50-48 glasses, 0.77 and $0.78 \mathrm{wt} \%$ respectively. Since both of these glasses had a salt layer form, the probability of complete $\mathrm{SO}_{4}{ }^{=}$solubility in the SRAT based glasses is low. In fact, the measured $\mathrm{SO}_{4}{ }^{\prime}$ concentrations in the SRAT-based glass suggest some degree of $\mathrm{SO}_{4}{ }^{=}$partitioning to the off-gas as all of the measured concentrations were lower than the targeted values. Given the SRAT products were produced targeting a 0.2 REDOX state, volatilization of sulfur as $\mathrm{SO}_{2}$ is likely. The total $\mathrm{SO}_{4}{ }^{=}$retained for the SRAT-based glasses ranges from $0.38 \mathrm{wt} \%$ (s-sp-50-30) to $0.72 \mathrm{wt} \%$ (s-sp-100-44).

\subsection{7 "Spiked" $\mathrm{Na}_{2} \mathrm{SO}_{4}$ Tests}

The data presented in Section 5.1.6 indicate that the batch chemical tests are "conservative" with respect to sulfur retention (i.e., little if any volatilization observed based on targeted versus measured $\mathrm{SO}_{4}{ }^{=}$ contents in glass). These data can also be considered conservative from a salt layer formation perspective since only $\mathrm{Na}_{2} \mathrm{SO}_{4}$ vapor is present instead of $\mathrm{SO}_{2}$ vapor. An example of this is provided by s-bc-100-40 in which a salt layer was observed but its SRAT-based counterpart (s-sp-100-40) did not have a salt layer. Therefore, establishing a $\mathrm{SO}_{4}{ }^{*}$ limit with the batch chemical tests would be conservative given potential volatility would not be accounted for.

Although full retention of $\mathrm{SO}_{4}{ }^{=}$was observed in the batch chemical based tests as a function of WL, the issue of $\mathrm{SO}_{4}{ }^{=}$solubility has still not been challenged at the lower WLs. That is, at $40 \% \mathrm{WL}$ the formation of the salt layer indicated that the $\mathrm{SO}_{4}{ }^{=}$solubility had been exceeded for that glass composition. The measured $\mathrm{SO}_{4}{ }^{=}$content in s-bc- $100-40$ was $0.68 \mathrm{wt} \%$ (compared to the $0.77 \mathrm{wt} \%$ target). At lower WLs, the measured $\mathrm{SO}_{4}{ }^{*}$ concentrations in glass matched the targeted values (given the analytical uncertainties of the SRTC-ML ICP-AES measurements the values are considered to be statistically the same) with no visual observation of a salt layer formation. These results give rise to the following question: "Would glasses at lower WLs retain higher concentrations of $\mathrm{SO}_{4}{ }^{=}$if available?" In other words, are the lower WL glasses approaching their $\mathrm{SO}_{4}{ }{ }^{2}$ solubility limit? To support programmatic objectives of establishing a "single point" $\mathrm{SO}_{4}{ }^{=}$solubility limit for the Frit $418-\mathrm{SB} 2 / 3$ system over a WL interval of interest, an assessment of the ability of the "lower WL" glasses (i.e., $<40 \% \mathrm{WL}$ ) to retain higher $\mathrm{SO}_{4}{ }^{\prime}$ concentrations without producing a salt layer was needed.

Two series of " $\mathrm{Na}_{2} \mathrm{SO}_{4}$-spiked" tests were performed to assess $\mathrm{SO}_{4}{ }^{=}$solubility as a function of WL (or glass composition). Two baseline glasses were selected: (1) s-bc-100-30 (30\% WL) and (2) s-bc-100-35 $(35 \% \mathrm{WL})$ - both batch chemical-based glasses. As discussed in Section 5.1.6, full retention of $\mathrm{SO}_{4}{ }^{-}$was observed in these glasses (based on measured $\mathrm{SO}_{4}{ }^{=}$concentrations by ICP-AES) without the formation of a salt layer. The basis for the "spiked" tests was to target higher concentrations of $\mathrm{SO}_{4}{ }^{=}$in these two glasses up to the $0.77 \mathrm{wt} \% \mathrm{SO}_{4}{ }{ }^{2}$ content in which a salt layer was observed for the s-bc-100-40 glass (as well as the s-bc-50-48 glass). $\mathrm{Na}_{2} \mathrm{SO}_{4}$ was added to increase the $\mathrm{SO}_{4}{ }^{=}$content of s-bc-100-30 from the nominal $0.58 \mathrm{wt} \%$ to $0.65,0.70$ and $0.77 \mathrm{wt} \%$. For the s-bc- $100-35$ system, the targeted $\mathrm{SO}_{4}{ }^{=}$ concentrations increased from the nominal $0.67 \mathrm{wt} \%$ to $0.70,0.73$, and $0.77 \mathrm{wt} \%$. Each glass (a total of six) was batched using reagent grade chemicals targeting the "spiked" $\mathrm{SO}_{4}{ }{ }$ concentrations and melted 
under oxidizing conditions. It should be noted that both series of glasses are based on the $100 \% \mathrm{~Np}$ transfer case.

It is recognized that the use of $\mathrm{Na}_{2} \mathrm{SO}_{4}$ does add not only $\mathrm{SO}_{4}{ }^{=}$to the system but $\mathrm{Na}_{2} \mathrm{O}$ as well. Previous research (and this study) has demonstrated that $\mathrm{SO}_{4}{ }^{=}$solubility is a function of the overall glass composition. However, the amount of $\mathrm{Na}_{2} \mathrm{SO}_{4}$ needed to increase the $\mathrm{SO}_{4}{ }^{\prime}$ content to the "spiked" concentrations is extremely small. To give some indication of the negligible impact, the authors used the relationship defined by Jantzen and Smith (2003) linking $\mathrm{SO}_{4}{ }^{=}$solubility to viscosity. The additional $\mathrm{Na}_{2} \mathrm{O}$ added to the "spiked" tests in this series of glasses, only shifts the predicted viscosity by approximately 1 Poise. Again, the minor amount of $\mathrm{Na}_{2} \mathrm{O}$ added to the system is not expected to have a major effect on the $\mathrm{SO}_{4}{ }^{=}$solubility.

Visual observations of the 30\%- and 35\%-spiked tests are summarized in Table 5-4 (also shown are the observations of the baseline glasses for completeness). Visual observations for the $30 \%$-spiked glasses indicate that the initial increase in $\mathrm{SO}_{4}{ }^{*}$ (from 0.58 to $0.65 \mathrm{wt} \%$ target) does not result in the formation of a salt layer. However, when $\mathrm{SO}_{4}{ }^{=}$contents of 0.70 and $0.77 \mathrm{wt} \%$ are targeted, a salt layer is observed. Characteristically, the layer is white and its morphology is highly dendritic on both glass surfaces similar to the layer observed in the s-bc-100-40 sample (see Figure 5-3).

Visual observations for the 35\%-spiked glasses indicate that increasing the targeted $\mathrm{SO}_{4}{ }^{=}$content from 0.67 to $0.70 \mathrm{wt} \%$ does not result in the formation of a salt layer. However, pushing the $\mathrm{SO}_{4}{ }^{=}$ concentrations higher $(0.73$ and $0.77 \mathrm{wt} \%)$ in this baseline glass does result in the formation of the white salt layer observed in previous systems.

Table 5-4. Visual Observations of the "SO $4{ }{ }^{~}$-Spiked" Glasses.

\begin{tabular}{|c|c|c|c|}
\hline "Glass ID & 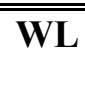 & $\begin{array}{c}\mathrm{SO}_{4}{ }^{=} \text {Target } \\
(\mathrm{wt} \%)\end{array}$ & SO $_{4}{ }^{=}$Observation \\
\hline s-bc-100-30 & 30 & 0.58 & No layer, deposits or coating \\
\hline s-bc-100-30s0.65 & 30 & 0.65 & No layer, deposits or coating \\
\hline s-bc-100-30s0.7 & 30 & 0.70 & White coating \\
\hline s-bc-100-30s0.77 & 30 & 0.77 & White coating \\
\hline s-bc-100-35 & 35 & 0.67 & No layer, deposits or coating \\
\hline s-bc-100-35s0.7 & 35 & 0.70 & No layer, deposits or coating \\
\hline s-bc-100-35s0.73 & 35 & 0.73 & White coating \\
\hline s-bc-100-35s0.77 & 35 & 0.77 & White coating \\
\hline
\end{tabular}

Although visual observations of a salt layer are important, the critical information resides in the $\mathrm{SO}_{4}{ }^{=}$ retention values in glass. Table 5-5 summarizes the target versus measured $\mathrm{SO}_{4}{ }^{=}$contents for this series of glasses. The results of the two baseline glasses are also shown for completeness. The measured $\mathrm{SO}_{4}{ }^{=}$ concentrations in two glasses (s-bc-100-30s 0.65 and s-bc-100-35s 0.7 ) are critical with respect to the objectives of this task. These glasses were targeted (or spiked) with the highest $\mathrm{SO}_{4}{ }^{=}$concentration in their respective series that resulted in a single phase glass (no salt layer). The measured $\mathrm{SO}_{4}{ }^{2}$ contents are slightly below the targeted $\mathrm{SO}_{4}{ }^{=}$contents but only by $0.01 \mathrm{wt} \%$ when accounting for the measurement uncertainty of the SRTC-ML ICP-AES (0.02 wt\%). 
Table 5-5. Target Versus Measured $\mathrm{SO}_{4}{ }^{=}$Contents in Glass for the "Spiked" Series.

\begin{tabular}{|c|c|c|c|}
\hline Glass ID & $\overline{\mathbf{W L}}$ & Target $\mathrm{SO}_{4}{ }^{=}$ & Measured $\mathrm{SO}_{4}{ }^{=}$ \\
\hline s-bc-100-30 & 30 & 0.58 & 0.58 \\
\hline s-bc-100-30s0.65 & 30 & 0.65 & 0.62 \\
\hline s-bc-100-30s0.7 & 30 & 0.7 & 0.62 \\
\hline s-bc-100-30s0.77 & 30 & 0.77 & 0.68 \\
\hline s-bc-100-35 & 35 & 0.67 & 0.68 \\
\hline $\mathrm{s}-\mathrm{bc}-100-35 \mathrm{~s} 0.7$ & 35 & 0.7 & 0.67 \\
\hline s-bc-100-35s0.73 & 35 & 0.73 & 0.68 \\
\hline s-bc-100-35s0.77 & 35 & 0.77 & 0.73 \\
\hline
\end{tabular}

These data suggest that there is a compositional effect (in this report expressed as a function of WL) on $\mathrm{SO}_{4}{ }^{=}$solubility. More specifically, at $30 \% \mathrm{WL}$ the data indicated that the $\mathrm{SO}_{4}{ }^{=}$solubility limit (based on the highest $\mathrm{SO}_{4}{ }^{=}$target without the formation of a salt layer) is $0.62 \mathrm{wt} \%$ (from s-bc-100-30s-0.65). At $35 \% \mathrm{WL}$, the $\mathrm{SO}_{4}{ }^{=}$solubility limit is approximately $0.67 \mathrm{wt} \%$ (based on s-bc-100-35s 0.7 ). As WL increases to $37 \% \mathrm{WL}$ (s-bc-100-37), the measured $\mathrm{SO}_{4}{ }^{\circ}$ content in glass was $0.69 \mathrm{wt} \%$ (no salt layer observed). The difference between the $30 \% \mathrm{WL} \mathrm{SO}_{4}{ }^{-}$limit of $0.62 \mathrm{wt} \%$ and the $37 \% \mathrm{WL}$ of $0.69 \%$ is statistically significant indicating a "sliding" $\mathrm{SO}_{4}{ }^{=}$limit as a function of WL (or glass composition). This trend agrees with the historical (primarily melter) data presented by Jantzen and Smith (2003).

\subsection{SMRF Test Results}

\subsubsection{SMRF Visual Observations}

As previously mentioned, the main purpose of the SMRF tests was to determine if the conditions of slurry feeding Frit 418 - SB2/3 in a small-scale melter would lower the sulfate solubility limit of the resultant glass versus the value determined by the crucible tests (kinetic versus "equilibrium"). With the $0.7 \mathrm{wt} \%$ target $\mathrm{SO}_{4}{ }$ feed, no sign of a sulfate layer was found in the cold cap sample (just after feeding was stopped) or the top of glass sample taken 30 minutes later. Throughout the tests the cold cap/top of glass pool was observed, but it was not possible to detect a sulfate layer by this technique. During the first day of the SMRF $0.7 \%$ target sulfate test (1/20/04), $11.9 \mathrm{~kg}$ of glass was made.

After 8 hours of idling at $1125^{\circ} \mathrm{C}$, the $0.7 \%$ target sulfate test was continued (1/21/04) and an additional $2.3 \mathrm{~kg}$ of glass was made. Immediately after feeding was stopped, a cold cap sample was taken and then a top of glass sample was taken 30 minutes later. At that time no sign of free sulfate was observed and therefore the $1.2 \%$ target sulfate test was started at 1233 . A later re-inspection of the top of glass sample taken (SMRF-136) showed that there were small white spots that were water soluble. This inspection was performed after the completion of all of the tests and, therefore, did not help in the decision as to whether or not to stop at the end of the $0.7 \%$ target sulfate test.

At the end of the $1.2 \%$ target sulfate test on $1 / 21 / 04$ (after $5.4 \mathrm{~kg}$ glass poured during feeding of $1.2 \%$ sulfate feed), a cold cap sample (SMRF-142) and a top of glass sample after 30 minutes of no feeding (SMRF-143) were taken. It was obvious that there was excess sulfate in the cold cap and top of glass 
samples (see Figure 5-13 and Figure 5-14). Times and dates on all sample pictures are the time when the picture was taken (not sample time).

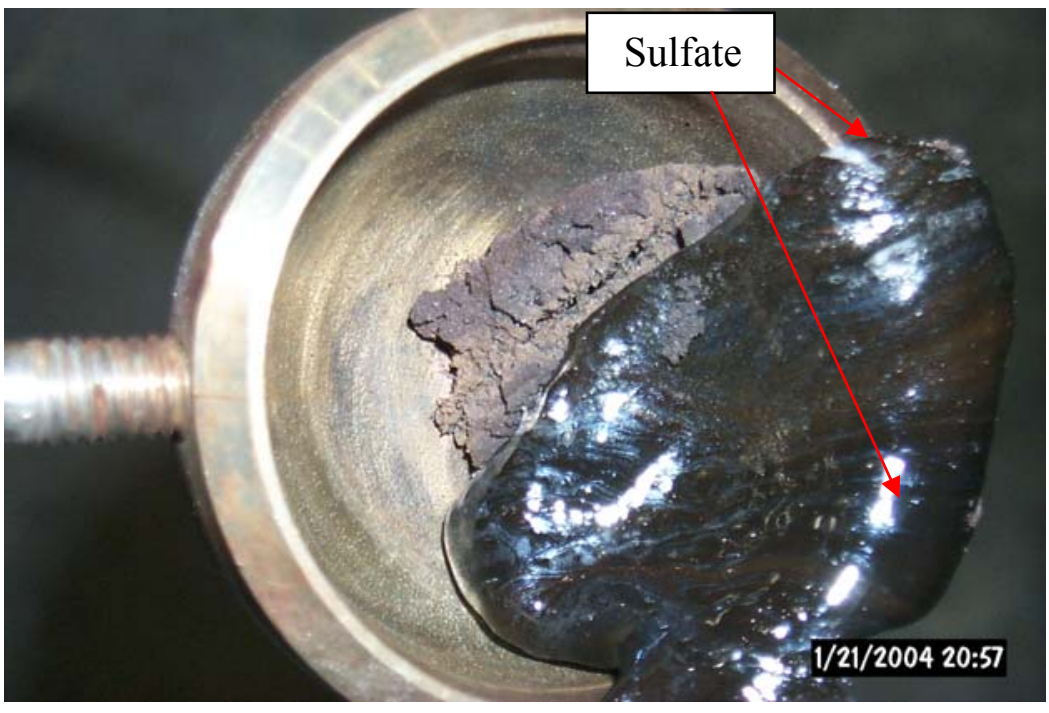

Figure 5-13. Cold Cap Sample at End of SMRF 1.2\% Target Sulfate Test.

(Sample SMRF-142: Note Very Small Spots in Glassy Portion of Sample)

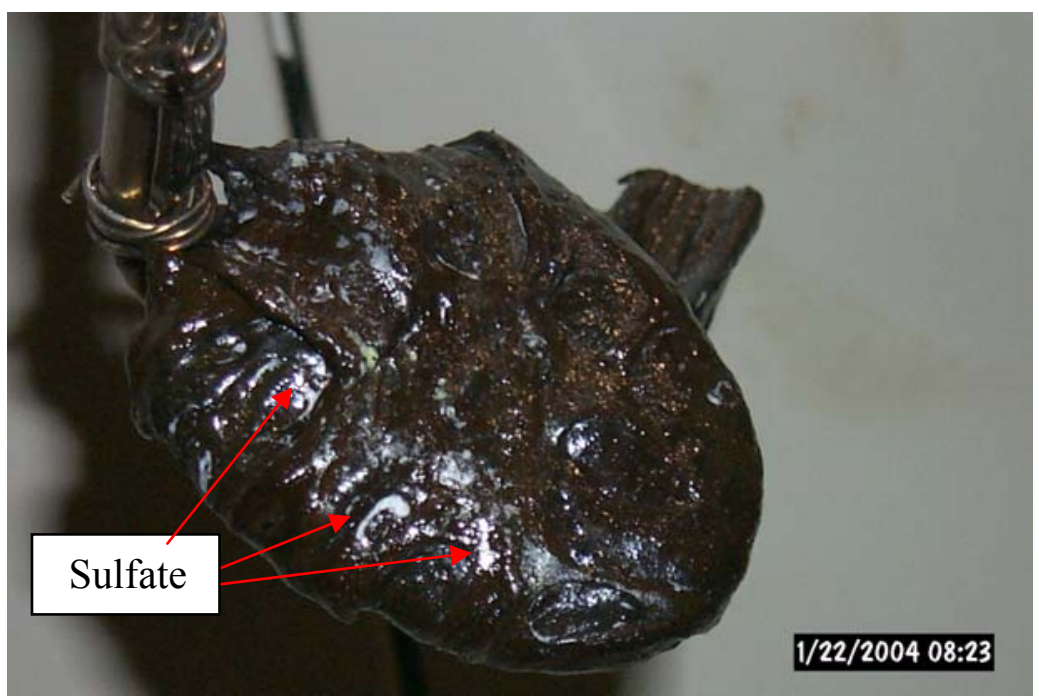

Figure 5-14. Top of Glass Sample (30 Minutes after Feeding Stopped) at End of SMRF 1.2\% Target Sulfate Test (Sample SMRF-143).

The $1.5 \%$ target sulfate test was performed on $1 / 22 / 04$ and produced $5.4 \mathrm{~kg}$ of glass poured. At the end of the test, a cold cap sample was taken (SMRF-147). After 30 minutes, a top of glass sample was taken (SMRF-148) as well as one 90 minutes after feeding was stopped (SMRF-149). All of these samples had signs of sulfate in them (See Figure 5-15 and Figure 5-16). 


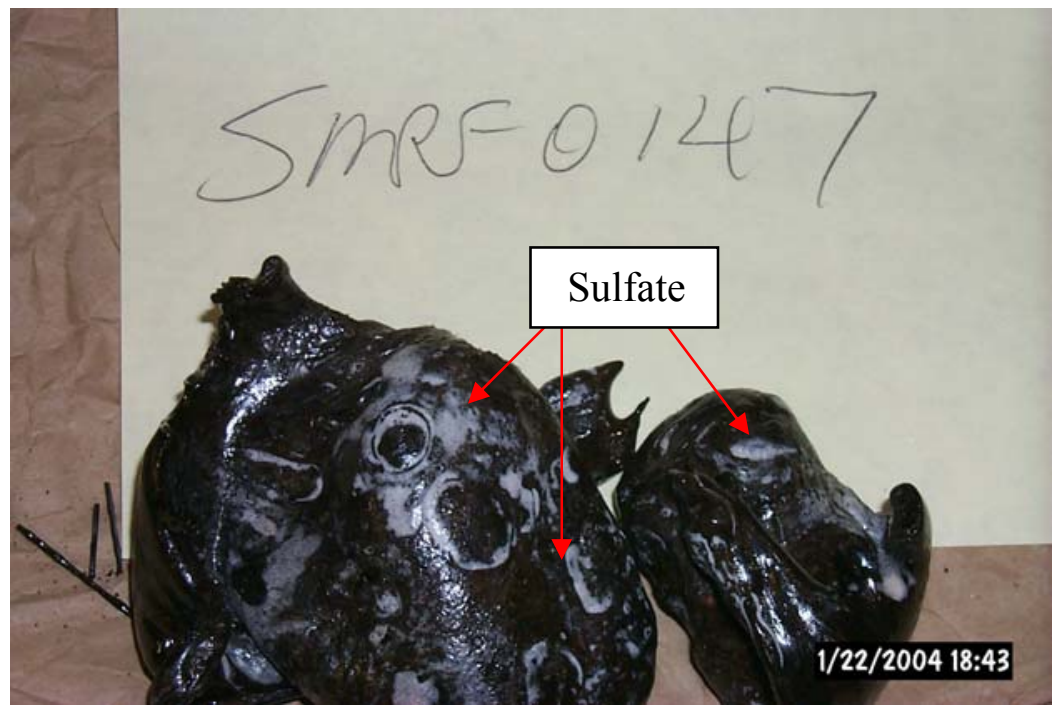

Figure 5-15. Cold Cap Sample at End of SMRF 1.5\% Target Sulfate Test (Sample SMRF-147)

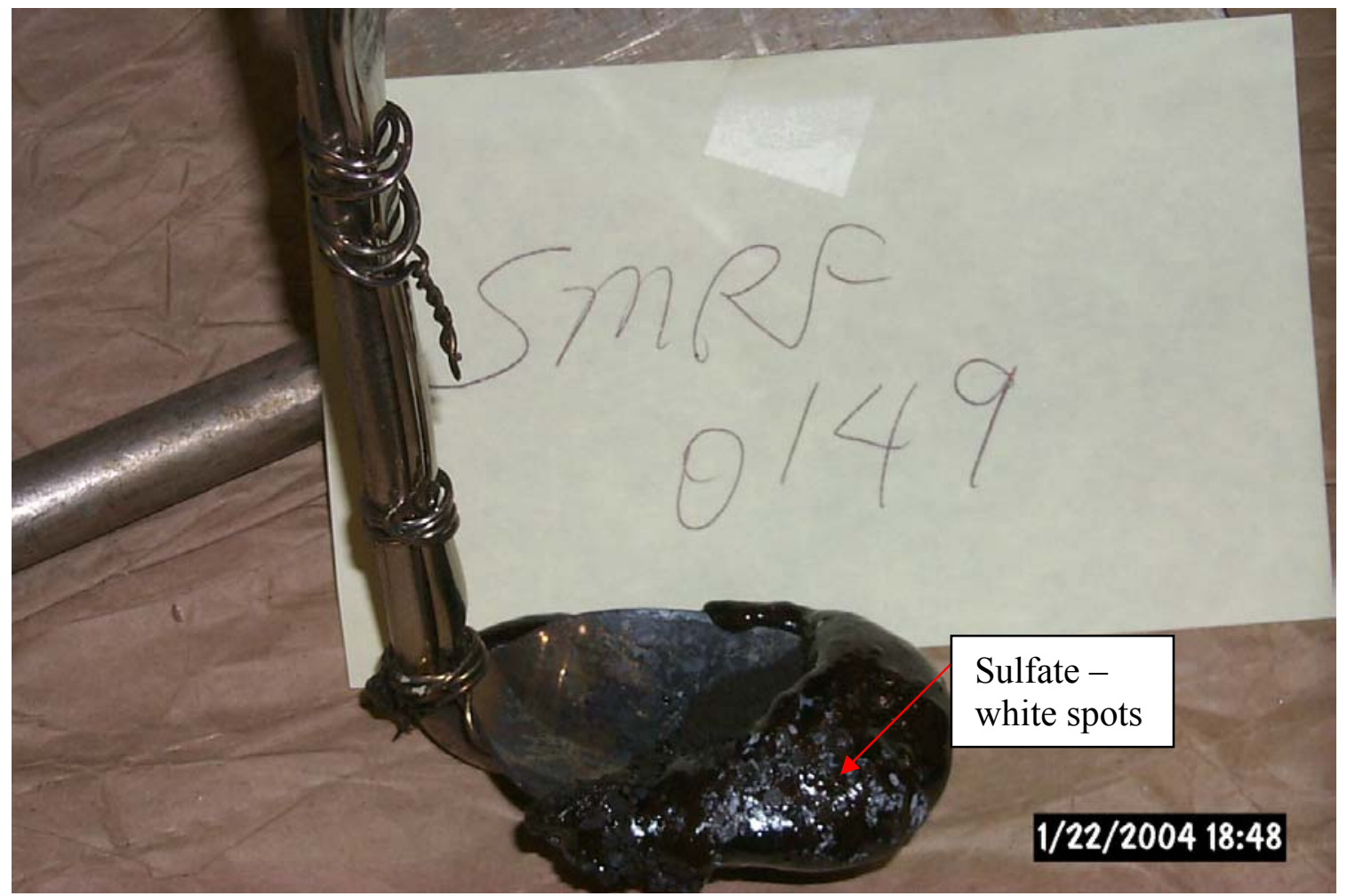

Figure 5-16. Top of Glass Sample (90 Minutes after Feeding Stopped) at End of SMRF 1.5\% Target Sulfate Test (Sample SMRF-149). 
During the subsequent draining of the SMRF, drain glass samples were taken. The drain sample taken after $4.6 \mathrm{~kg}$ of glass had been drained contained white spots that were water soluble.

\subsubsection{SMRF Analytical Results}

The samples used in Section 5.2.1 for visual confirmation as well as others were submitted for analytical verification of sulfate by ICP - AES. The first types of samples submitted were the glass pour/glass drain samples. Table 5-6 shows when the samples were taken (kg of glass produced) and the wt\% sulfate measured. A complete oxide analysis for these glass samples is given in Appendix C.

Table 5-6. Sulfate Levels (Weight \%) in SMRF Glass Samples.

\begin{tabular}{||c|c|c||}
\hline Sample ID & Description & $\begin{array}{c}\text { Measured } \\
\text { Weight } \text {. SO }_{4}{ }^{=}\end{array}$ \\
\hline SMRF-128 & Pour sample after 4 kg 0.7\% sulfate fed & 0.78 \\
\hline SMRF-130 & Pour sample after 8 kg 0.7\% sulfate fed & 0.76 \\
\hline SMRF-136 & Pour sample at end of 0.7\% sulfate test & 0.80 \\
\hline SMRF-141 & Pour sample at end of 1.2\% sulfate test & 0.98 \\
\hline SMRF-146 & Pour sample at end of 1.5\% sulfate test & 1.17 \\
\hline SMRF-152 & Drain sample 13 minutes after drain started & 1.21 \\
\hline SMRF-154 & Drain sample after 4.6 kg drained & 1.46 \\
\hline
\end{tabular}

Note: Sulfate values cited are average of duplicate analyses

Sample SMRF-136 was the first glass pour sample analyzed after spots that appeared to be sulfate were observed in a top of glass pool sample. This sample was taken after feeding had been stopped at the end of the target $0.7 \%$ sulfate test. Therefore, the best guess for a solubility limit for the SB2/3 Frit 418 glass at $\sim 40 \%$ waste loading would be somewhere between 0.80 and 0.76 (the value measured in the glass for the previous glass sample SMRF-130). This limit range would be lowered by about $0.02 \%$ due to the uncertainty of the measurement technique. This limit should not be applied to all waste loadings for this glass as the crucible scale data, as well as Jantzen and Smith (2003), have shown that sulfate solubility is a function of glass composition. Before the limit could be compared with the crucible tests results, the spots observed had to be analyzed to make sure that the spots were indeed some form of sulfate. Therefore, cold cap and top of glass pool samples that had white soluble spots were analyzed by SEM/EDS. Of most interest was the top of glass sample (SMRF-138) where the white "sulfate" spots were first observed. Figure 5-17 is the SEM picture of a portion of this sample. 


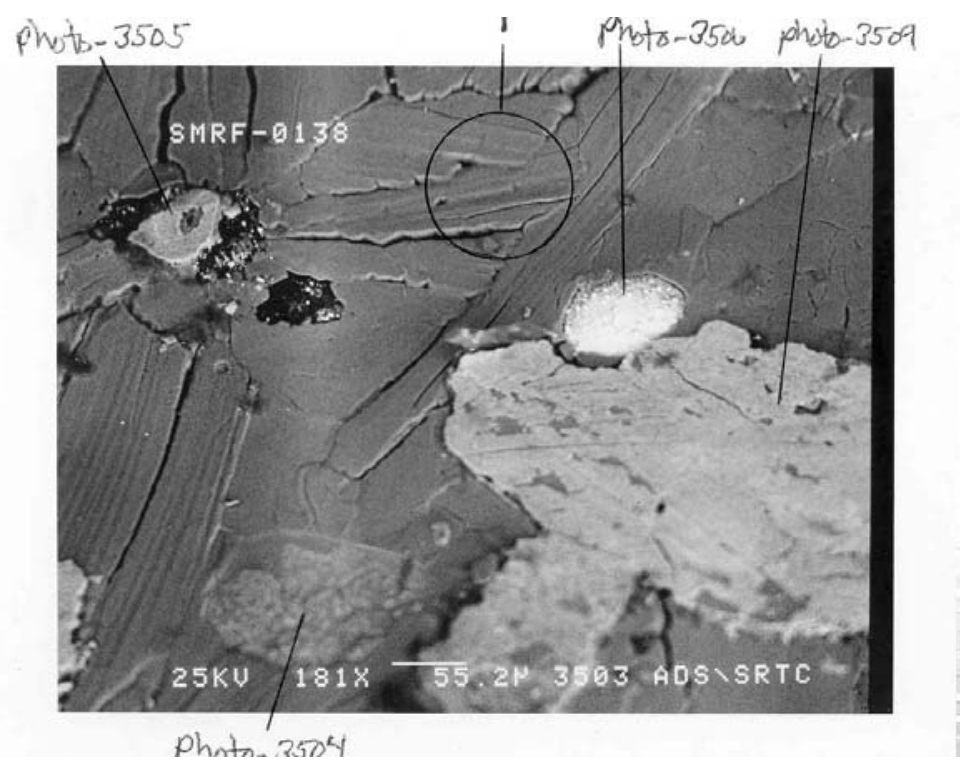

Figure 5-17. SEM Micrograph of Top of Glass Sample at End of SMRF 0.7\% Target Sulfate Test.

Various spots on this SEM were analyzed. Spot one was determined to be mostly sodium and sulfate and therefore was probably sodium sulfate (see Figure 5-18). SEM Spot 3504 was silicon, iron, manganese, and sodium. SEM Spot 3505 was sodium, sulfur, iron, and chrome. SEM Spot 3509 was mostly iron and sulfur.

These analyses confirmed the belief that the white spots observed at the top of the melt pool were indeed forms of sulfur. By visually estimating the relative amounts of the various "spots" on the SEM, most of the area of the SEM image for this sample was composed of sodium sulfate. All top of glass pool samples taken after the end of the $0.7 \%$ target sulfate test had forms of sulfur measured in them as well. As the sulfate level increased in the glass, sulfate was also observed in the pour sample at the end of the $1.5 \%$ target sulfate test. This would verify that the glass was becoming supersaturated in sulfur (sulfur weight $\%$ was 1.17 in this sample as given in Table 5-6). Table 5-7 summarizes the observations and analytical findings of the high sulfate SMRF tests. 


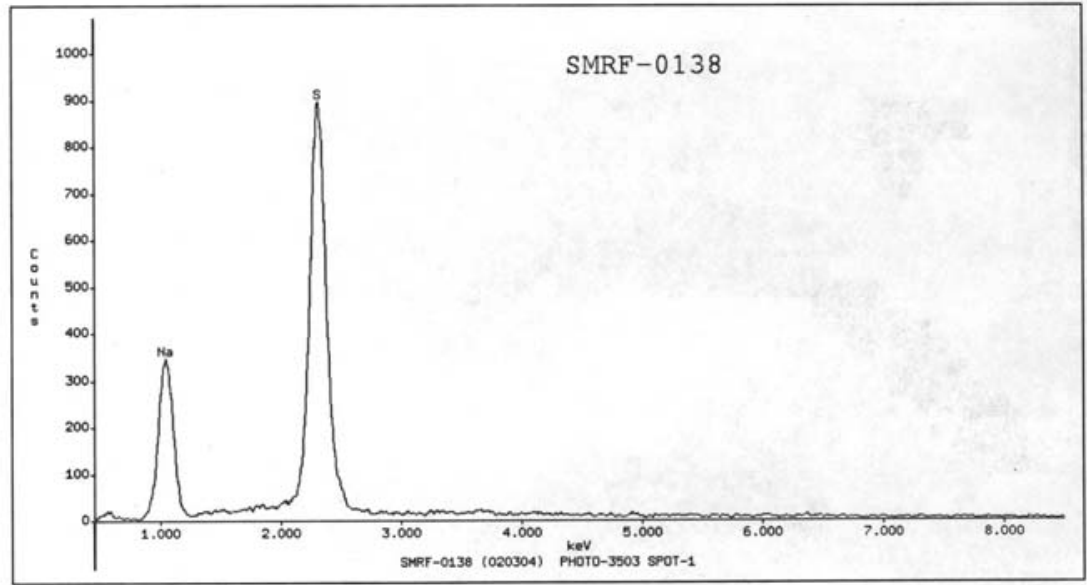

SMRF-0138 (020304) PHOTO-3503 SPOT-1

Accelerating Voltage: $25 \mathrm{KeV}$ Take Off Angle: $32.8918^{\circ}$ Live Time: 17.79 seconds Dead Time: 1.637 seconds

Figure 5-18. EDS Spectra of Spot 1 Shown in Figure 5-17.

Table 5-7. Summary of SMRF SB2/3 Frit 418 High Sulfate Tests.

\begin{tabular}{||l|c|c|l||}
\hline \multicolumn{1}{|c|}{ Description } & $\begin{array}{l}\text { Wt \% } \\
\text { Sulfate }\end{array}$ & $\begin{array}{c}\text { *Calculated Glass } \\
\text { Waste Loading }\end{array}$ & \multicolumn{1}{||}{ Comments } \\
\hline $\begin{array}{l}\text { Pour sample after 8 kg } \\
\text { glass for 0.7 sulfate } \\
\text { feeding }\end{array}$ & 0.76 & 40.0 & $\begin{array}{l}\text { No sulfate layer observed on top of glass pool or } \\
\text { in glass sample }\end{array}$ \\
$\begin{array}{l}\text { Pour sample @ end of } \\
0.7 \text { sulfate feeding } \\
(11.7 \mathrm{~kg})\end{array}$ & 0.80 & 38.4 & $\begin{array}{l}\text { Some sulfate observed/measured** on melt pool } \\
\text { top (not observed in glass) }\end{array}$ \\
$\begin{array}{l}\text { Pour sample @ end of } \\
1.2 \text { sulfate feeding } \\
17.1 \mathrm{~kg})\end{array}$ & 0.98 & 37.1 & $\begin{array}{l}\text { Sulfate observed/measured** on melt pool top } \\
\text { (not observed in glass) }\end{array}$ \\
\hline $\begin{array}{l}\text { Pour sample @ end of } \\
1.5 \text { sulfate feeding } \\
21.7 \mathrm{~kg})\end{array}$ & 1.17 & 39.3 & $\begin{array}{l}\text { Sulfate observed/measured** on melt pool top } \\
\& \text { observed in pour glass }\end{array}$ \\
$\begin{array}{l}\text { Drain sample after 13 } \\
\text { minutes of draining }\end{array}$ & 1.21 & 39.3 & Sulfate observed in drain sample \\
\hline $\begin{array}{l}\text { Drain sample near end } \\
\text { of drain (melt pool top } \\
\text { drain) }\end{array}$ & 1.46 & 38.6 & Sulfate observed \& measured** in sample \\
\hline \hline
\end{tabular}

* Waste loading determined by $\mathrm{Li}_{2} \mathrm{O}$ "normalization" method (Frit 418 used in test had $7.99 \mathrm{wt} \% \mathrm{Li}_{2} \mathrm{O}$ )

** Measured by SEM/EDS 
The information from this table indicates that during slurry feeding of the SMRF with high sulfate SB2/3 Frit 418 feed (at $\sim 40 \%$ waste loading), a sulfate layer was beginning to buildup at a glass pool sulfate concentration between 0.76 and $0.80 \mathrm{wt} \%$. Concentrations of sulfate in the glass at or above $0.98 \mathrm{wt} \%$ resulted in the supersaturation of the glass for sulfate. The actual point of supersaturation was not determined. SEM/EDS analyses of the glass samples at the end of the 0.7 and $1.2 \%$ target sulfate tests showed free sulfate in the glass that could not be seen without magnification.

As discussed before, the intent of these SMRF tests was not to determine the sulfate limit for the DWPF feed for SB2/3 Frit 418 feed. The limit being presented to HLW/DWPF is based on the crucible tests given in this report. The SMRF tests were more confirmatory in nature. Since the sulfate solubility limit (about 0.8 ) as determined by the SMRF 38\% WL glass (for pour glass sample at end of $0.7 \%$ target sulfate feeding - see calculated waste loadings given in Table 5-7) was higher than that shown by the crucible tests for similar waste loadings $(0.69$ for $37 \%$ waste loading with no observed sulfate and 0.68 with observed sulfate layer at $40 \%$ waste loading), the crucible tests can be considered to be conservative.

Finally, a comparison between the SRTC-ML sulfur analysis technique (ICP-AES) and the SRTC Analytical Development Section (ADS) analysis technique (X-ray Fluorescence - (XRF)) was performed. During the draining of the SMRF, two drain samples (SMRF-150 and 151) were taken in graphite crucibles to obtain a smooth "puck" sample that could be measured by XRF without further sample preparation. Under similar conditions, an additional drain sample was taken (SMRF-152) and measured for sulfate by ICP-AES. The measured sulfate amounts per the XRF were $1.15 \%$ and $1.19 \%$ for SMRF150 and 151, respectively, while the ICP-AES technique indicated $1.17 \%$ and $1.22 \%$ for SMRF-152 (same sample analyzed twice). These values agree quite well and help confirm that accurate glass sulfate retention values were being given in this report. 
WSRC-TR-2004-00081

Revision 0

This page intentionally left blank. 


\subsection{DEFINING THE $\mathrm{SO}_{4}$ SOLUBILITY LIMIT FOR THE FRIT 418 - SB2/3 SYSTEM: TECHNICAL BASIS}

In this section, the technical basis for establishing a new $\mathrm{SO}_{4}{ }^{-}$solubility limit specific to the Frit $418-$ $\mathrm{SB} 2 / 3$ system is discussed. Data from previous sections are presented in a manner to demonstrate that setting a "single point" solubility limit for this system will cover a WL interval of interest to DWPF. Figure 6-1 is a schematic of the measured $\mathrm{SO}_{4}{ }^{=}$concentration (in glass) versus targeted WL for all glasses (batch chemical and SRAT-based) assessed in this study.

The black circles represent those glasses produced from batch chemicals that were visually homogeneous with respect to a salt layer (i.e., no salt layer observed). The gray circles represent those glasses produced from SRAT product. The open (or white) circles represent the batch chemical-based glasses that resulted in a white salt layer coating on the surface of the glass (i.e., these four glasses are from the "spiked" series at $30 \%$ and $35 \% \mathrm{WL}$ ). The yellow circles represent the two batch chemical-based glasses (s-bc-100-40 and s-bc-50-48) that were visually characterized as having both a yellow salt layer accumulated around the meniscus of the melt line and a white salt layer on the surface of the glass.

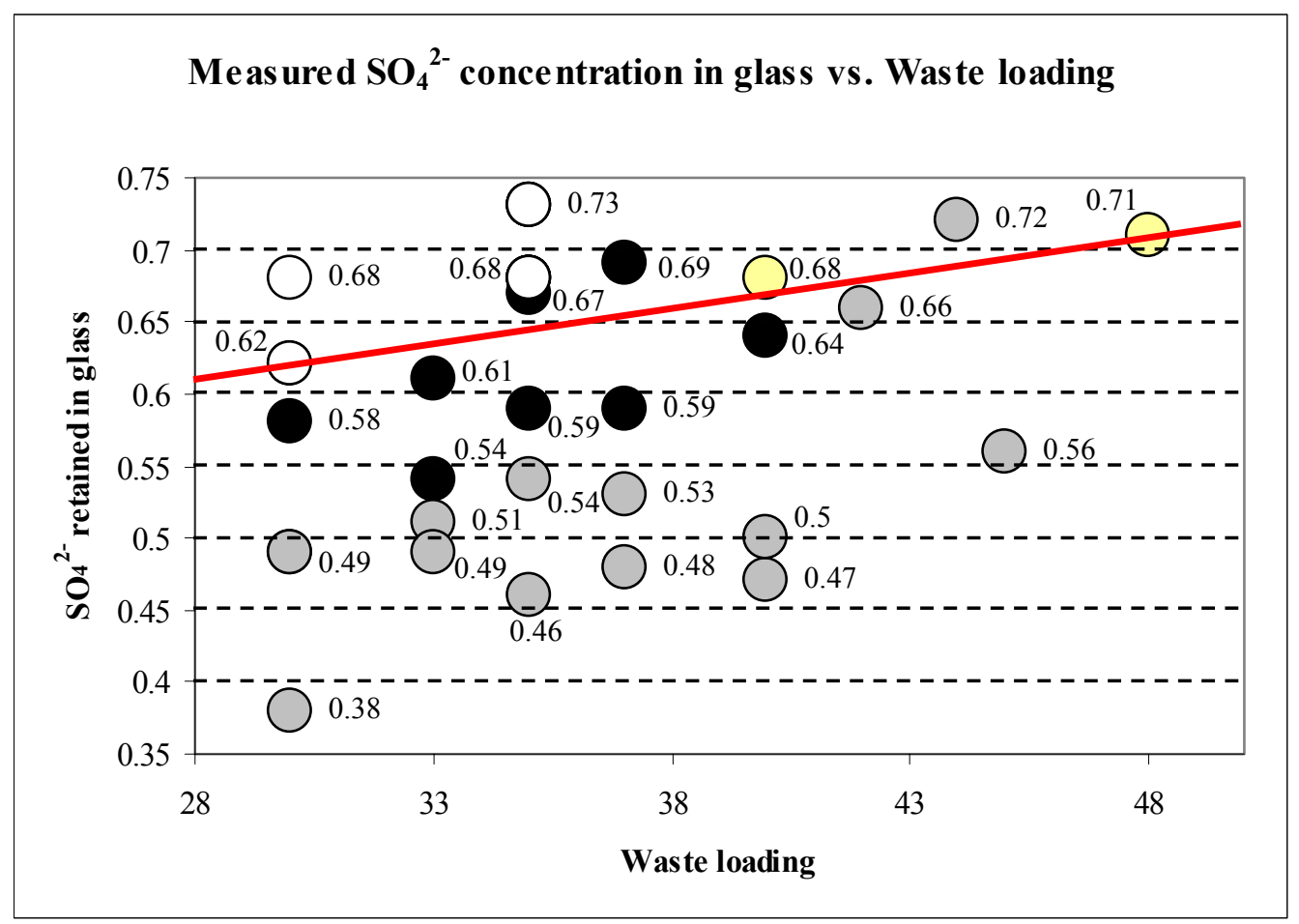

Figure 6-1. Sulfur Retention vs Waste Loading for Crucible Study Glasses. 
As previously discussed, the results of the SRAT-based product did indicate some degree of volatilization presumably as a result of $\mathrm{SO}_{2}$ partitioning due to the more reduced melting conditions. The result is that the SRAT-based glasses are primarily located at lower $\mathrm{SO}_{4}{ }^{=}$retention values than their counterpart batchchemical based glasses. It is noted that the $\mathrm{SO}_{4}{ }^{2}$ concentrations up to $0.72 \mathrm{wt} \%$ (s-sp-100-44) were measured from this series of glasses without the formation of a salt layer.

The batch-chemical based tests are considered more "conservative" with respect to the formation of a salt layer. That is, salt layers were not observed in the SRAT-based glasses but were observed in the counterpart batch chemical-based glasses (targeting the same $\mathrm{SO}_{4}{ }^{2}$ concentration) due to partial volatility induced by the differences in the oxidation states. Therefore, the primary data to be used to establish the "single point" $\mathrm{SO}_{4}{ }^{=}$limit will be the batch chemical based data.

To meet programmatic objectives for SB2/3, a "single point" $\mathrm{SO}_{4}{ }^{=}$solubility limit is required. This limit needs to be effective or applicable over a WL interval in which DWPF is expected to process for the Frit 418 - SB2/3 system $(30-40 \% \mathrm{WL})$ - regardless of potential compositional effects on $\mathrm{SO}_{4}{ }^{=}$solubility. The red line in Figure 6-1 is inserted to suggest that the $\mathrm{SO}_{4}{ }^{-}$solubility limit (as defined in this report) is a function of composition (expressed as WL in this report for this limited composition region). This line is not intended to represent a "statistical" fit of the relevant data but is being used as a guide for the discussion.

The critical data point that defines the $\mathrm{SO}_{4}{ }^{2}$ solubility limit for the Frit $418-\mathrm{SB} 2 / 3$ system (as a function of WL) is the s-bc-100-30s0.65 glass. This glass was a "spiked" $30 \% \mathrm{WL}$ glass targeting $0.65 \mathrm{wt} \% \mathrm{SO}_{4}{ }^{2}$. The measured $\mathrm{SO}_{4}{ }^{=}$content in this glass was $0.62 \mathrm{wt} \%$. Applying the SRTC-ML ICP-AES uncertainties $(0.02 \mathrm{wt} \%)$ to establish a $\mathrm{SO}_{4}{ }{ }$ solubility limit for the Frit $418-\mathrm{SB} 2 / 3$ system of $0.60 \mathrm{wt} \%$ (in glass) would provide a "set point" limit that covers the anticipated WL interval of interest. This concept is shown in Figure 6-2. The red line represents the recommended $\mathrm{SO}_{4}{ }^{=}$limit for the Frit $418-\mathrm{SB} 2 / 3$ system of $0.60 \mathrm{wt} \%$ (in glass). All glasses falling below this line were classified as homogeneous (i.e., no salt layer). It is noted that there are glasses above the $0.60 \mathrm{wt} \% \mathrm{SO}_{4}{ }^{=}$limit that were homogeneous (at higher WLs) reinforcing the existence of a compositional effect on $\mathrm{SO}_{4}{ }^{2}$ solubility even within this specific system. If one were to set the limit based on the higher WL results (e.g., $0.66 \mathrm{wt} \% \mathrm{SO}_{4}{ }^{{ }}$), then applying the higher limit to lower WLs over which DWPF may operate to maximize throughput may compromise the desire to eliminate the formation of a salt layer.

It is recognized that the crucible scale tests are static and inherently do not directly incorporate kinetic effects of $\mathrm{SO}_{4}{ }^{=}$solubility that arise in a slurry feeding situation that has active convection. The results presented in Section 5.2 (SMRF) do provide a measure of confidence that applying the $0.6 \mathrm{wt} \% \mathrm{SO}_{4}{ }^{=}$ limit in PCCS for this system should eliminate the potential formation of a salt layer. These data are also consistent with the historical information (primarily melter data from longer term campaigns) reported by Jantzen and Smith (2003) indicating similar $\mathrm{SO}_{4}{ }^{=}$limits are reasonable for implementation.

In terms of conservatism, the new limit has been set without taking credit for potential volatilization that may occur in DWPF. The historical review by Jantzen and Smith (2003) indicated partitioning of sulfur (presumably as $\mathrm{SO}_{2}$ ) can be significant under certain operating conditions. The $0.60 \mathrm{wt} \% \mathrm{SO}_{4}{ }^{=}$limit is also set based on the minimum $\mathrm{SO}_{4}{ }^{=}$concentration measured in glass (without a salt layer) over a WL interval of $30-40 \%$ and therefore does not account for potential "beneficial" compositional effects (i.e., increased $\mathrm{SO}_{4}{ }^{=}$solubility) at the higher WLs. 


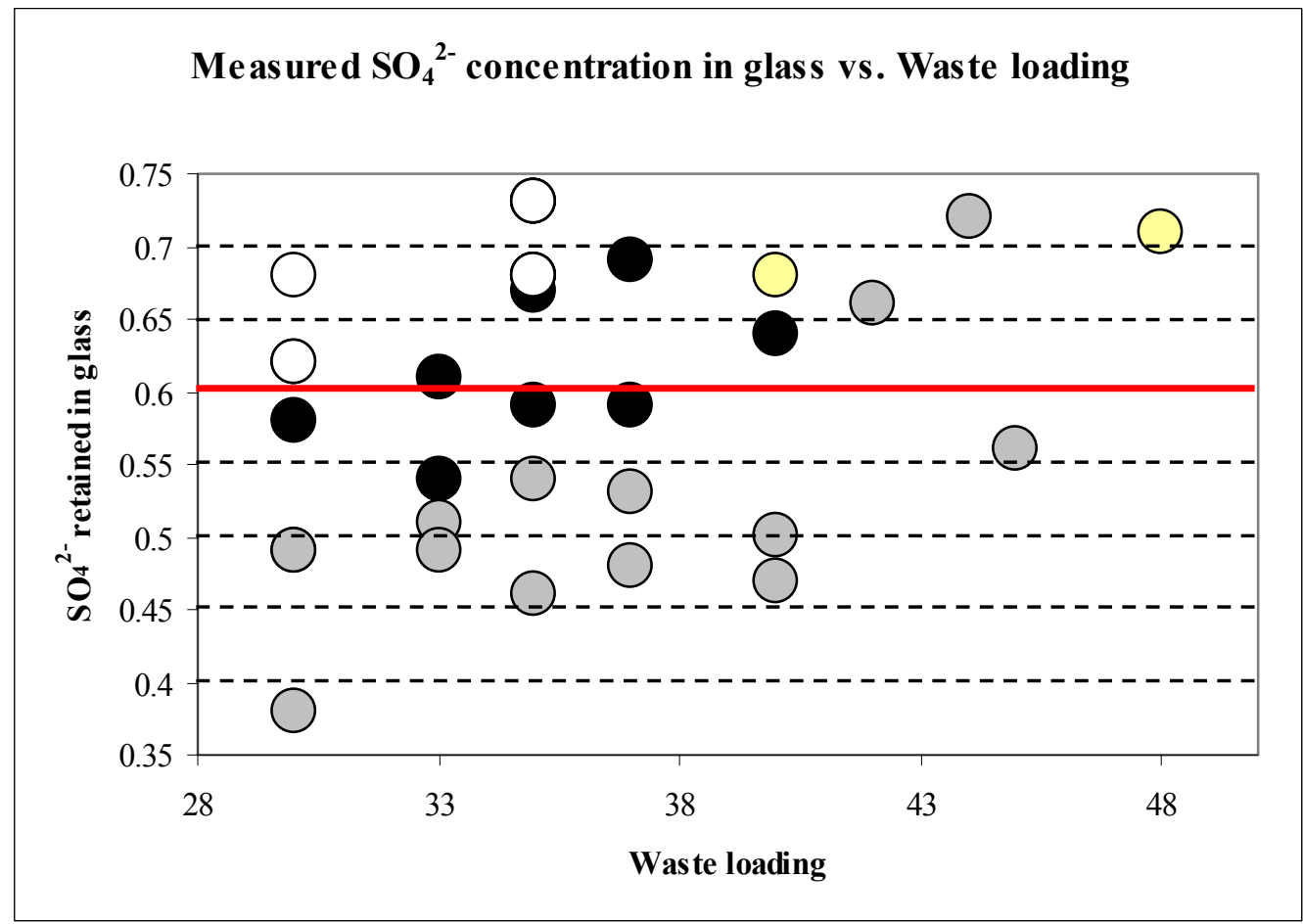

Figure 6-2. Application of the $0.60 \mathrm{wt}^{\mathrm{O}} \mathrm{SO}_{4}{ }^{=}$Limit of the Crucible Scale Glasses. 
WSRC-TR-2004-00081

Revision 0

This page intentionally left blank. 


\subsection{SUMMARY}

The objective of this report was to establish a "single point" $\mathrm{SO}_{4}{ }^{\text {" }}$ solubility limit or constraint for the Frit 418 - SB2/3 system. Based on the results of this study, it is recommended that the $\mathrm{SO}_{4}{ }^{=}$limit in $\mathrm{PCCS}$ for the Frit $418-\mathrm{SB} 2 / 3$ system be set at $0.60 \mathrm{wt} \%$ ( $\mathrm{g} \mathrm{SO}_{4}{ }^{-} / 100 \mathrm{~g}$ glass) (or $0.88 \mathrm{wt} \%$ expressed as $\mathrm{Na}_{2} \mathrm{SO}_{4}$ ). The new limit has been set based solely on sealed crucible scale data and does not take credit or account for potential volatilization that may occur in DWPF. Although the limit is established based on sealed crucible scale tests, supplementary testing using the SMRF provides a measure of confidence that applying the $0.6 \mathrm{wt} \% \mathrm{SO}_{4}{ }^{=}$limit in PCCS will prevent the formation of a salt layer. These data are consistent with the historical information (primarily melter data from longer campaigns) reported by Jantzen and Smith (2003) indicating similar $\mathrm{SO}_{4}{ }^{=}$limits are reasonable for implementation. Given this new limit, business decisions regarding the transfer volume of $\mathrm{Np}$-solution and potential impact to DWPF in terms of operational flexibility (i.e., potential waste loading targets) can be assessed for SB2/3.

The critical data point that was used to define the $\mathrm{SO}_{4}{ }^{2}$ solubility limit for this system was from the s-bc$100-30 \mathrm{~s} 0.65$ glass. This glass was a "spiked" $30 \% \mathrm{WL}$ glass targeting $0.65 \mathrm{wt} \% \mathrm{SO}_{4}{ }^{*}$. The measured $\mathrm{SO}_{4}{ }^{\prime}$ content in this glass was $0.62 \mathrm{wt} \%$. Applying the SRTC-ML ICP-AES uncertainties $(0.02 \mathrm{wt} \%)$ to establish a $\mathrm{SO}_{4}{ }{ }^{\text {s }}$ solubility limit for the Frit 418 - $\mathrm{SB} 2 / 3$ system of $0.60 \mathrm{wt} \%$ (in glass) provides a "single point" limit that covers the anticipated WL interval of interest. It is noted that there are glasses above the $0.60 \mathrm{wt} \% \mathrm{SO}_{4}{ }^{=}$limit that were homogeneous reinforcing the theory of a compositional effect on $\mathrm{SO}_{4}{ }^{=}$ solubility within this specific system. However, if one were to set the limit based on the higher WL results (e.g., $0.66 \mathrm{wt}^{\%} \mathrm{SO}_{4}{ }^{-}$), then applying that to lower WLs over which DWPF may operate to maximize throughput may compromise the desire to prevent the formation of a salt layer. 
WSRC-TR-2004-00081

Revision 0

This page intentionally left blank. 


\subsection{RECOMMENDATIONS}

Based on the results of this study, the following recommendations are made:

(1) $\mathrm{The}_{\mathrm{SO}_{4}}{ }$ solubility limit in PCCS for the Frit 418 - SB2/3 system should be set at $0.60 \mathrm{wt} \%$ (g $\mathrm{SO}_{4}{ }^{=} / 100$ g glass) (or $0.88 \mathrm{wt} \%$ expressed as $\mathrm{Na}_{2} \mathrm{SO}_{4}$ ).

(2) $\mathrm{The}_{\mathrm{SO}_{4}}{ }$ solubility limit for future sludge batches should be revisited given the dependence on overall glass composition.

(3) An experimental program should be developed to assess $\mathrm{SO}_{4}{ }^{=}$solubility as a function of composition. Integrated into this program would be potential frit additives known to have a positive impact on $\mathrm{SO}_{4}{ }^{*}$ solubility. 
WSRC-TR-2004-00081

Revision 0

This page intentionally left blank. 


\subsection{REFERENCES}

Baich, MA, DR Best, TK Snyder, and MF Williams. 2004. Sludge Batch 2-3 Blend Flowsheet Simulations: Determination of Acid Addition Window, WSRC-TR-2004-00042, Revision 0, Westinghouse Savannah River Company, Aiken, South Carolina.

Bickford, DF and CM Jantzen. 1986. Inhibitor Limits for Washed Precipitate Based on Glass Quality and Solubility Limits, U.S. DOE Report DPST-86-546, E.I. duPont deNemours \& Co., Savannah River Laboratory, Aiken, South Carolina.

Bickford, DF, A Applewhite-Ramsey, CM Jantzen, and KG Brown. 1990. Control of Radioactive Waste Glass Melters: I, Preliminary General Limits at Savannah River, J. Am. Ceram. Soc, 73 [10] 2896-2902.

Brown, KG, RL Postles, and TB Edwards. 2002. SME Acceptability Determination for DWPF Process Control, WSRC-TR-95-0364, Revision 4, Westinghouse Savannah River Company, Aiken, South Carolina.

Click, DR and JM Pareizs. 2003. Composition of SRAT Feed for the Sludge Batch 3 Acceptance Evaluation in the SRTC Shielded Cells, WSRC-RP-2003-01003, Revision 0, Westinghouse Savannah River Company, Aiken, South Carolina.

Edwards, TB. 2004. Chemical Composition Assessments of the Frit 418 - SB2/3 Sulfate Solubility Glasses, WSRC-TR-2004-00088, Revision 0, Westinghouse Savannah River Company, Aiken, South Carolina.

Jantzen, CM and ME Smith. 2003. Revision of the Defense Waste Processing Facility (DWPF) Sulfate Solubility Limit, WSRC-TR-2003-00518, Revision 0, Westinghouse Savannah River Company, Aiken, South Carolina.

Lilliston, GR. 2003. Personal communication, October 14, 2003.

Lilliston, GR and HH Elder. 2003. Disposal Strategy and Path Forward for Effluents from the H-Canyon Np Stabilization Campaign, CBU-PED-2003-00030, Revision 0, Westinghouse Savannah River Company, Aiken, South Carolina.

Peeler, DK and TB Edwards. 2003. Projected Operating Windows or Various Sludge Batch 2/3 Blends: A Progression from a PAR to a MAR Assessment, WSRC-TR-2003-00509, Revision 0, Westinghouse Savannah River Company, Aiken, South Carolina.

Peeler, DK. 2003. Task Technical and QA Plan: Investigation of Slow Melting Cold Cap Chemistry and Chemical Additives to Improve Melt Rate, WSRC-RP-2003-01003, Revision 0, Westinghouse Savannah River Company, Aiken, South Carolina.

Rios-Armstrong, MA. 2004. Sludge Batch 3 Sulfate Solubility Limit, Technical Task Request, HLW/DWPF/TTR-04-0002, Westinghouse Savannah River Company, Aiken, South Carolina. 
Schumacher, RF, ME Smith, and JF Sproull. 1991. Review of Background Applicable to the Potential for a Steam Explosion in the DWPF Melter, WSRC-RD-91-15, Westinghouse Savannah River Company, Aiken, South Carolina.

Smith, ME, TH Lorier, and TM Jones. 2003. SMRF and MRF Melt Rate Testing for SB2/SB3 (Case 6B250 Canisters), WSRC-TR-2003-00466, Revision 0, Westinghouse Savannah River Company, Aiken, South Carolina. 
WSRC-TR-2004-00081

Revision 0

APPENDIX A 
Table A- 1. SMRF Feed Analyses (oxide wt\%) for 0.7, 1.2, and 1.5\% Target Sulfate Tests.

(Minor Oxides $<0.05 \%$ not Included)

\begin{tabular}{|c|c|c|c|c|c|c|c|c|c|c|c|c|c|c|c|}
\hline & $\mathrm{A} 12 \mathrm{O} 3$ & $\overline{\mathrm{B} 2 \mathrm{O} 3}$ & $\overline{\mathrm{CaO}}$ & $\mathrm{Cr} 2 \mathrm{O} 3$ & $\overline{\mathrm{CuO}}$ & $\mathrm{Fe} 2 \mathrm{O} 3$ & 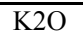 & 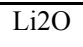 & $\mathrm{MgO}$ & $\mathrm{MnO}$ & $\mathrm{Na} 2 \mathrm{O}$ & $\mathrm{SO}^{*}{ }^{*}$ & $\overline{\mathrm{SiO} 2}$ & $\overline{\mathrm{ZnO}}$ & $\overline{\mathrm{ZrO} 2}$ \\
\hline $\begin{array}{l}\text { SMRF } 127 \\
\text { (A) }\end{array}$ & 5.99 & 5.67 & 1.27 & 0.086 & 0.080 & 14.6 & 0.061 & 5.29 & 1.46 & 1.90 & 13.37 & 0.686 & 48.2 & 0.131 & 0.186 \\
\hline $\begin{array}{c}\text { SMRF } 127 \\
\text { (B) }\end{array}$ & 6.07 & 5.41 & 1.26 & 0.086 & 0.079 & 14.2 & 0.061 & 5.16 & 1.44 & 1.92 & 12.87 & 0.708 & 48.4 & 0.129 & 0.250 \\
\hline $\begin{array}{c}\text { SMRF } 139 \\
\text { (A) }\end{array}$ & 6.05 & 5.28 & 1.25 & 0.085 & 0.079 & 14.2 & 0.060 & 5.18 & 1.42 & 1.86 & 13.16 & 1.33 & 47.9 & 0.130 & 0.234 \\
\hline $\begin{array}{l}\text { SMRF } 139 \\
\text { (B) }\end{array}$ & 5.93 & 5.31 & 1.24 & 0.086 & 0.079 & 14.0 & 0.058 & 5.27 & 1.44 & 1.84 & 12.92 & 1.31 & 49.0 & 0.129 & 0.254 \\
\hline $\begin{array}{l}\text { SMRF 144 } \\
\text { (A) }\end{array}$ & 6.09 & 5.22 & 1.25 & 0.086 & 0.070 & 14.1 & 0.059 & 5.18 & 1.45 & 1.91 & 13.26 & 1.58 & 47.7 & 0.130 & 0.221 \\
\hline $\begin{array}{l}\text { SMRF 144 } \\
\text { (B) }\end{array}$ & 6.09 & 5.18 & 1.25 & 0.088 & 0.070 & 14.3 & 0.055 & 5.12 & 1.46 & 1.96 & 13.35 & 1.50 & 47.1 & 0.130 & 0.250 \\
\hline
\end{tabular}

NOTE: Feed samples SMRF-127, 139, and 144 are from 0.7, 1.2. and 1.5\% SMRF sulfate feeds respectively (A and B connote duplicate analyses)

${ }^{*}$ Reported sulfate values are rerun Mobile Lab ICP-AES analyses which dried the feed at $110^{\circ} \mathrm{C}$ and then converted the results to calcined solids (versus calcining feed at $1100^{\circ} \mathrm{C}$ ) (See Section 3.3). 
WSRC-TR-2004-00081

Revision 0

\section{APPENDIX B}




\section{Table B-1: Average Measured and Bias-Corrected Chemical Compositions Versus Targeted Compositions by Oxide for $\mathrm{SO}_{4}$ Study Glasses}

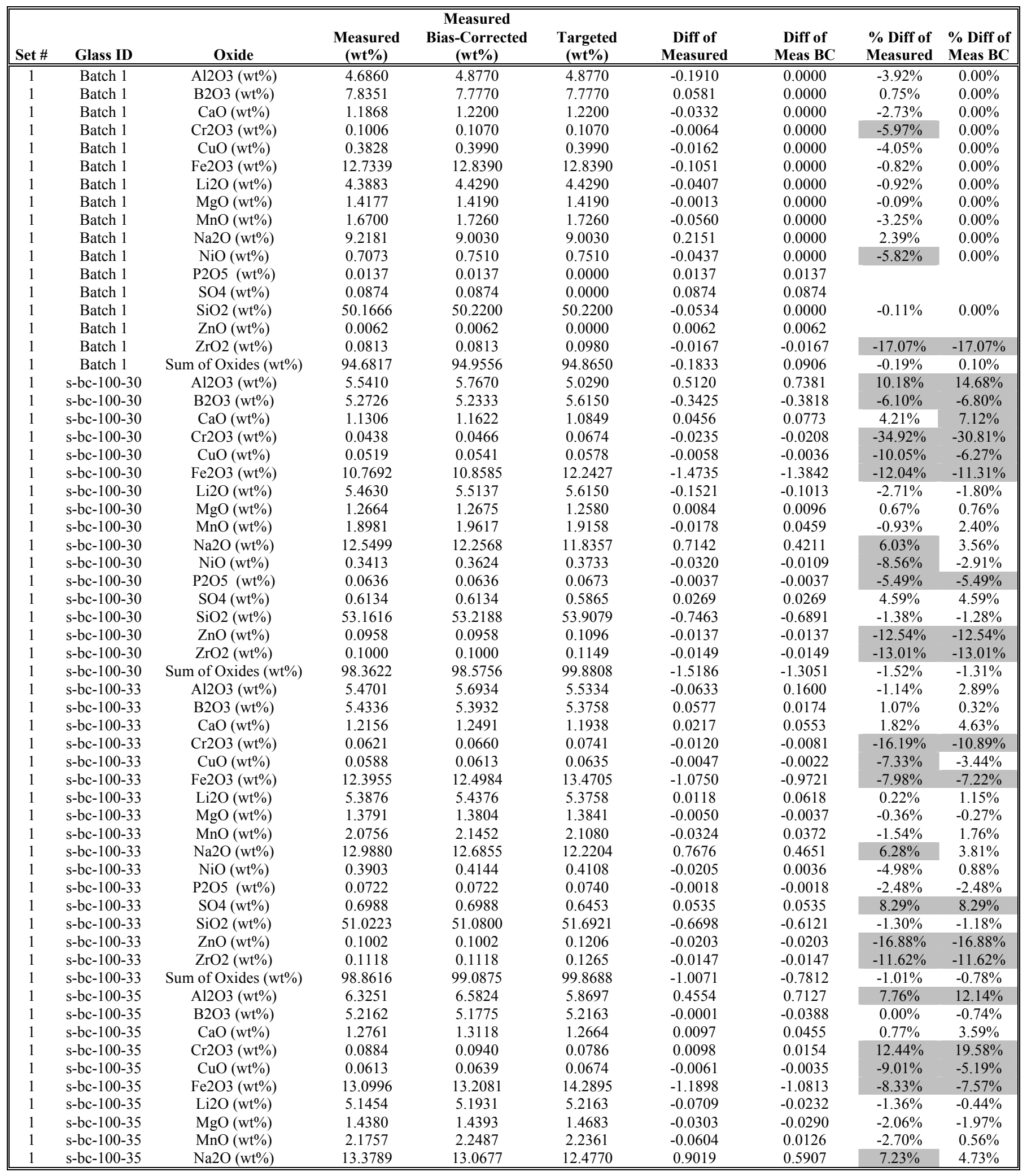



Targeted Compositions by Oxide for $\mathrm{SO}_{4}$ Study Glasses

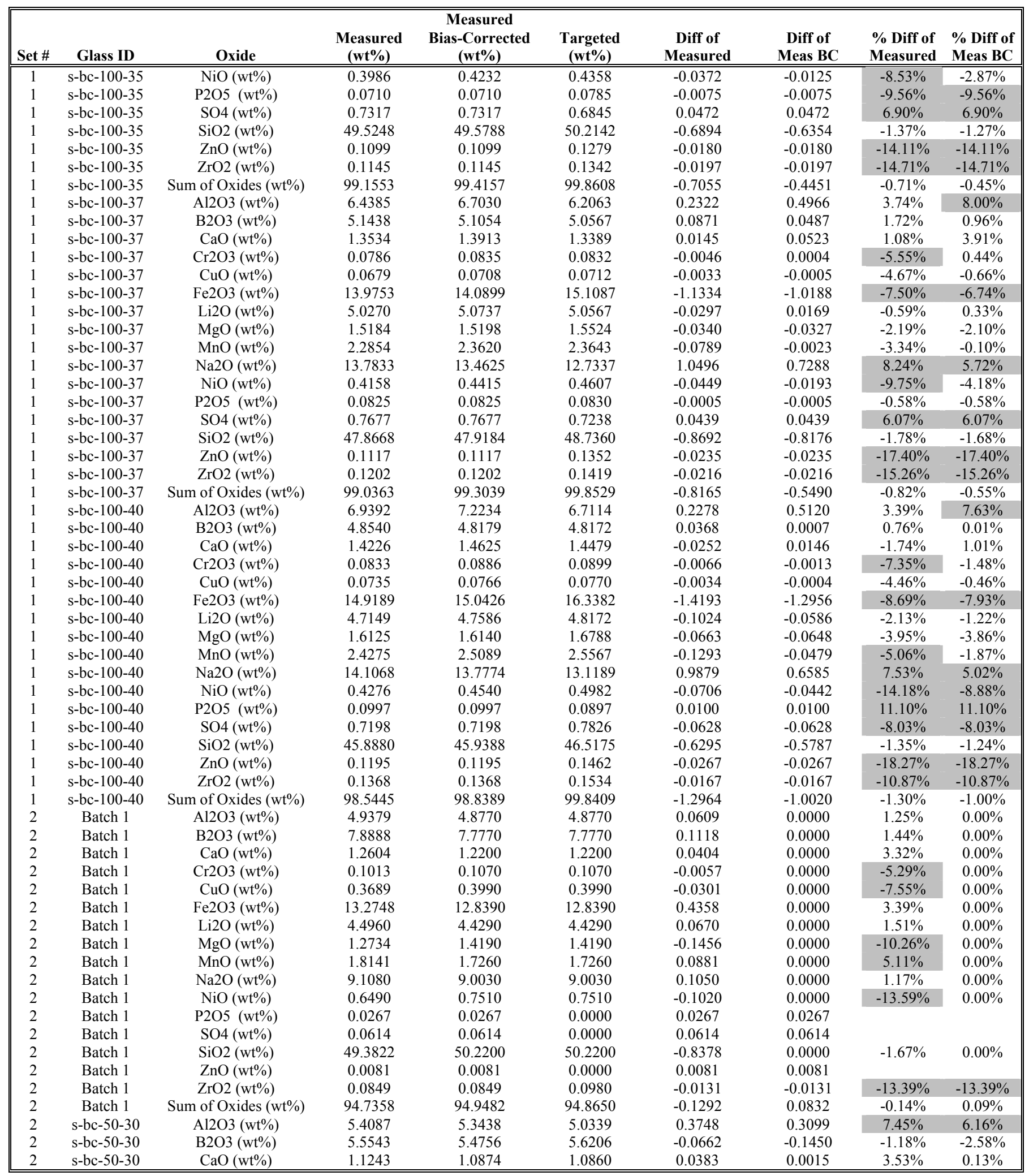



Targeted Compositions by Oxide for $\mathrm{SO}_{4}$ Study Glasses

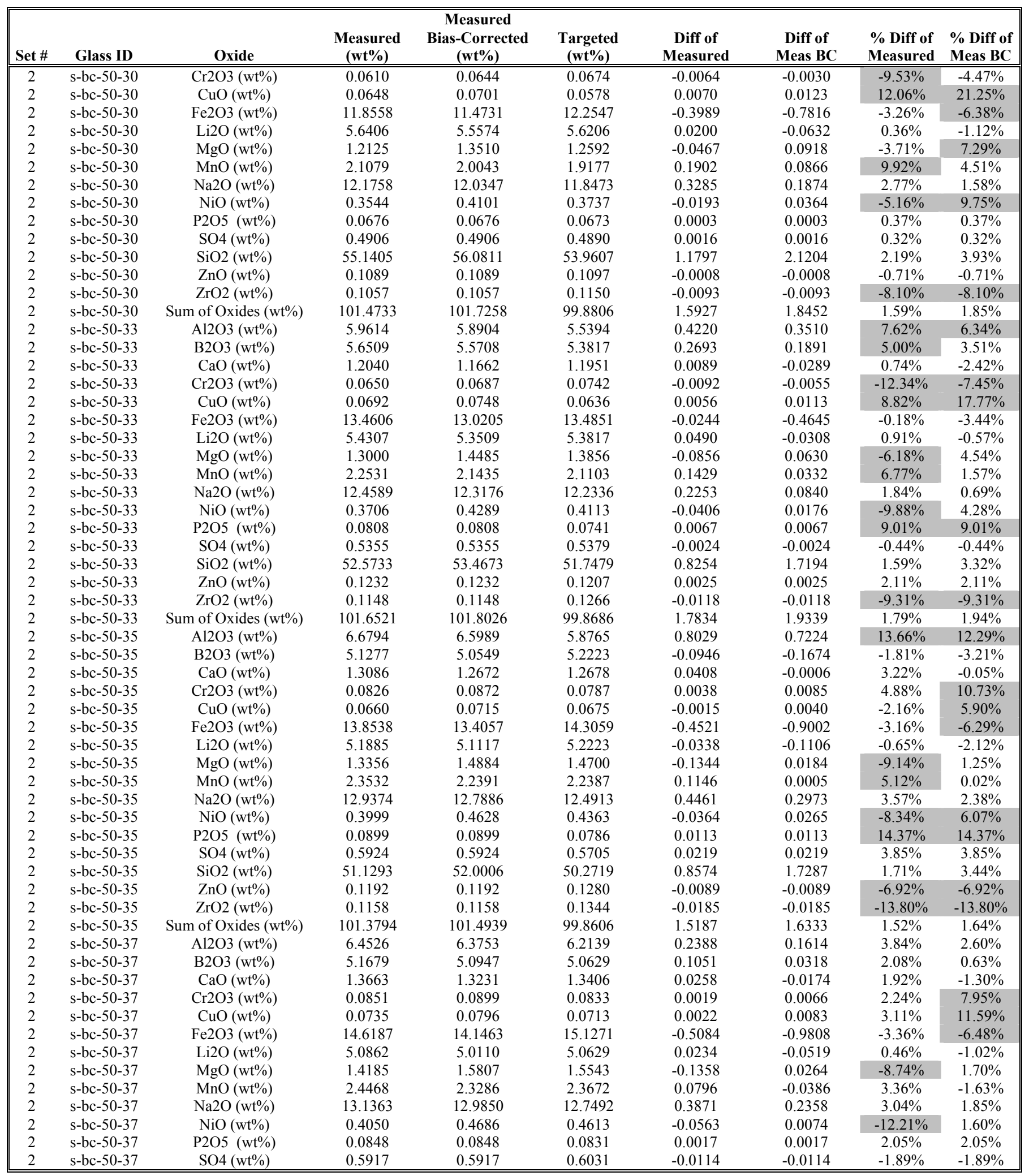



Targeted Compositions by Oxide for $\mathrm{SO}_{4}$ Study Glasses

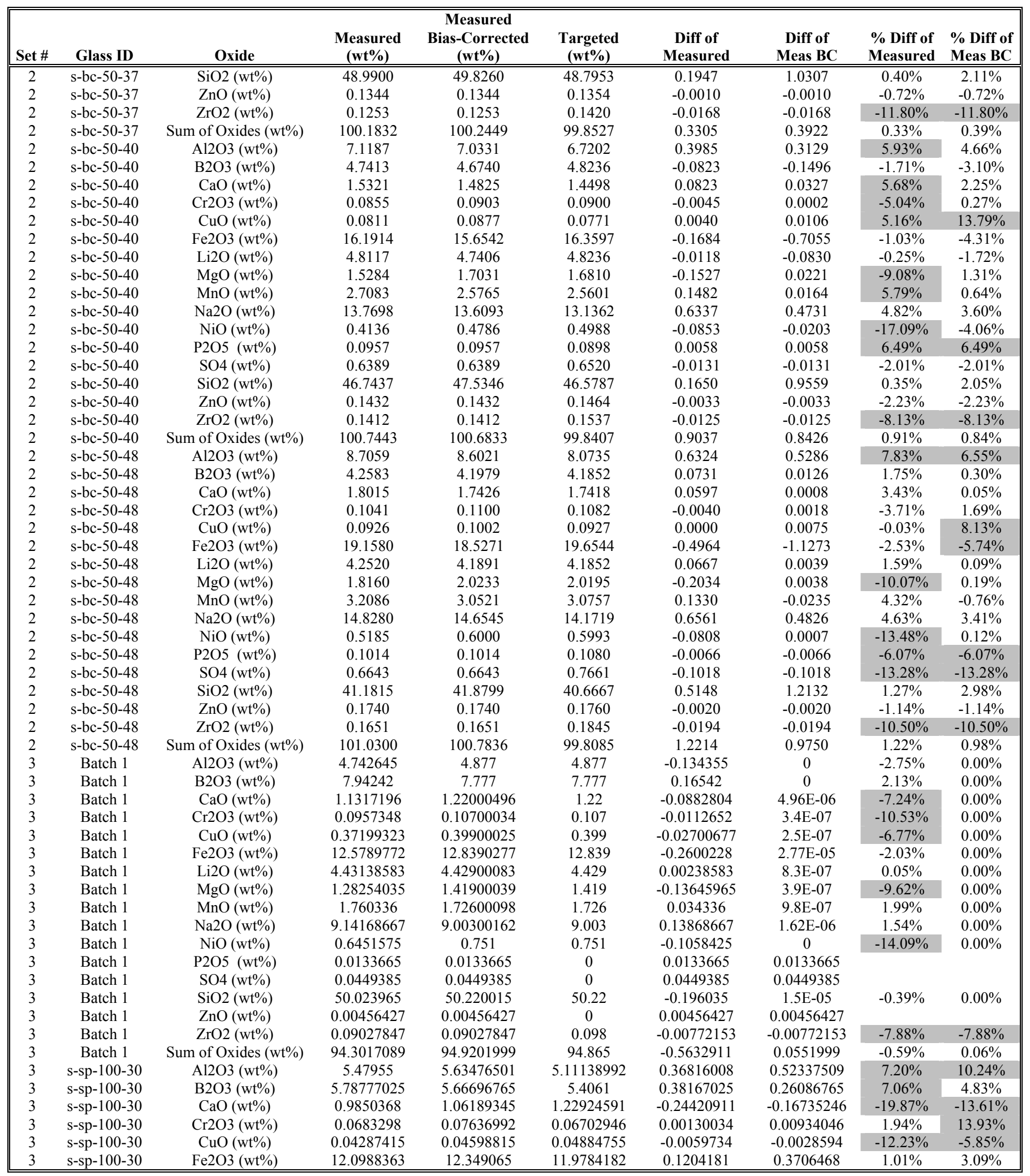




\section{Table B-1: Average Measured and Bias-Corrected Chemical Compositions Versus Targeted Compositions by Oxide for $\mathrm{SO}_{4}$ Study Glasses}

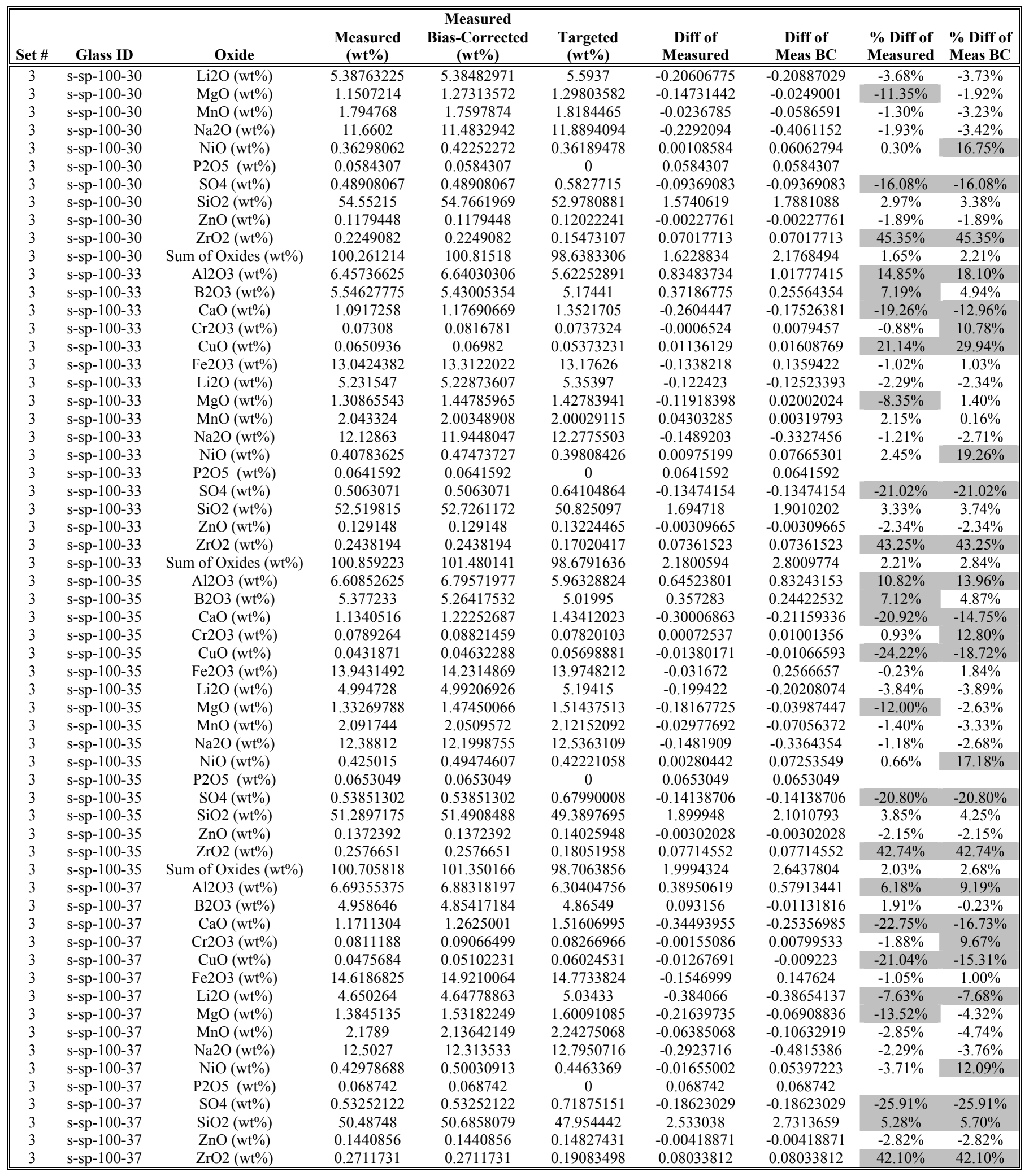




\section{Table B-1: Average Measured and Bias-Corrected Chemical Compositions Versus Targeted Compositions by Oxide for $\mathrm{SO}_{4}$ Study Glasses}

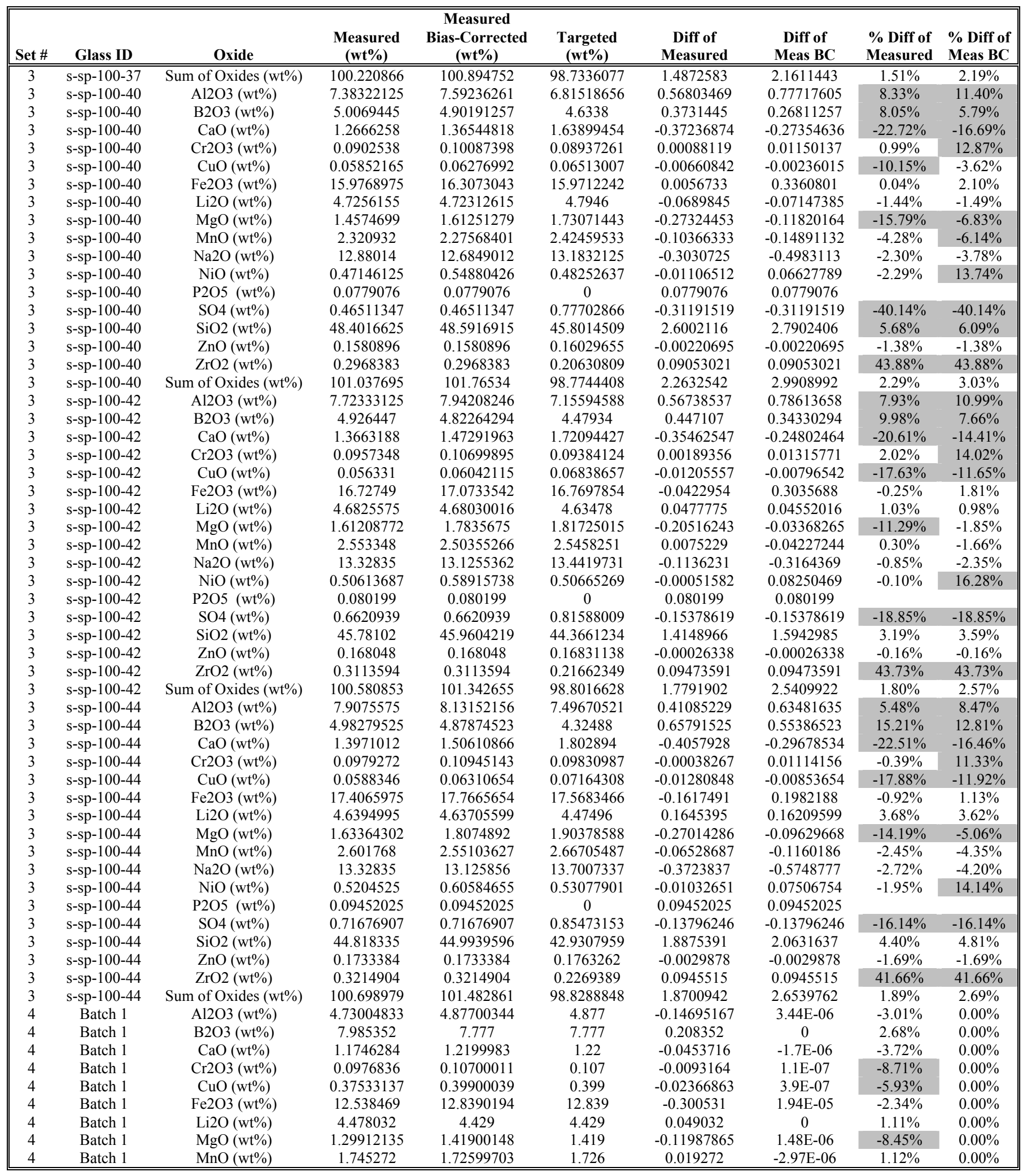




\section{Table B-1: Average Measured and Bias-Corrected Chemical Compositions Versus Targeted Compositions by Oxide for $\mathrm{SO}_{4}$ Study Glasses}

\begin{tabular}{|c|c|c|c|c|c|c|c|c|c|}
\hline Set \# & Glass ID & Oxide & $\begin{array}{c}\text { Measured } \\
(w t \%)\end{array}$ & $\begin{array}{c}\text { Measured } \\
\text { Bias-Corrected } \\
(w t \%)\end{array}$ & $\begin{array}{c}\text { Targeted } \\
(\mathbf{w t} \%)\end{array}$ & $\begin{array}{c}\text { Diff of } \\
\text { Measured }\end{array}$ & $\begin{array}{c}\text { Diff of } \\
\text { Meas BC }\end{array}$ & $\begin{array}{c}\% \text { Diff of } \\
\text { Measured }\end{array}$ & $\begin{array}{l}\% \text { Diff of } \\
\text { Meas BC }\end{array}$ \\
\hline 4 & Batch 1 & $\mathrm{Na} 2 \mathrm{O}(\mathrm{wt} \%)$ & 9.14393333 & 9.00299835 & 9.003 & 0.14093333 & 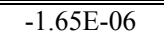 & $1.57 \%$ & $0.00 \%$ \\
\hline 4 & Batch 1 & $\mathrm{NiO}(\mathrm{wt} \%)$ & 0.65470125 & 0.75100029 & 0.751 & -0.09629875 & $2.9 \mathrm{E}-07$ & $-12.82 \%$ & $0.00 \%$ \\
\hline 4 & Batch 1 & $\mathrm{P} 2 \mathrm{O} 5(\mathrm{wt} \%)$ & 0.015276 & 0.015276 & 0 & 0.015276 & 0.015276 & & \\
\hline 4 & Batch 1 & $\mathrm{SO} 4(\mathrm{wt} \%)$ & 0.05192893 & 0.05192893 & 0 & 0.05192893 & 0.05192893 & & \\
\hline 4 & Batch 1 & $\mathrm{SiO} 2(\mathrm{wt} \%)$ & 49.70307 & 50.2199696 & 50.22 & -0.51693 & $-3.04 \mathrm{E}-05$ & $-1.03 \%$ & $0.00 \%$ \\
\hline 4 & Batch 1 & $\mathrm{ZnO}\left(\mathrm{wt}^{0} \%\right)$ & 0.00290453 & 0.00290453 & 0 & 0.00290453 & 0.00290453 & & \\
\hline 4 & Batch 1 & $\mathrm{ZrO} 2(\mathrm{wt} \%)$ & 0.09005333 & 0.09005333 & 0.098 & -0.00794667 & -0.00794667 & $-8.11 \%$ & $-8.11 \%$ \\
\hline 4 & Batch 1 & Sum of Oxides (wt $\%)$ & 94.0858054 & 94.9271513 & 94.865 & -0.7791946 & 0.0621513 & $-0.82 \%$ & $0.07 \%$ \\
\hline 4 & s-sp-50-30 & $\mathrm{A} 12 \mathrm{O} 3(\mathrm{wt} \%)$ & 6.10780875 & 6.29764972 & 5.01472624 & 1.09308251 & 1.28292348 & $21.80 \%$ & $25.58 \%$ \\
\hline 4 & s-sp-50-30 & $\mathrm{B} 2 \mathrm{O} 3(\mathrm{wt} \%)$ & 5.54627775 & 5.40245091 & 5.4061 & 0.14017775 & -0.00364909 & $2.59 \%$ & $-0.07 \%$ \\
\hline 4 & s-sp- $50-30$ & $\mathrm{CaO}\left(\mathrm{wt}^{\circ} \%\right)$ & 0.947958 & 0.98464428 & 1.10695869 & -0.15900069 & -0.12231441 & $-14.36 \%$ & $-11.05 \%$ \\
\hline 4 & s-sp- $50-30$ & $\mathrm{Cr} 2 \mathrm{O} 3(\mathrm{wt} \%)$ & 0.0697914 & 0.07644719 & 0.06511412 & 0.00467728 & 0.01133307 & $7.18 \%$ & $17.40 \%$ \\
\hline 4 & s-sp- $50-30$ & $\mathrm{CuO}\left(\mathrm{wt}^{\circ} \%\right)$ & 0.06478065 & 0.06886546 & 0.05520266 & 0.00957799 & 0.0136628 & $17.35 \%$ & $24.75 \%$ \\
\hline 4 & s-sp- $50-30$ & $\mathrm{Fe} 2 \mathrm{O} 3(\mathrm{wt} \%)$ & 11.7878765 & 12.0704184 & 12.1097213 & -0.3218448 & -0.0393029 & $-2.66 \%$ & $-0.32 \%$ \\
\hline 4 & s-sp- $50-30$ & $\mathrm{Li} 2 \mathrm{O}(\mathrm{wt} \%)$ & 5.360721 & 5.30227916 & 5.5937 & -0.232979 & -0.29142084 & $-4.17 \%$ & $-5.21 \%$ \\
\hline 4 & s-sp- $50-30$ & $\mathrm{MgO}(\mathrm{wt} \%)$ & 1.12170465 & 1.22521133 & 1.29871531 & -0.17701066 & -0.07350398 & $-13.63 \%$ & $-5.66 \%$ \\
\hline 4 & s-sp-50-30 & $\mathrm{MnO}\left(\mathrm{wt}^{0} \%\right)$ & 1.701156 & 1.68235585 & 1.83040413 & -0.12924813 & -0.14804828 & $-7.06 \%$ & $-8.09 \%$ \\
\hline 4 & s-sp- $50-30$ & $\mathrm{Na} 2 \mathrm{O}(\mathrm{wt} \%)$ & 11.73097 & 11.5503206 & 12.0730279 & -0.3420579 & -0.5227073 & $-2.83 \%$ & $-4.33 \%$ \\
\hline 4 & s-sp-50-30 & $\mathrm{NiO}\left(\mathrm{wt}^{\circ} \%\right)$ & 0.348665 & 0.39994895 & 0.36317542 & -0.01451042 & 0.03677353 & $-4.00 \%$ & $10.13 \%$ \\
\hline 4 & s-sp-50-30 & $\mathrm{P} 2 \mathrm{O} 5(\mathrm{wt} \%)$ & 0.0595764 & 0.0595764 & 0 & 0.0595764 & 0.0595764 & & \\
\hline 4 & s-sp- $50-30$ & SO4 (wt $\%)$ & 0.37973032 & 0.37973032 & 0.48810777 & -0.10837745 & -0.10837745 & $-22.20 \%$ & $-22.20 \%$ \\
\hline 4 & s-sp- $50-30$ & $\mathrm{SiO} 2\left(\mathrm{wt}^{\circ} \%\right)$ & 54.33822 & 54.9040861 & 52.969113 & 1.369107 & 1.9349731 & $2.58 \%$ & $3.65 \%$ \\
\hline 4 & s-sp- $50-30$ & $\mathrm{ZnO}(\mathrm{wt} \%)$ & 0.113588 & 0.113588 & 0.11678711 & -0.00319911 & -0.00319911 & $-2.74 \%$ & $-2.74 \%$ \\
\hline 4 & s-sp- $50-30$ & $\mathrm{ZrO} 2(\mathrm{wt} \%)$ & 0.2205181 & 0.2205181 & 0.1503097 & 0.0702084 & 0.0702084 & $46.71 \%$ & $46.71 \%$ \\
\hline 4 & s-sp- $50-30$ & Sum of Oxides (wt $\%)$ & 99.8993425 & 100.738091 & 98.6411633 & 1.2581792 & 2.0969277 & $1.28 \%$ & $2.13 \%$ \\
\hline 4 & s-sp-50-33 & $\mathrm{Al} 2 \mathrm{O} 3(\mathrm{wt} \%)$ & 5.8668975 & 6.04923032 & 5.51619886 & 0.35069864 & 0.53303146 & $6.36 \%$ & $9.66 \%$ \\
\hline 4 & s-sp- $50-33$ & $\mathrm{~B} 2 \mathrm{O} 3(\mathrm{wt} \%)$ & 5.38528275 & 5.24316753 & 5.17441 & 0.21087275 & 0.06875753 & $4.08 \%$ & $1.33 \%$ \\
\hline 4 & s-sp- $50-33$ & $\mathrm{CaO}(\mathrm{wt} \%)$ & 1.0780836 & 1.11982453 & 1.21765456 & -0.13957096 & -0.09783003 & $-11.46 \%$ & $-8.03 \%$ \\
\hline 4 & s-sp- $50-33$ & $\mathrm{Cr} 2 \mathrm{O} 3(\mathrm{wt} \%)$ & 0.0778302 & 0.08525074 & 0.07162553 & 0.00620467 & 0.01362521 & $8.66 \%$ & $19.02 \%$ \\
\hline 4 & s-sp-50-33 & $\mathrm{CuO}(\mathrm{wt} \%)$ & 0.0726044 & 0.07718317 & 0.06072293 & 0.01188147 & 0.01646024 & $19.57 \%$ & $27.11 \%$ \\
\hline 4 & s-sp-50-33 & $\mathrm{Fe} 2 \mathrm{O} 3(\mathrm{wt} \%)$ & 12.9852503 & 13.2965242 & 13.3206934 & -0.3354431 & -0.0241692 & $-2.52 \%$ & $-0.18 \%$ \\
\hline 4 & s-sp-50-33 & $\mathrm{Li} 2 \mathrm{O}(\mathrm{wt} \%)$ & 5.23692925 & 5.17970703 & 5.35397 & -0.11704075 & -0.17426297 & $-2.19 \%$ & $-3.25 \%$ \\
\hline 4 & s-sp- $50-33$ & $\mathrm{MgO}(\mathrm{wt} \%)$ & 1.31280068 & 1.4339405 & 1.42858684 & -0.11578616 & 0.00535366 & $-8.10 \%$ & $0.37 \%$ \\
\hline 4 & s-sp- $50-33$ & $\mathrm{MnO}\left(\mathrm{wt}^{\circ} \%\right)$ & 1.933572 & 1.91220816 & 2.01344454 & -0.07987254 & -0.10123638 & $-3.97 \%$ & $-5.03 \%$ \\
\hline 4 & s-sp-50-33 & $\mathrm{Na} 2 \mathrm{O}(\mathrm{wt} \%)$ & 11.97361 & 11.7892222 & 12.4795307 & -0.5059207 & -0.6903085 & $-4.05 \%$ & $-5.53 \%$ \\
\hline 4 & s-sp- $50-33$ & $\mathrm{NiO}(\mathrm{wt} \%)$ & 0.40910875 & 0.46928329 & 0.39949296 & 0.00961579 & 0.06979033 & $2.41 \%$ & $17.47 \%$ \\
\hline 4 & s-sp-50-33 & $\mathrm{P} 2 \mathrm{O} 5(\mathrm{wt} \%)$ & 0.07046055 & 0.07046055 & 0 & 0.07046055 & 0.07046055 & & \\
\hline 4 & s-sp-50-33 & $\mathrm{SO} 4(\mathrm{wt} \%)$ & 0.48608478 & 0.48608478 & 0.53691855 & -0.05083377 & -0.05083377 & $-9.47 \%$ & $-9.47 \%$ \\
\hline 4 & s-sp-50-33 & $\mathrm{SiO} 2\left(\mathrm{wt}^{\circ} \%\right)$ & 52.19892 & 52.7422101 & 50.8152242 & 1.3836958 & 1.9269859 & $2.72 \%$ & $3.79 \%$ \\
\hline 4 & s-sp-50-33 & $\mathrm{ZnO}\left(\mathrm{wt}^{\circ} \%\right)$ & 0.1325712 & 0.1325712 & 0.12846582 & 0.00410538 & 0.00410538 & $3.20 \%$ & $3.20 \%$ \\
\hline 4 & s-sp-50-33 & $\mathrm{ZrO} 2(\mathrm{wt} \%)$ & 0.253275 & 0.253275 & 0.16534067 & 0.08793433 & 0.08793433 & $53.18 \%$ & $53.18 \%$ \\
\hline 4 & s-sp- $50-33$ & Sum of Oxides (wt $\%$ ) & 99.4732809 & 100.340143 & 98.6822796 & 0.7910013 & 1.6578634 & $0.80 \%$ & $1.68 \%$ \\
\hline 4 & s-sp- $50-35$ & $\mathrm{~A} 12 \mathrm{O} 3(\mathrm{wt} \%)$ & 6.14559875 & 6.33649768 & 5.85051394 & 0.29508481 & 0.48598374 & $5.04 \%$ & $8.31 \%$ \\
\hline 4 & s-sp-50-35 & $\mathrm{B} 2 \mathrm{O} 3(\mathrm{wt} \%)$ & 5.2001385 & 5.06425037 & 5.01995 & 0.1801885 & 0.04430037 & $3.59 \%$ & $0.88 \%$ \\
\hline 4 & s-sp- $50-35$ & $\mathrm{CaO}\left(\mathrm{wt}^{0} \%\right)$ & 1.1102652 & 1.15330406 & 1.2914518 & -0.1811866 & -0.13814774 & $-14.03 \%$ & $-10.70 \%$ \\
\hline 4 & s-sp- $50-35$ & $\mathrm{Cr} 2 \mathrm{O} 3(\mathrm{wt} \%)$ & 0.0811188 & 0.08885401 & 0.07596648 & 0.00515232 & 0.01288753 & $6.78 \%$ & $16.96 \%$ \\
\hline 4 & s-sp- $50-35$ & $\mathrm{CuO}\left(\mathrm{wt}^{\circ} \%\right)$ & 0.07416915 & 0.07884604 & 0.06440311 & 0.00976604 & 0.01444293 & $15.16 \%$ & $22.43 \%$ \\
\hline 4 & s-sp- $50-35$ & $\mathrm{Fe} 2 \mathrm{O} 3(\mathrm{wt} \%)$ & 13.6643578 & 13.9920006 & 14.1280082 & -0.4636504 & -0.1360076 & $-3.28 \%$ & $-0.96 \%$ \\
\hline 4 & s-sp-50-35 & $\mathrm{Li} 2 \mathrm{O}(\mathrm{wt} \%)$ & 5.145431 & 5.08924748 & 5.19415 & -0.048719 & -0.10490252 & $-0.94 \%$ & $-2.02 \%$ \\
\hline 4 & s-sp-50-35 & $\mathrm{MgO}(\mathrm{wt} \%)$ & 1.3198476 & 1.4416351 & 1.51516786 & -0.19532026 & -0.07353276 & $-12.89 \%$ & $-4.85 \%$ \\
\hline 4 & s-sp-50-35 & $\mathrm{MnO}\left(\mathrm{wt}^{\circ} \%\right)$ & 2.011044 & 1.98884922 & 2.13547149 & -0.12442749 & -0.14662227 & $-5.83 \%$ & $-6.87 \%$ \\
\hline 4 & s-sp-50-35 & $\mathrm{Na} 2 \mathrm{O}(\mathrm{wt} \%)$ & 12.10841 & 11.9216845 & 12.7505326 & -0.6421226 & -0.8288481 & $-5.04 \%$ & $-6.50 \%$ \\
\hline 4 & s-sp- $50-35$ & $\mathrm{NiO}\left(\mathrm{wt}^{\circ} \%\right)$ & 0.41038125 & 0.47074296 & 0.42370466 & -0.01332341 & 0.0470383 & $-3.14 \%$ & $11.10 \%$ \\
\hline 4 & s-sp-50-35 & $\mathrm{P} 2 \mathrm{O} 5(\mathrm{wt} \%)$ & 0.07389765 & 0.07389765 & 0 & 0.07389765 & 0.07389765 & & \\
\hline 4 & s-sp-50-35 & SO4 (wt $\%)$ & 0.45612577 & 0.45612577 & 0.56945906 & -0.11333329 & -0.11333329 & $-19.90 \%$ & $-19.90 \%$ \\
\hline 4 & s-sp- $50-35$ & $\mathrm{SiO} 2\left(\mathrm{wt}^{\circ} \%\right)$ & 51.022305 & 51.5524185 & 49.3792984 & 1.6430066 & 2.1731201 & $3.33 \%$ & $4.40 \%$ \\
\hline 4 & s-sp- $50-35$ & $\mathrm{ZnO}\left(\mathrm{wt}^{\circ} \%\right)$ & 0.1341272 & 0.1341272 & 0.13625163 & -0.00212443 & -0.00212443 & $-1.56 \%$ & $-1.56 \%$ \\
\hline 4 & s-sp- $50-35$ & $\mathrm{ZrO} 2\left(\mathrm{wt}^{\circ} \%\right)$ & 0.2610421 & 0.2610421 & 0.17536131 & 0.08568079 & 0.08568079 & $48.86 \%$ & $48.86 \%$ \\
\hline 4 & s-sp- $50-35$ & Sum of Oxides (wt $\%)$ & 99.2182597 & 100.103523 & 98.7096905 & 0.5085692 & 1.3938325 & $0.52 \%$ & $1.41 \%$ \\
\hline 4 & s-sp-50-37 & $\mathrm{A} 12 \mathrm{O} 3(\mathrm{wt} \%)$ & 6.57546 & 6.77962383 & 6.18482903 & 0.39063097 & 0.5947948 & $6.32 \%$ & $9.62 \%$ \\
\hline 4 & s-sp-50-37 & $\mathrm{B} 2 \mathrm{O} 3(\mathrm{wt} \%)$ & 5.023044 & 4.89288953 & 4.86549 & 0.157554 & 0.02739953 & $3.24 \%$ & $0.56 \%$ \\
\hline
\end{tabular}


WSRC-TR-2003-00081

REVISION: 0

\section{Table B-1: Average Measured and Bias-Corrected Chemical Compositions Versus Targeted Compositions by Oxide for $\mathrm{SO}_{4}$ Study Glasses}

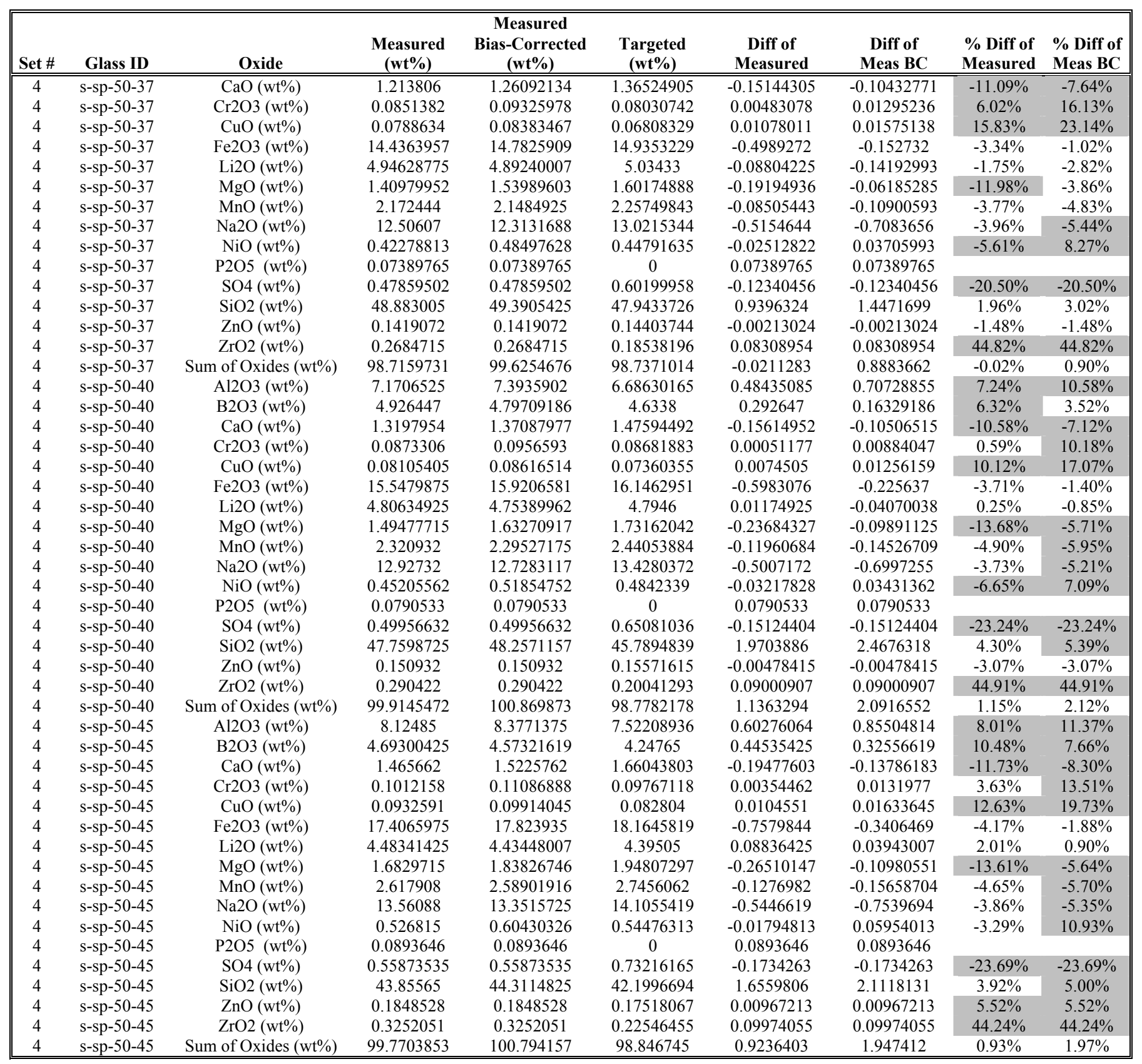


WSRC-TR-2003-00081

REVISION: 0

\section{Table B-1: Average Measured and Bias-Corrected Chemical Compositions Versus Targeted Compositions by Oxide for $\mathrm{SO}_{4}$ Study Glasses}

\begin{tabular}{|c|c|c|c|c|c|}
\hline Type & Glass ID & Prep & ICP Blk & SO4 (wt\%) & WL \\
\hline Crucible & s-bc-100-30 & 1 & 1 & 0.6141595 & 30 \\
\hline Crucible & s-bc-100-30 & 2 & 1 & 0.6051718 & 30 \\
\hline Crucible & s-bc-100-30 & 1 & 2 & 0.6231472 & 30 \\
\hline Crucible & s-bc-100-30 & 2 & 2 & 0.6111636 & 30 \\
\hline Crucible & s-bc-100-33 & 1 & 1 & 0.6920529 & 33 \\
\hline Crucible & s-bc-100-33 & 2 & 1 & 0.6740775 & 33 \\
\hline Crucible & s-bc-100-33 & 1 & 2 & 0.7309996 & 33 \\
\hline Crucible & s-bc-100-33 & 2 & 2 & 0.6980447 & 33 \\
\hline Crucible & s-bc-100-35 & 1 & 1 & 0.719016 & 35 \\
\hline Crucible & s-bc-100-35 & 2 & 1 & 0.7280037 & 35 \\
\hline Crucible & s-bc-100-35 & 1 & 2 & 0.7459791 & 35 \\
\hline Crucible & s-bc-100-35 & 2 & 2 & 0.7339955 & 35 \\
\hline Crucible & s-bc-100-37 & 1 & 1 & 0.7519709 & 37 \\
\hline Crucible & s-bc-100-37 & 2 & 1 & 0.7729422 & 37 \\
\hline Crucible & s-bc-100-37 & 1 & 2 & 0.7759381 & 37 \\
\hline Crucible & s-bc-100-37 & 2 & 2 & 0.7699463 & 37 \\
\hline Crucible & s-bc-100-40 & 1 & 1 & 0.7130242 & 40 \\
\hline Crucible & s-bc-100-40 & 2 & 1 & 0.7100283 & 40 \\
\hline Crucible & s-bc-100-40 & 1 & 2 & 0.7369914 & 40 \\
\hline Crucible & s-bc-100-40 & 2 & 2 & 0.719016 & 40 \\
\hline Crucible & s-bc-50-30 & 1 & 1 & 0.5063071 & 30 \\
\hline Crucible & s-bc-50-30 & 2 & 1 & 0.4883317 & 30 \\
\hline Crucible & s-bc-50-30 & 1 & 2 & 0.4943235 & 30 \\
\hline Crucible & s-bc-50-30 & 2 & 2 & 0.4733522 & 30 \\
\hline Crucible & s-bc-50-33 & 1 & 1 & 0.5302743 & 33 \\
\hline Crucible & s-bc-50-33 & 2 & 1 & 0.539262 & 33 \\
\hline Crucible & s-bc-50-33 & 1 & 2 & 0.5452538 & 33 \\
\hline Crucible & s-bc-50-33 & 2 & 2 & 0.5272784 & 33 \\
\hline Crucible & s-bc-50-35 & 1 & 1 & 0.6201513 & 35 \\
\hline Crucible & s-bc-50-35 & 2 & 1 & 0.5931882 & 35 \\
\hline Crucible & s-bc-50-35 & 1 & 2 & 0.5752128 & 35 \\
\hline Crucible & s-bc-50-35 & 2 & 2 & 0.5812046 & 35 \\
\hline Crucible & s-bc-50-37 & 1 & 1 & 0.59918 & 37 \\
\hline Crucible & s-bc-50-37 & 2 & 1 & 0.5931882 & 37 \\
\hline Crucible & s-bc-50-37 & 1 & 2 & 0.5752128 & 37 \\
\hline Crucible & s-bc-50-37 & 2 & 2 & 0.59918 & 37 \\
\hline Crucible & s-bc-50-40 & 1 & 1 & 0.6531062 & 40 \\
\hline Crucible & s-bc-50-40 & 2 & 1 & 0.6411226 & 40 \\
\hline Crucible & s-bc-50-40 & 1 & 2 & 0.6111636 & 40 \\
\hline Crucible & s-bc-50-40 & 2 & 2 & 0.6501103 & 40 \\
\hline Crucible & s-bc-50-48 & 1 & 1 & 0.6680857 & 48 \\
\hline Crucible & s-bc-50-48 & 2 & 1 & 0.659098 & 48 \\
\hline Crucible & s-bc-50-48 & 1 & 2 & 0.659098 & 48 \\
\hline Crucible & s-bc-50-48 & 2 & 2 & 0.6710816 & 48 \\
\hline SMRF & SMRF 0128 & 1 & 1 & 0.783 & . \\
\hline SMRF & SMRF 0128 & 1 & 2 & 0.786 & . \\
\hline SMRF & SMRF 0130 & 1 & 1 & 0.765 & . \\
\hline SMRF & SMRF 0130 & 1 & 2 & 0.75 & . \\
\hline SMRF & SMRF 0136 & 1 & 1 & 0.786 & . \\
\hline SMRF & SMRF 0136 & 1 & 2 & 0.804 & . \\
\hline SMRF & SMRF 0141 & 1 & 1 & 0.963 & . \\
\hline SMRF & SMRF 0141 & 1 & 2 & 0.989 & . \\
\hline SMRF & SMRF 0146 & 1 & 1 & 1.17 & . \\
\hline SMRF & SMRF 0146 & 1 & 2 & 1.17 & . \\
\hline SMRF & SMRF 0152 & 1 & 1 & 1.22 & . \\
\hline SMRF & SMRF 0152 & 1 & 2 & 1.19 &. \\
\hline SMRF & SMRF 0154 & 1 & 1 & 1.46 & . \\
\hline SMRF & SMRF 0154 & 1 & 2 & 1.45 & . \\
\hline Crucible & s-sp-50-30 & 1 & 1 & 0.3774834 & 30 \\
\hline Crucible & s-sp-50-30 & 2 & 1 & 0.3804793 & 30 \\
\hline Crucible & s-sp-50-30 & 1 & 2 & 0.3834752 & 30 \\
\hline Crucible & s-sp-50-30 & 2 & 2 & 0.3774834 & 30 \\
\hline Crucible & s-sp-50-33 & 1 & 1 & 0.4733522 & 33 \\
\hline Crucible & s-sp-50-33 & 2 & 1 & 0.4883317 & 33 \\
\hline Crucible & s-sp-50-33 & 1 & 2 & 0.4973194 & 33 \\
\hline
\end{tabular}

\begin{tabular}{|c|c|c|c|c|c|}
\hline Type & Glass ID & Prep & ICP Blk & SO4 (wt\%) & WL \\
\hline Crucible & s-sp-50-33 & 2 & 2 & 0.4853358 & 33 \\
\hline Crucible & s-sp-50-35 & 1 & 1 & 0.4553768 & 35 \\
\hline Crucible & s-sp-50-35 & 2 & 1 & 0.4553768 & 35 \\
\hline Crucible & s-sp-50-35 & 1 & 2 & 0.449385 & 35 \\
\hline Crucible & s-sp-50-35 & 2 & 2 & 0.4643645 & 35 \\
\hline Crucible & s-sp-50-37 & 1 & 1 & 0.479344 & 37 \\
\hline Crucible & s-sp-50-37 & 2 & 1 & 0.4883317 & 37 \\
\hline Crucible & s-sp-50-37 & 1 & 2 & 0.4733522 & 37 \\
\hline Crucible & s-sp-50-37 & 2 & 2 & 0.4733522 & 37 \\
\hline Crucible & s-sp-50-40 & 1 & 1 & 0.5033112 & 40 \\
\hline Crucible & s-sp-50-40 & 2 & 1 & 0.4913276 & 40 \\
\hline Crucible & s-sp-50-40 & 1 & 2 & 0.4973194 & 40 \\
\hline Crucible & s-sp-50-40 & 2 & 2 & 0.5063071 & 40 \\
\hline Crucible & s-sp-50-45 & 1 & 1 & 0.5662251 & 45 \\
\hline Crucible & s-sp-50-45 & 2 & 1 & 0.5482497 & 45 \\
\hline Crucible & s-sp-50-45 & 1 & 2 & 0.5632292 & 45 \\
\hline Crucible & s-sp-50-45 & 2 & 2 & 0.5572374 & 45 \\
\hline Crucible & s-sp-100-30 & 1 & 1 & 0.4883317 & 30 \\
\hline Crucible & s-sp-100-30 & 2 & 1 & 0.4823399 & 30 \\
\hline Crucible & s-sp-100-30 & 1 & 2 & 0.4943235 & 30 \\
\hline Crucible & s-sp-100-30 & 2 & 2 & 0.4913276 & 30 \\
\hline Crucible & s-sp-100-33 & 1 & 1 & 0.5152948 & 33 \\
\hline Crucible & s-sp-100-33 & 2 & 1 & 0.4913276 & 33 \\
\hline Crucible & s-sp-100-33 & 1 & 2 & 0.4973194 & 33 \\
\hline Crucible & s-sp-100-33 & 2 & 2 & 0.5212866 & 33 \\
\hline Crucible & s-sp-100-35 & 1 & 1 & 0.5362661 & 35 \\
\hline Crucible & s-sp-100-35 & 2 & 1 & 0.5452538 & 35 \\
\hline Crucible & s-sp-100-35 & 1 & 2 & 0.5362661 & 35 \\
\hline Crucible & s-sp-100-35 & 2 & 2 & 0.5362661 & 35 \\
\hline Crucible & s-sp-100-37 & 1 & 1 & 0.539262 & 37 \\
\hline Crucible & s-sp-100-37 & 2 & 1 & 0.5182907 & 37 \\
\hline Crucible & s-sp-100-37 & 1 & 2 & 0.5332702 & 37 \\
\hline Crucible & s-sp-100-37 & 2 & 2 & 0.539262 & 37 \\
\hline Crucible & s-sp-100-40 & 1 & 1 & 0.4583727 & 40 \\
\hline Crucible & s-sp-100-40 & 2 & 1 & 0.4763481 & 40 \\
\hline Crucible & s-sp-100-40 & 1 & 2 & 0.4643645 & 40 \\
\hline Crucible & s-sp-100-40 & 2 & 2 & 0.4613686 & 40 \\
\hline Crucible & s-sp-100-42 & 1 & 1 & 0.6561021 & 42 \\
\hline Crucible & s-sp-100-42 & 2 & 1 & 0.6680857 & 42 \\
\hline Crucible & s-sp-100-42 & 1 & 2 & 0.659098 & 42 \\
\hline Crucible & s-sp-100-42 & 2 & 2 & 0.6650898 & 42 \\
\hline Crucible & s-sp-100-44 & 1 & 1 & 0.7160201 & 44 \\
\hline Crucible & s-sp-100-44 & 2 & 1 & 0.7130242 & 44 \\
\hline Crucible & s-sp-100-44 & 1 & 2 & 0.7160201 & 44 \\
\hline Crucible & s-sp-100-44 & 2 & 2 & 0.7220119 & 44 \\
\hline Crucible & BC-100-33R & 1 & 1 & 0.606 & 33 \\
\hline Crucible & BC-100-33R & 1 & 2 & 0.615 & 33 \\
\hline Crucible & BC-100-37R & 1 & 1 & 0.687 & 37 \\
\hline Crucible & BC-100-37R & 1 & 2 & 0.693 & 37 \\
\hline Crucible & BC-30\%-0.65 & 1 & 1 & 0.627 & 30 \\
\hline Crucible & BC-30\%- 0.65 & 1 & 2 & 0.621 & 30 \\
\hline Crucible & BC- $30 \%-0.70$ & 1 & 1 & 0.618 & 30 \\
\hline Crucible & BC-30\%-0.70 & 1 & 2 & 0.627 & 30 \\
\hline Crucible & BC-30\%-0.77 & 1 & 1 & 0.675 & 30 \\
\hline Crucible & BC-30\%-0.77 & 1 & 2 & 0.693 & 30 \\
\hline Crucible & BC- $35 \%-0.70$ & 1 & 1 & 0.675 & 35 \\
\hline Crucible & BC-35\%-0.70 & 1 & 2 & 0.666 & 35 \\
\hline Crucible & BC-35\%-0.73 & 1 & 1 & 0.684 & 35 \\
\hline Crucible & BC-35\%-0.73 & 1 & 2 & 0.675 & 35 \\
\hline Crucible & BC-35\%-0.77 & 1 & 1 & 0.729 & 35 \\
\hline Crucible & BC-35\%-0.77 & 1 & 2 & 0.732 & 35 \\
\hline
\end{tabular}


Figure B-1: Average Measured and Bias-Corrected (bc) Versus Targeted Compositions for Study Glasses and Batch 1 by Oxide
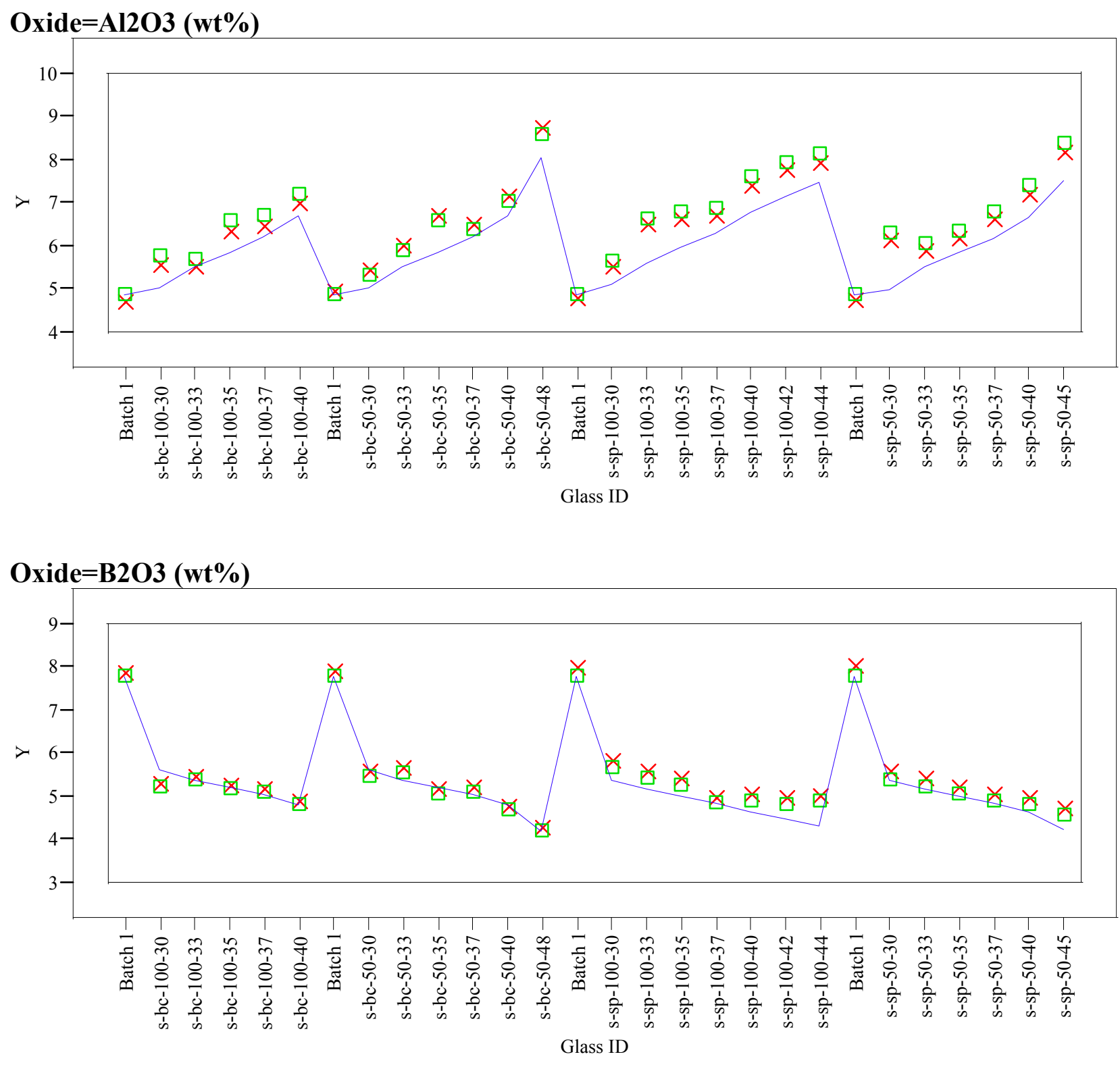

$\mathrm{Y} \times$ Measured $\square$ Measured bc - Targeted 
Figure B-1: Average Measured and Bias-Corrected (bc) Versus Targeted Compositions for Study Glasses and Batch 1 by Oxide
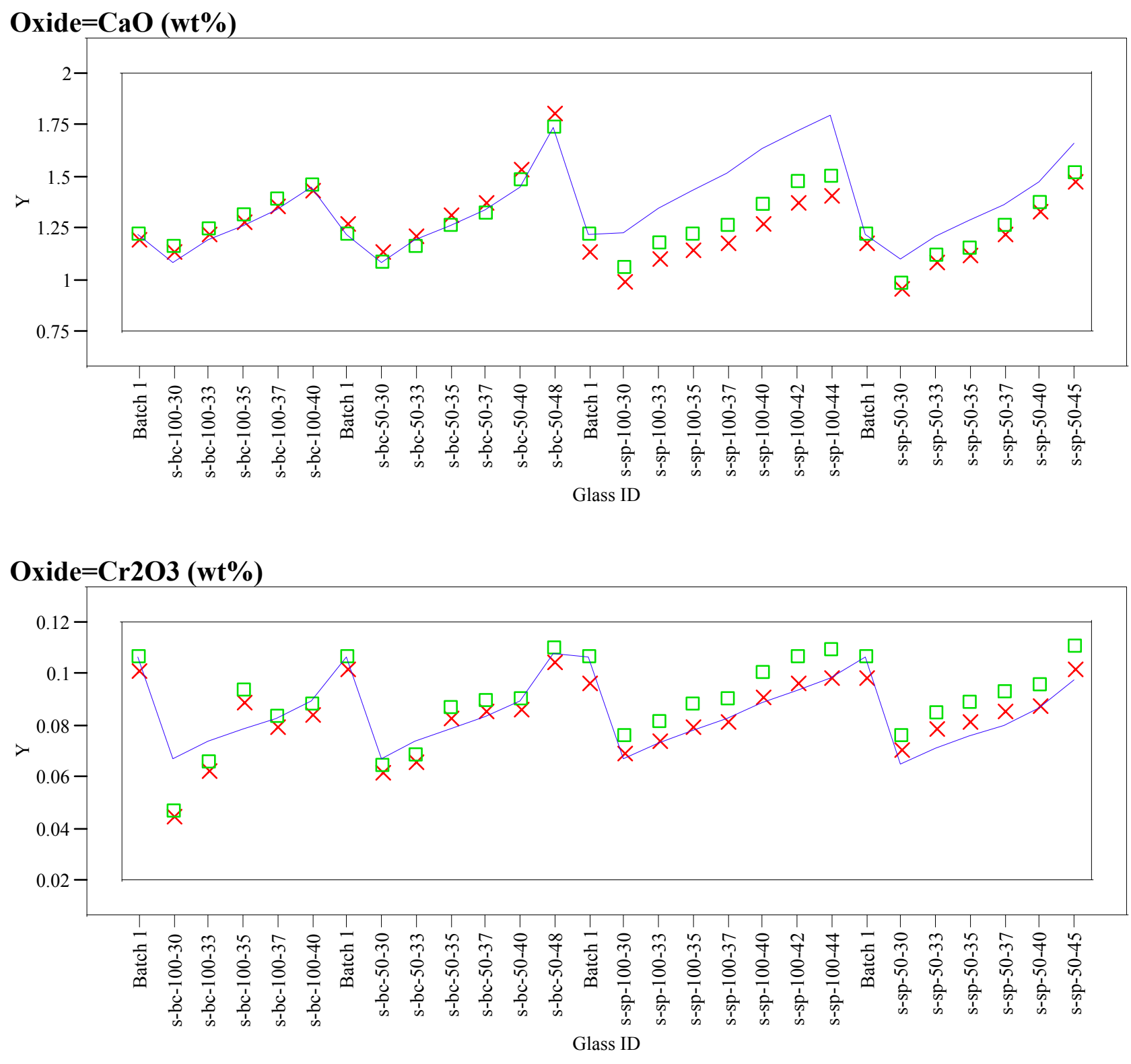

$\mathrm{Y} \times$ Measured $\square$ Measured bc - Targeted 
Figure B-1: Average Measured and Bias-Corrected (bc) Versus Targeted Compositions for Study Glasses and Batch 1 by Oxide
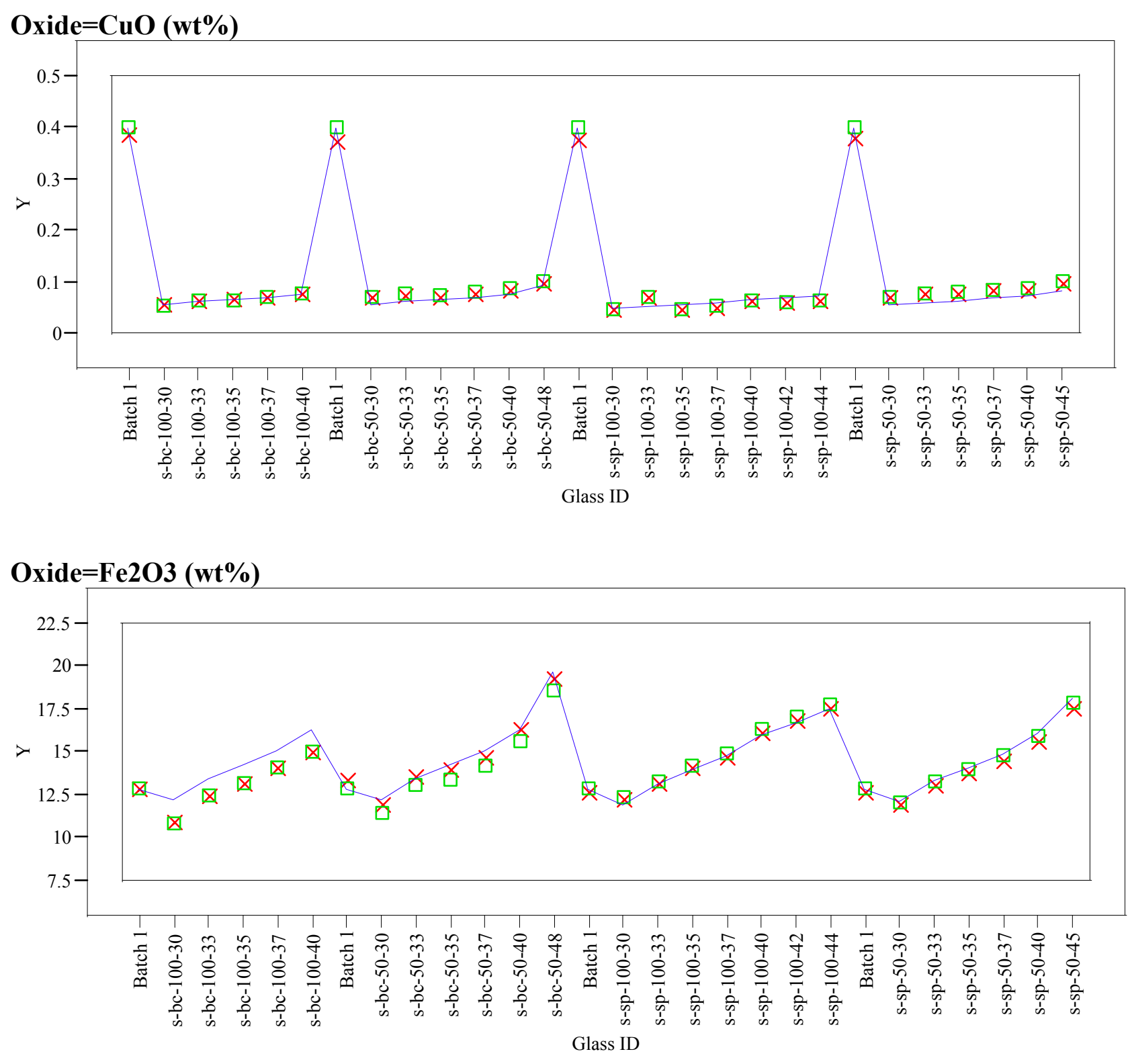

$\mathrm{Y} \times$ Measured $\square$ Measured bc - Targeted 
Figure B-1: Average Measured and Bias-Corrected (bc) Versus Targeted Compositions for Study Glasses and Batch 1 by Oxide
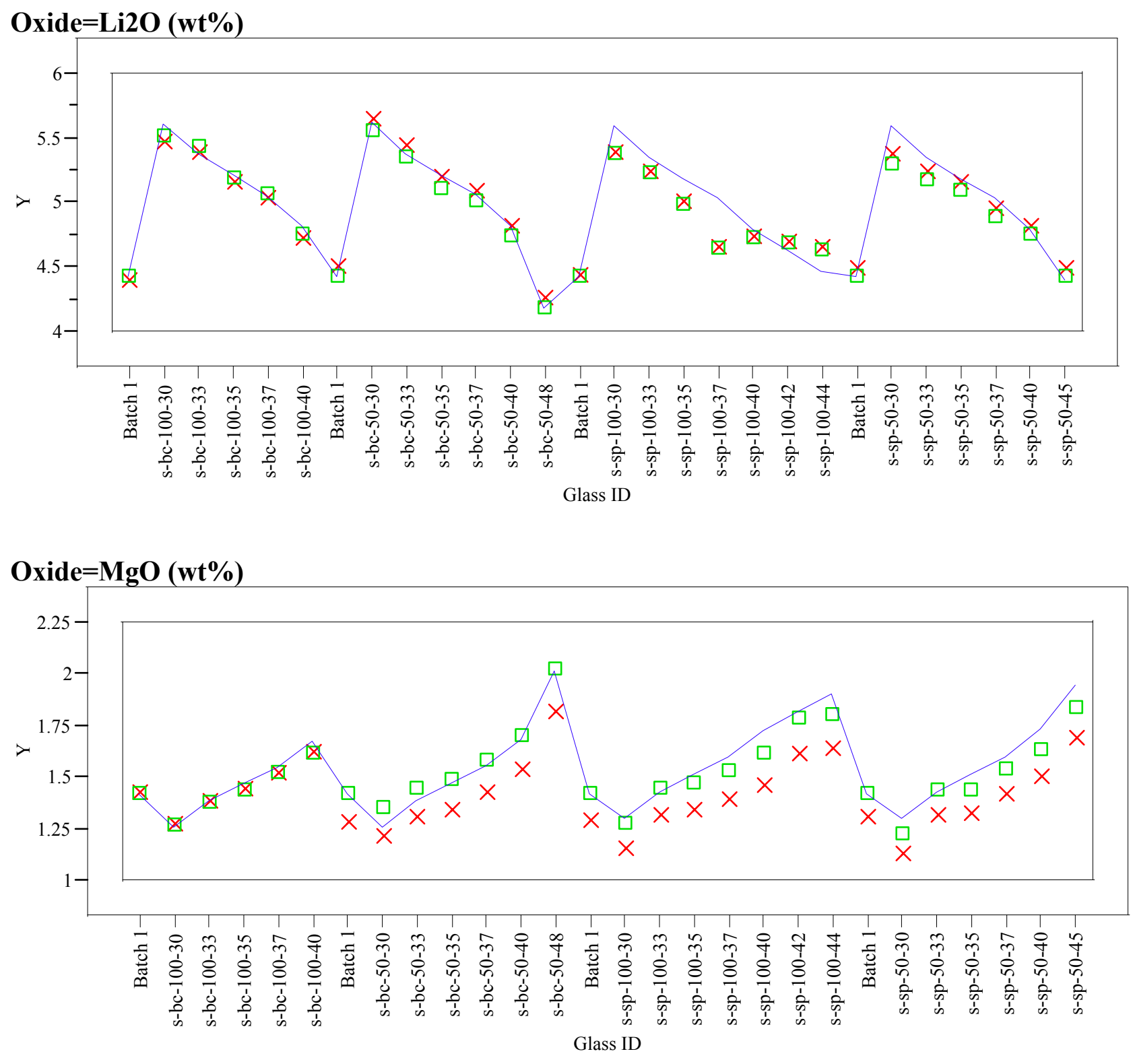

$\mathrm{Y} \times$ Measured $\square$ Measured bc - Targeted 
Figure B-1: Average Measured and Bias-Corrected (bc) Versus Targeted Compositions for Study Glasses and Batch 1 by Oxide
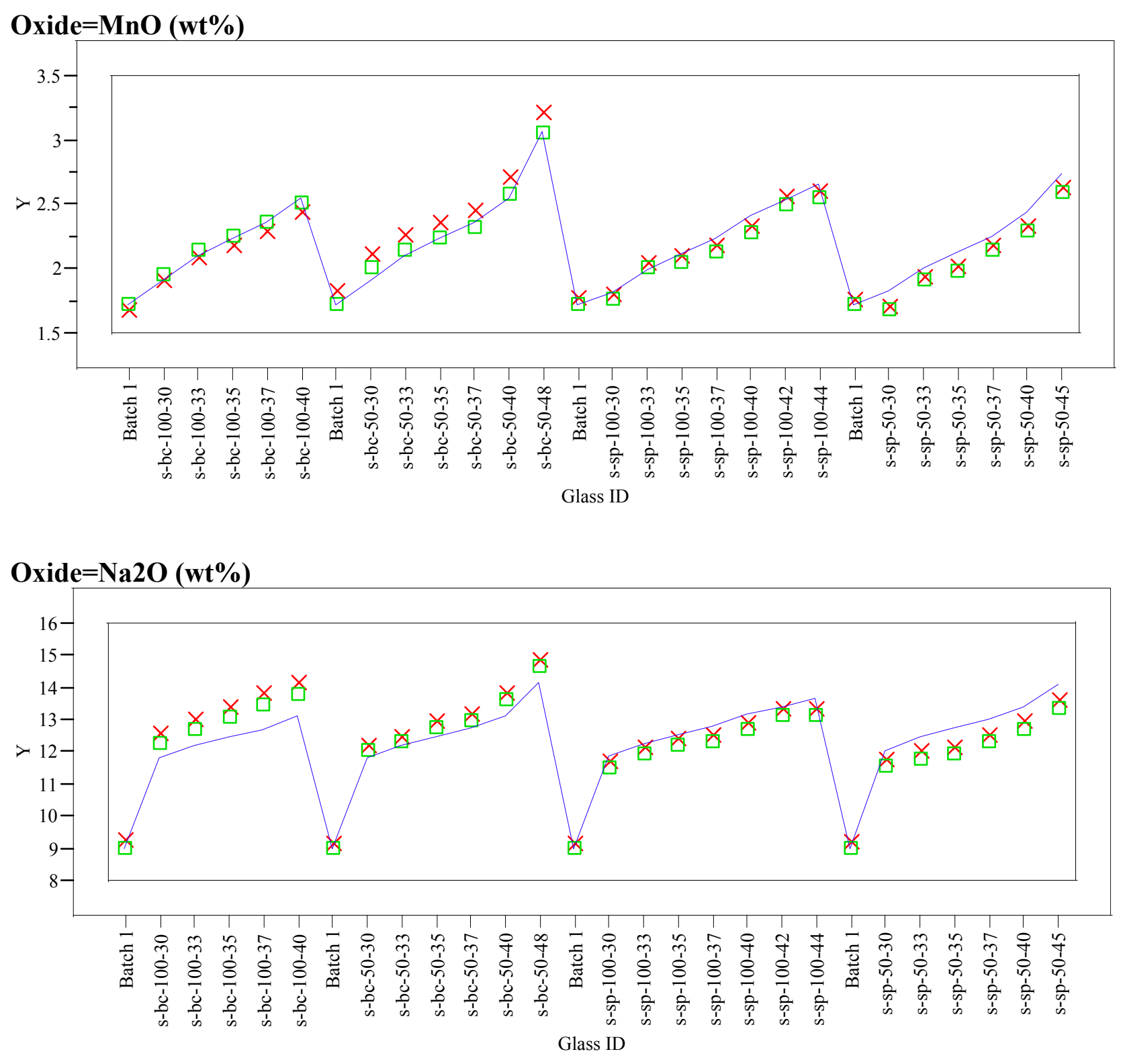

$\mathrm{Y} \times$ Measured $\square$ Measured bc - Targeted 


\section{Figure B-1: Average Measured and Bias-Corrected (bc) Versus Targeted Compositions for Study Glasses and Batch 1 by Oxide}
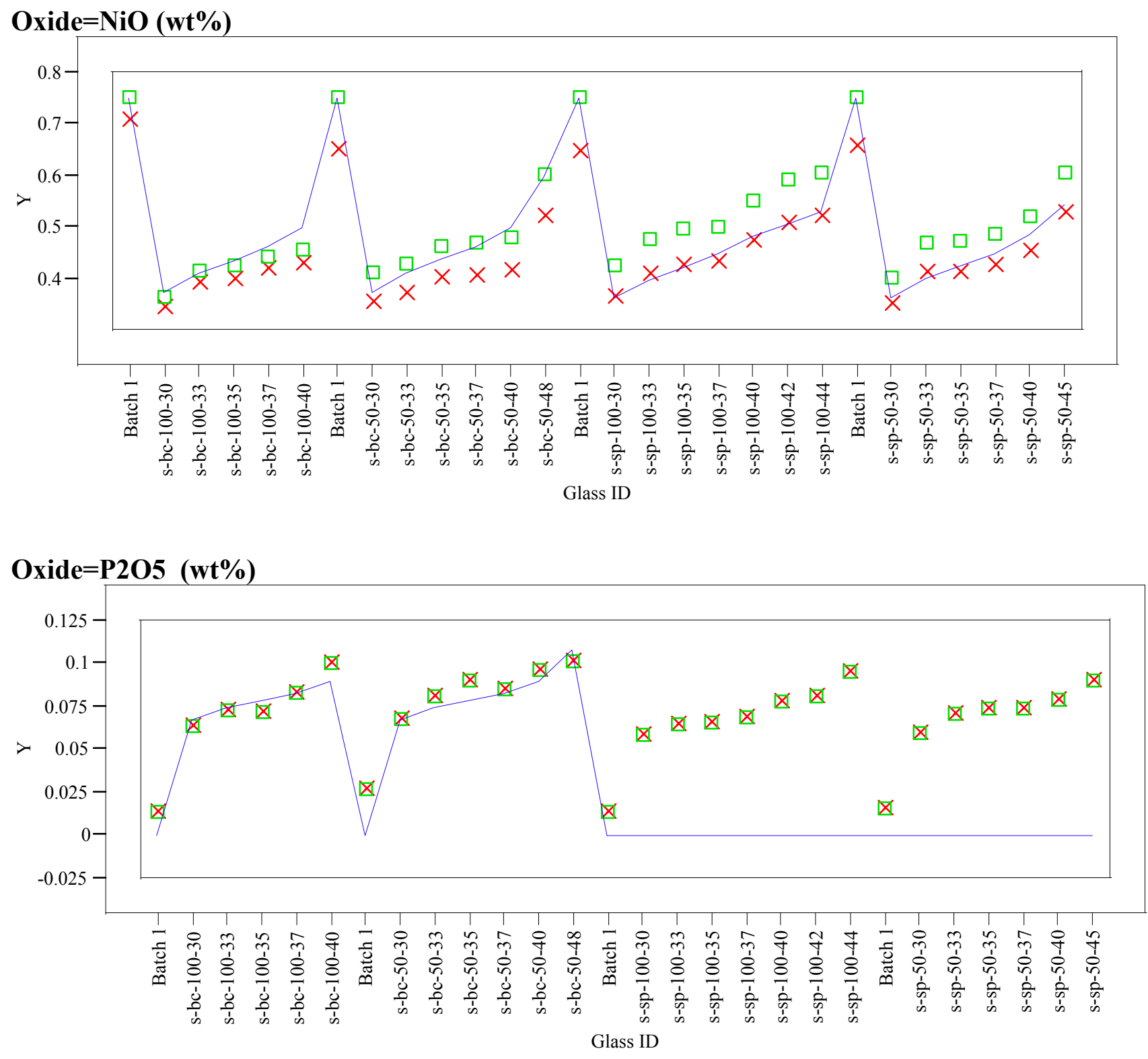

$\mathrm{Y} \times$ Measured $\square$ Measured $\mathrm{bc}$ - Targeted 
Figure B-1: Average Measured and Bias-Corrected (bc) Versus Targeted

Compositions for Study Glasses and Batch 1 by Oxide
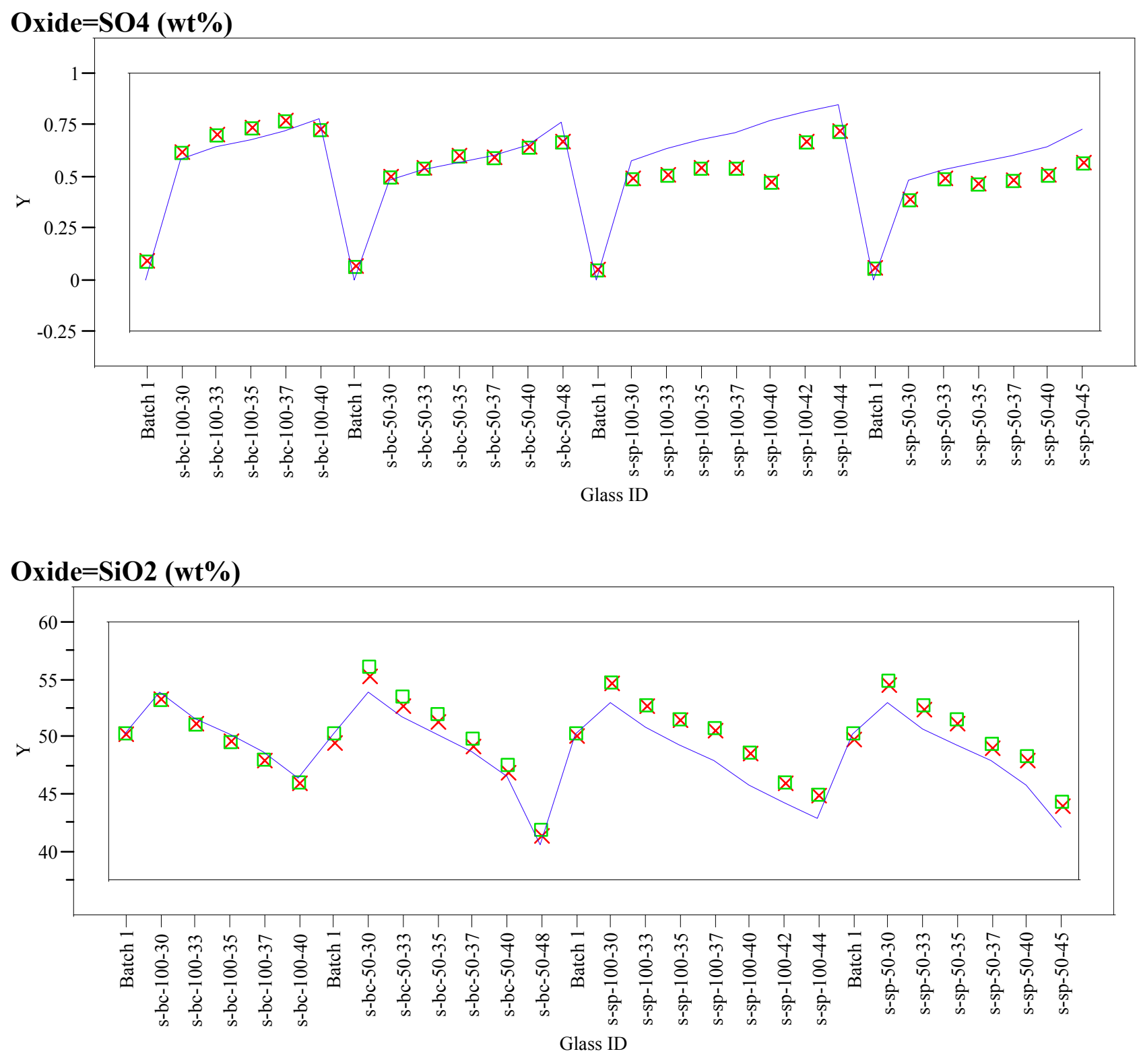

$\mathrm{Y} \times$ Measured $\square$ Measured bc - Targeted 


\section{Figure B-1: Average Measured and Bias-Corrected (bc) Versus Targeted Compositions for Study Glasses and Batch 1 by Oxide}
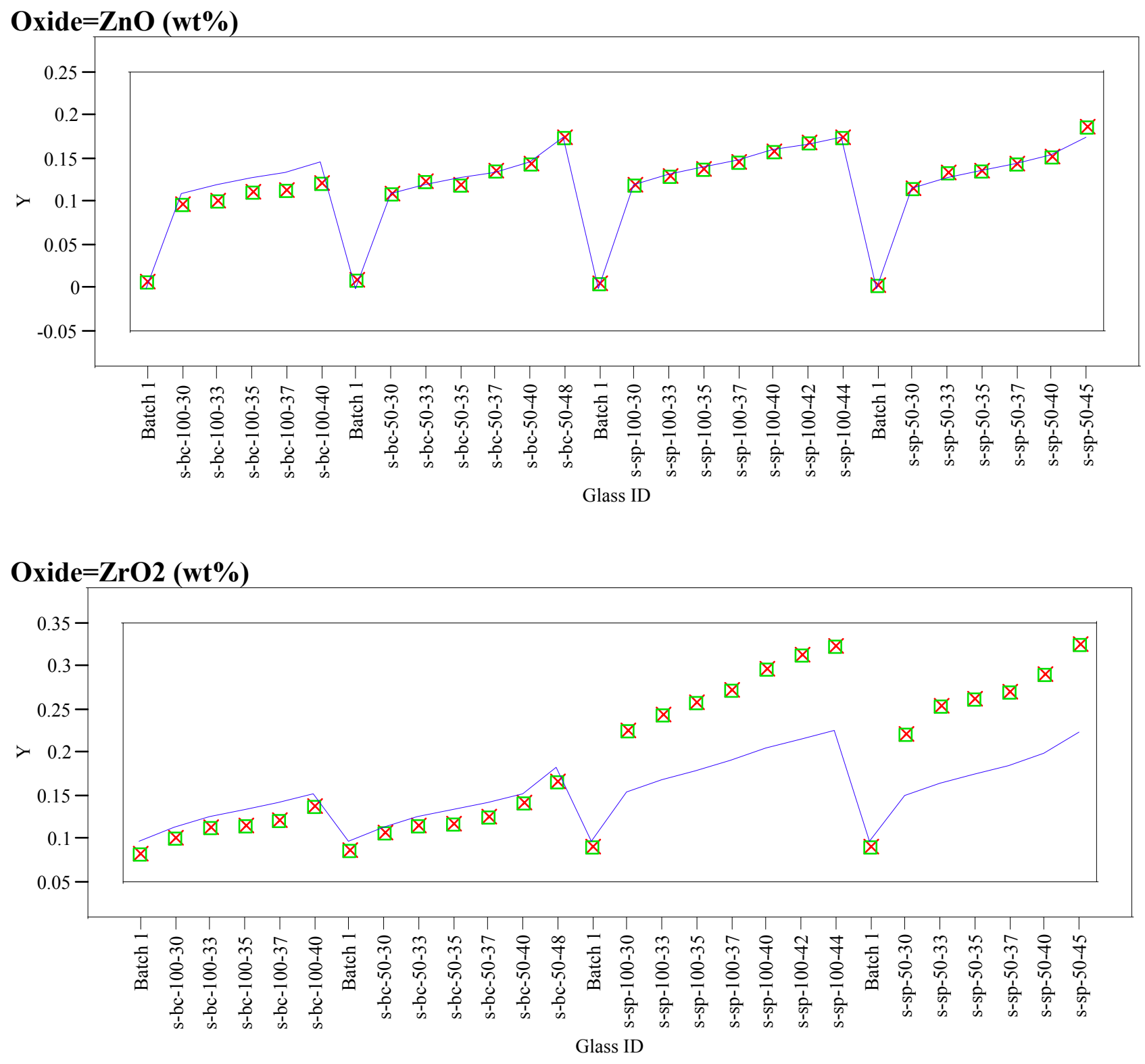

$\mathrm{Y} \times$ Measured $\square$ Measured bc - Targeted 
Figure B-1: Average Measured and Bias-Corrected (bc) Versus Targeted

Compositions for Study Glasses and Batch 1 by Oxide

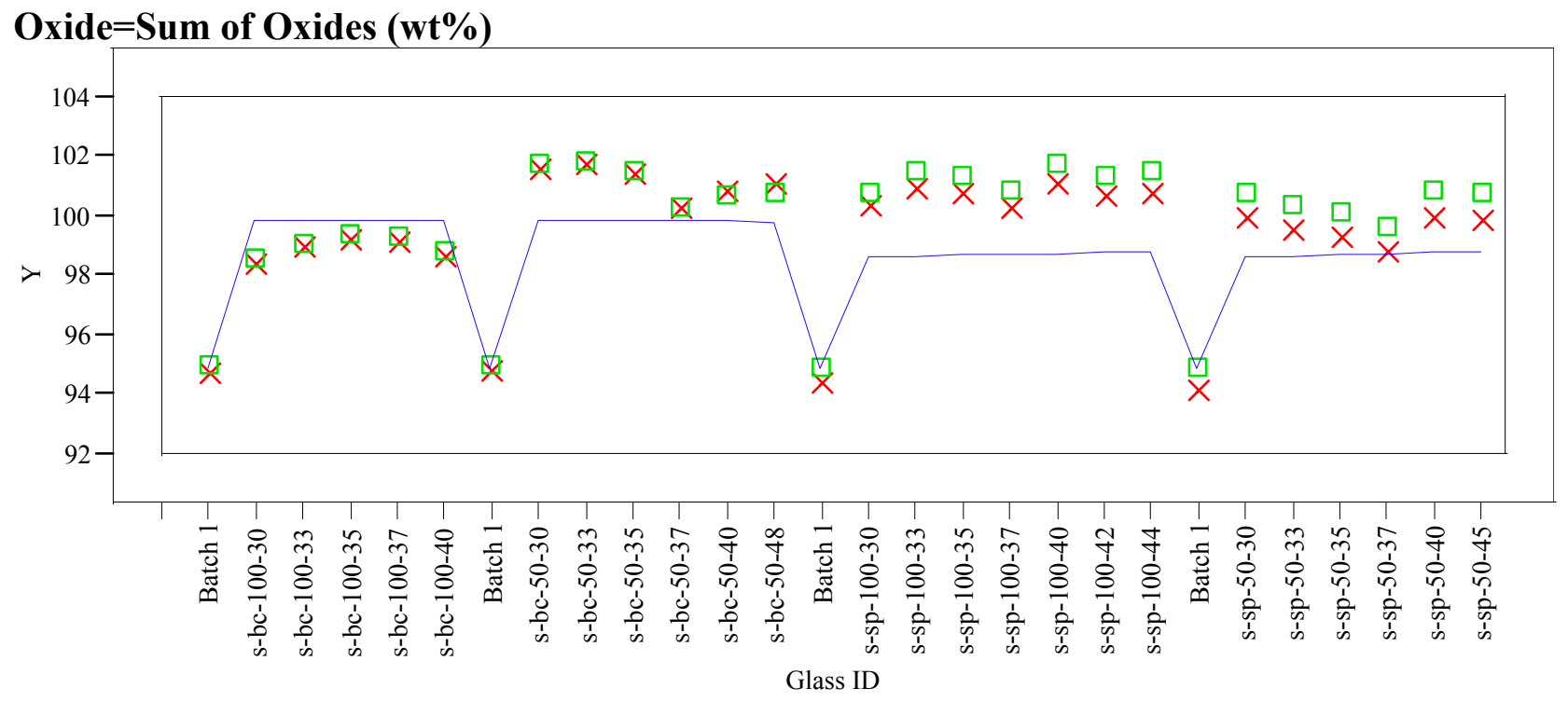

$\mathrm{Y} \times$ Measured $\square$ Measured bc - Targeted 
Figure B-2: Estimation of Variation in $\mathrm{SO}_{4}$ Measurement Due to ICP Calibration

Oneway Analysis of Mean(SO4 (wt\%)) By Glass ID (LM)

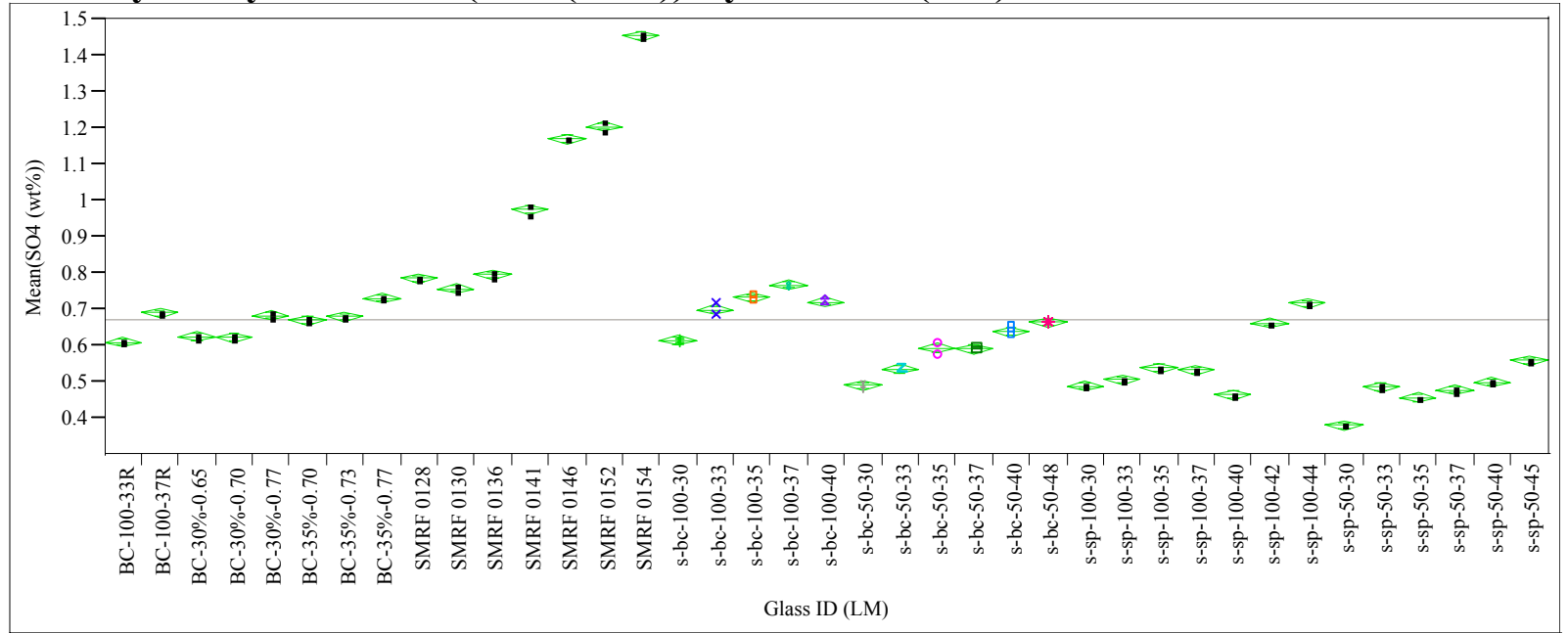

Oneway Anova

Summary of Fit

Rsquare

Adj Rsquare

Root Mean Square Error

Mean of Response

Observations (or Sum Wgts)

Analysis of $V$ ariance

Source

Glass ID (LM)

Error

C. Total
0.999081

0.998186

0.009109

0.673554

78

Sum of Squares

3.5187367

0.0032362

3.5219729
Mean Square
0.092598
0.000083

F Ratio

1115.92

Prob $>$ F

$<.0001$ 
Figure B-3: Estimation of Variation in $\mathrm{SO}_{4}$ Measurement Due to Sample Preparation

Oneway Analysis of Mean(SO4 (wt\%)) By Glass ID (LM)

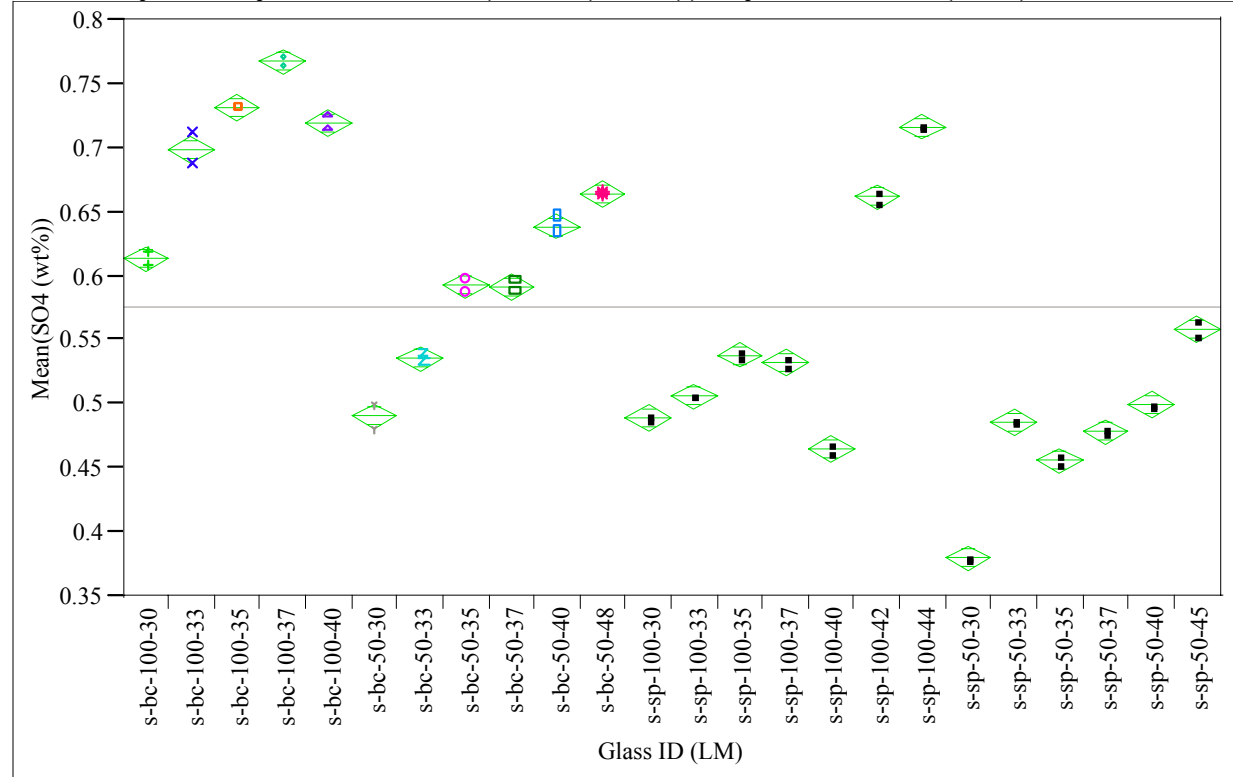

Oneway Anova

Summary of Fit

Rsquare

Adj Rsquare

Root Mean Square Error

Mean of Response

Observations (or Sum Wgts)

Analysis of Variance

Source

Glass ID (LM)

Error

C. Total
0.997852

0.995793

0.006713

0.575587

48

Sum of Squares

0.50238774

0.00108154

0.50346927
Mean Square
0.021843
0.000045

F Ratio

484.7086

Prob $>$ F

$<.0001$ 
WSRC-TR-2004-00081

REVISION: 0

This page intentionally left blank. 
WSRC-TR-2004-00081

REVISION: 0

\section{APPENDIX C}


Table C-1: SMRF Glass Pour/Glass Drain Analyses (oxide wt\%) for 0.7, 1.2, and 1.5\% Target Sulfate Tests

\begin{tabular}{|c|c|c|c|c|c|c|c|c|c|c|c|c|c|c|c|c|}
\hline Sample ID & $\mathrm{A} 12 \mathrm{O} 3$ & $\mathrm{~B} 2 \mathrm{O} 3$ & $\mathrm{CaO}$ & $\mathrm{Cr} 2 \mathrm{O} 3$ & $\mathrm{CuO}$ & $\mathrm{Fe} 2 \mathrm{O} 3$ & $\mathrm{~K} 2 \mathrm{O}$ & $\mathrm{Li} 2 \mathrm{O}$ & $\mathrm{MgO}$ & $\mathrm{MnO}$ & $\mathrm{Na} 2 \mathrm{O}$ & $\mathrm{NiO}$ & SO4 & $\mathrm{SiO} 2$ & $\mathrm{ZnO}$ & $\mathrm{ZrO} 2$ \\
\hline $\begin{array}{c}\text { SMRF } 128 \\
\text { (A) }\end{array}$ & 6.84 & 4.80 & 1.57 & 0.100 & 0.083 & 14.3 & 0.056 & 4.63 & 1.59 & 2.36 & 15.0 & 0.440 & 0.783 & 44.9 & 0.137 & 0.169 \\
\hline $\begin{array}{l}\text { SMRF } 128 \\
\text { (B) }\end{array}$ & 7.03 & 5.08 & 1.57 & 0.100 & 0.085 & 15.1 & 0.052 & 4.70 & 1.62 & 2.46 & 14.5 & 0.444 & 0.786 & 46.5 & 0.140 & 0.158 \\
\hline $\begin{array}{c}\text { SMRF } 130 \\
\text { (A) }\end{array}$ & 6.60 & 5.05 & 1.46 & 0.104 & 0.071 & 14.4 & 0.060 & 4.77 & 1.55 & 2.24 & 13.8 & 0.417 & 0.765 & 47.3 & 0.128 & 0.216 \\
\hline $\begin{array}{l}\text { SMRF } 130 \\
\text { (B) }\end{array}$ & 6.59 & 5.02 & 1.42 & 0.102 & 0.071 & 14.1 & 0.061 & 4.79 & 1.51 & 2.20 & 14.2 & 0.406 & 0.750 & 46.9 & 0.132 & 0.211 \\
\hline $\begin{array}{c}\text { SMRF } 0136 \\
\text { (A) }\end{array}$ & 6.32 & 5.11 & 1.30 & 0.074 & 0.063 & 14.3 & 0.061 & 4.98 & 1.46 & 2.05 & 13.2 & 0.412 & 0.786 & 49.2 & 0.128 & 0.258 \\
\hline $\begin{array}{l}\text { SMRF } 136 \\
\text { (B) }\end{array}$ & 6.22 & 5.10 & 1.34 & 0.074 & 0.064 & 14.2 & 0.067 & 4.92 & 1.47 & 2.03 & 13.4 & 0.411 & 0.804 & 48.8 & 0.137 & 0.263 \\
\hline $\begin{array}{c}\text { SMRF } 141 \\
\text { (A) }\end{array}$ & 6.12 & 5.02 & 1.33 & 0.082 & 0.066 & 13.8 & 0.078 & 4.95 & 1.44 & 1.97 & 13.4 & 0.465 & 0.963 & 48.3 & 0.123 & 0.262 \\
\hline $\begin{array}{l}\text { SMRF } 141 \\
\text { (B) }\end{array}$ & 6.77 & 5.20 & 1.31 & 0.081 & 0.066 & 14.7 & 0.067 & 5.22 & 1.44 & 2.12 & 12.9 & 0.422 & 0.989 & 50.3 & 0.122 & 0.257 \\
\hline $\begin{array}{c}\text { SMRF } 146 \\
\text { (A) }\end{array}$ & 6.22 & 5.08 & 1.31 & 0.069 & 0.070 & 14.5 & 0.074 & 4.95 & 1.39 & 2.04 & 13.4 & 0.407 & 1.17 & 49.7 & 0.122 & 0.253 \\
\hline $\begin{array}{l}\text { SMRF } 146 \\
\text { (B) }\end{array}$ & 6.38 & 5.17 & 1.29 & 0.071 & 0.070 & 14.7 & 0.065 & 4.97 & 1.42 & 2.05 & 13.3 & 0.422 & 1.17 & 50.3 & 0.122 & 0.257 \\
\hline $\begin{array}{l}\text { SMRF } 152 \\
\text { (A) }\end{array}$ & 6.37 & 5.16 & 1.29 & 0.074 & 0.068 & 14.8 & 0.067 & 4.96 & 1.41 & 2.06 & 13.0 & 0.426 & 1.22 & 50.7 & 0.130 & 0.252 \\
\hline $\begin{array}{l}\text { SMRF } 152 \\
\text { (B) }\end{array}$ & 6.40 & 5.19 & 1.23 & 0.071 & 0.064 & 14.8 & 0.066 & 5.02 & 1.35 & 2.07 & 12.6 & 0.407 & 1.19 & 51.0 & 0.115 & 0.243 \\
\hline $\begin{array}{l}\text { SMRF } 154 \\
\text { (A) }\end{array}$ & 6.12 & 4.95 & 1.32 & 0.207 & 0.073 & 15.5 & 0.077 & 4.93 & 1.42 & 2.00 & 12.5 & 0.724 & 1.46 & 47.6 & 0.128 & 0.250 \\
\hline $\begin{array}{l}\text { SMRF } 154 \\
\text { (B) }\end{array}$ & 6.04 & 4.84 & 1.36 & 0.202 & 0.074 & 15.6 & 0.075 & 4.91 & 1.45 & 2.03 & 12.4 & 0.721 & 1.45 & 47.7 & 0.130 & 0.258 \\
\hline
\end{tabular}

SMRF 128 - Pour sample after $4 \mathrm{~kg}$ of $0.7 \%$ sulfate glass produced

SMRF 130 - Pour sample after $8 \mathrm{~kg}$ of $0.7 \%$ sulfate glass produced

SMRF 136 - Pour sample at end of $0.7 \%$ sulfate test

SMRF 141 - Pour sample at end of $1.2 \%$ sulfate test

SMRF 146 - Pour sample at end of $1.5 \%$ sulfate test

SMRF 152 - Drain sample at 1726 on 1/22/04 (13 minutes after SMRF draining started)

SMRF 154 - Drain sample at 1800 on 1/22/04 (after $4.6 \mathrm{~kg}$ glass drained) 